OPEN ACCESS

Edited by: loannis Nezis, University of Warwick,

United Kingdom

Reviewed by:

Sushil Devkota,

University of California, San Diego,

United States

Viktor Zarsky

Charles University, Czechia

*Correspondence:

Devrim Gozuacik

dgozuacik@sabanciuniv.edu

Specialty section:

This article was submitted to

Membrane Traffic,

a section of the journal

Frontiers in Cell and Developmental

Biology

Received: 09 July 2018

Accepted: 13 September 2018

Published: 02 October 2018

Citation:

Kocaturk NM and Gozuacik D (2018)

Crosstalk Between Mammalian Autophagy and the

Ubiquitin-Proteasome System.

Front. Cell Dev. Biol. 6:128.

doi: 10.3389/fcell.2018.00128

\section{Crosstalk Between Mammalian Autophagy and the Ubiquitin-Proteasome System}

\author{
Nur Mehpare Kocaturk ${ }^{1}$ and Devrim Gozuacik ${ }^{1,2,3 *}$ \\ ${ }^{1}$ Molecular Biology, Genetics and Bioengineering Program, Faculty of Engineering and Natural Sciences, Sabanci University, \\ Istanbul, Turkey, ${ }^{2}$ Center of Excellence for Functional Surfaces and Interfaces for Nano Diagnostics (EFSUN), Sabanci \\ University, Istanbul, Turkey, ${ }^{3}$ Nanotechnology Research and Application Center (SUNUM), Sabanci University, Istanbul, \\ Turkey
}

Autophagy and the ubiquitin-proteasome system (UPS) are the two major intracellular quality control and recycling mechanisms that are responsible for cellular homeostasis in eukaryotes. Ubiquitylation is utilized as a degradation signal by both systems, yet, different mechanisms are in play. The UPS is responsible for the degradation of shortlived proteins and soluble misfolded proteins whereas autophagy eliminates long-lived proteins, insoluble protein aggregates and even whole organelles (e.g., mitochondria, peroxisomes) and intracellular parasites (e.g., bacteria). Both the UPS and selective autophagy recognize their targets through their ubiquitin tags. In addition to an indirect connection between the two systems through ubiquitylated proteins, recent data indicate the presence of connections and reciprocal regulation mechanisms between these degradation pathways. In this review, we summarize these direct and indirect interactions and crosstalks between autophagy and the UPS, and their implications for cellular stress responses and homeostasis.

Keywords: autophagy, UPS, proteasome, ubiquitylation, protein quality control, mitophagy, proteostasis, organelle homeostasis

\section{INTRODUCTION}

The ubiquitin-proteasome system (UPS) and macroautophagy (hereafter referred as autophagy) are two major intracellular protein degradation pathways. Degradation of short-lived proteins through the UPS is initiated by sequential addition of ubiquitin chains to target proteins (Hershko, 1983, 2005; Finley, 2009). Polyubiquitylated proteins are then recognized by the subunits of multicatalytic protease complexes called proteasomes (Hershko and Ciechanover, 1998; Schwartz and Ciechanover, 2009).

Proteasomes are extremely efficient organelles that degrade short-lived proteins and soluble unfolded/misfolded proteins and polypeptides. On the other hand, long-lived proteins, insoluble protein aggregates (usually originating from misfolded proteins, disease-related mutant proteins) and dysfunctional organelles, such as degenerated mitochondria and peroxisomes, are eliminated by the autophagy-lysosome system (Groll and Huber, 2003, 2004; Klionsky, 2007). Autophagy is characterized by the formation of double-membrane structures termed as autophagosomes, which later on fuse with lysosomes, forming autolysosomes degrading autophagosome contents.

The UPS and autophagy are interconnected, and inhibition of one system was shown to affect the other. There is accumulating evidence in the literature about connections between the UPS 


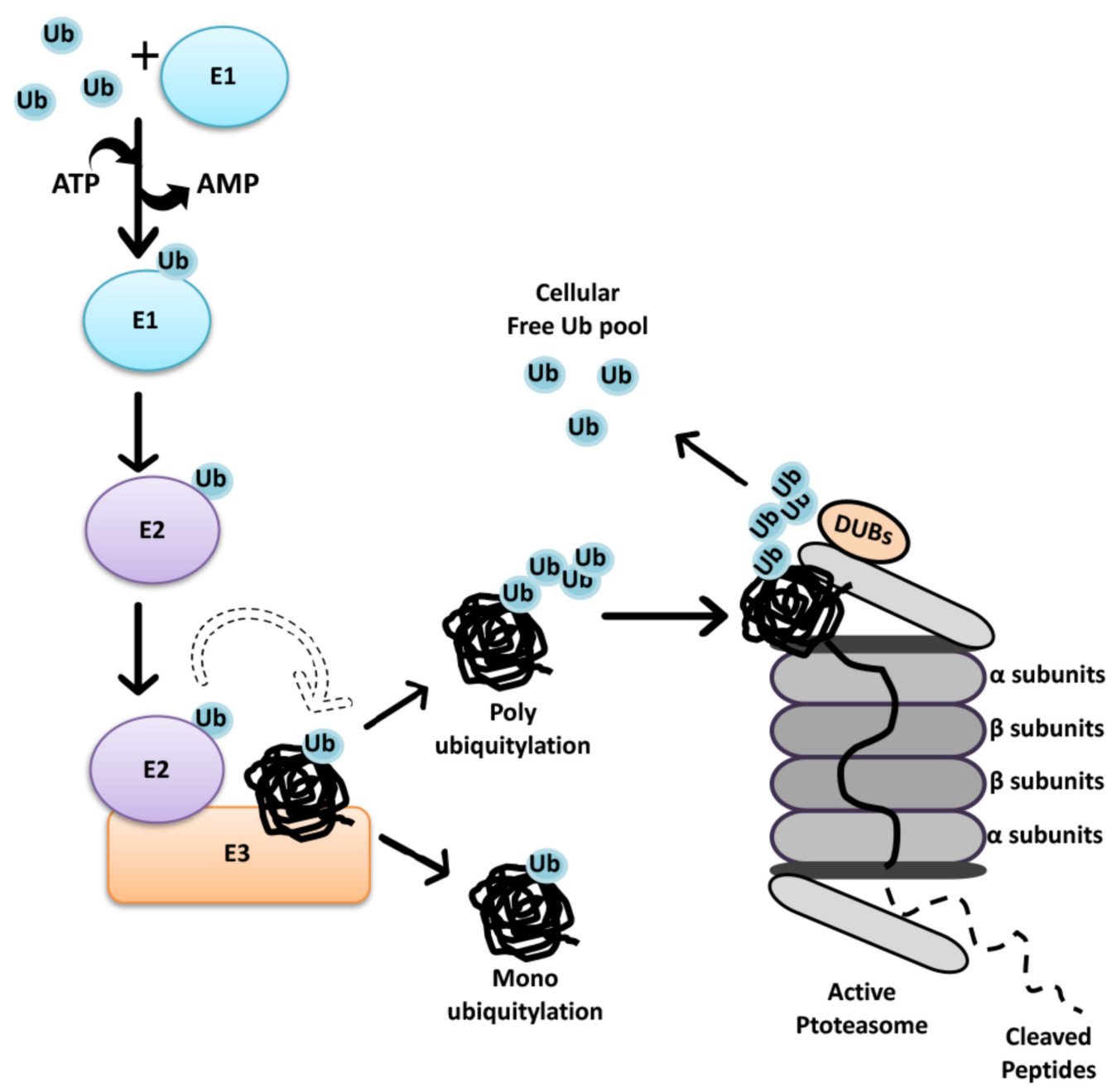

FIGURE 1 | The Ubiquitin-Proteasome System. Initially through C-terminal glycine, ubiquitin is attached to a cysteine residue of an activating enzyme, E1, in an ATP-dependent manner. The active ubiquitin is then associated with a cysteine residue of an ubiquitin conjugating enzyme, E2. Finally, specificity of ubiquitin transfer is ensured by E3 ubiquitin ligase family of proteins that bind to selected protein subsets (Hershko and Ciechanover, 1998). In the case of RING finger E3 ligases, the transfer of ubiquitin is direct from E2-ubiquitin to the substrate, even if the presence of E3 is required for substrate selection. At present, 2 genes are known to encode E1 isoforms, at least 40 genes encode E2's, and over 600 E3 ubiquitin ligases were defined in the human genome (Pickart and Eddins, 2004; Clague et al., 2015). Each E1 isoform reveals a distinct preference for different E2 enzymes, while association of E2 and E3 depend on cellular context, generating extensive combinatorial complexity.

and autophagy. In this review article, we will first briefly summarize the two systems, and then discuss in detail various examples of coordination and crosstalk between them. For more detailed discussion on individual systems, the readers are referred to recently published excellent review articles (Collins and Goldberg, 2017; Kwon and Ciechanover, 2017; Mizushima, 2018; Yu et al., 2018). This review article mainly focuses on the mammalian system and advances in this field. For crosstalk in other systems, such as plants, readers should check other recent and relevant reviews [for example see, (Minina et al., 2017)].

\section{The Ubiquitin-Proteasome System}

Ubiquitylation-dependent degradation is involved in the regulation of several cellular processes, including protein quality control, transcription, cell cycle progression, DNA repair, cell stress response and apoptosis. For example during cell cycle regulation, timely progression of each phase of the cycle rely on sequential transcription and degradation of cell cycle proteins, such as cyclins (Glotzer et al., 1991; Benanti, 2012). During apoptosis, ubiquitylation leading the degradation of survivin depends on ubiquitin ligase XIAP (Arora et al., 2007; Altieri, 2010; Delgado et al., 2014).

Ubiquitylation involves the addition of the small protein ubiquitin to specific lysine residues on the target proteins. Covalent attachment of ubiquitin to protein targets occurs through a three-step mechanism involving E1 (ubiquitin-activating), E2 (ubiquitin-conjugating) and E3 (ubiquitin ligase) enzymes as summarized in Figure $\mathbf{1}$ (Hershko and Ciechanover, 1998). At least seven lysine (K) residues in the ubiquitin protein are involved in the polyubiquitin chain 
formation (K6, K11, K27, K29, K33, K48, or K63). Initially, K48-linked ubiquitin chain formation was introduced as the degradation signal for proteasomal degradation. In contrast, K11 or K63 chains or single ubiquitin moieties (monoubiquitylation) were initially connected to non-proteolytic functions (Welchman et al., 2005; Behrends and Harper, 2011). However, recent reports indicate that K63-linked ubiquitin chains as well as various other chains prime substrates for autophagic elimination (Tan et al., 2008b).

The 26S proteasome is an ATP-dependent protease complex, consisting of a core complex, the $20 \mathrm{~S}$ proteasome and a regulatory complex, the $19 \mathrm{~S}$ proteasome cap. The $20 \mathrm{~S}$ proteasome forms a barrel-shape structure with two end rings formed by $\alpha$ subunits regulating the entry of unfolded proteins, and two middle rings are composed of $\beta$ subunits harboring proteolytic activity (Heinemeyer et al., 2004). Substrates must be unfolded and then guided by $\alpha$ subunits prior to catalytic cleavage. At the end, polypeptides are chopped into 3-25 amino acid long fragments, and further cleavage to single amino acids is carried out by peptidases (Tomkinson and Lindås, 2005) (Figure 1). By this way, recycling of proteins result in the generation of amino acids that are ultimately reused by cells in the synthesis of new proteins.

The 26S proteasome contains an additional 19S cap structure that further regulates the internalization of ubiquitylated substrates (Lander et al., 2012). The central part of the 19S cap consists of six AAA ATPases (Rpt1-Rpt6) forming the Rpt ring that is responsible for substrate binding and unfolding as well as substrate transfer through the channel (Collins and Goldberg, 2017). Non-ATPase proteins such as Rpn10 and Rpn13 in the $19 \mathrm{~S}$ cap, possess ubiquitin-binding domains and therefore function as receptors for ubiquitin-labeled substrates (Finley, 2009).

Recent studies showed that ubiquitylation is a reversible phenomenon. Deubiquitinating enzymes (DUBs) are proteases that remove ubiquitin or ubiquitin-like molecules from substrates and disassemble polyubiquitin chains. DUBs regulate UPS-mediated degradation in different cellular contexts (Reyes-Turcu et al., 2009; He et al., 2016; Pinto-Fernandez and Kessler, 2016). Moreover, they play an important role in the control of available free ubiquitin pool in cells, allowing recycling and reuse of ubiquitin. Some DUBs are also responsible for processing newly synthesized ubiquitin precursors (Komander et al., 2009; Lee et al., 2011; Grou et al., 2015; Collins and Goldberg, 2017).

\section{Autophagy}

There are three major types of autophagy: Macroautophagy, microautophagy and chaperon-mediated autophagy (CMA). In this review, we chose to focus on macroautophagy (herein autophagy). CMA and microautophagy were discussed in elsewhere (Kaushik and Cuervo, 2018; Oku and Sakai, 2018).

Autophagy is characterized by the engulfment of cargo molecules by double-membrane vesicles, called autophagosomes (Klionsky, 2007; Mizushima, 2010, 2018; Lamb et al., 2013). Following closure, autophagosomes are transported by the microtubule system, leading to their fusion with late endosomes and lysosomes, forming autolysosomes. In this new compartment, sequestered cargos are degraded by the action of lysosomal hydrolases. Building blocks that are generated by hydrolysis of macromolecules (e.g., amino acids from protein degradation) are then transferred back to cytosol for reuse (Figure 2). Active at a basal level, autophagy is upregulated following a number of stimuli and stress conditions. Amino acid deprivation, serum starvation and growth factor deprivation, hypoxia, exposure to various chemicals and toxins might be counted among stress conditions activating autophagy.

Most autophagy inducing signals converge at the level of mTOR protein complexes (mTORC1 and mTORC2) that coordinate anabolic and catabolic processes (Sabatini, 2017; Saxton and Sabatini, 2017) (Figure 2). Cellular energy sensor AMPK directly regulates mTOR and therefore contributes to the regulation of the autophagic activity. Moreover, the ERK/RSK pathway, PI3K/AKT pathway, amino acid sensor RAG system as well as hypoxia are among autophagy-related pathways converging at the level of mTOR. Under normal conditions, mTORC1 limits the autophagic activity through inactivation of the ULK1/2 autophagy complex. mTORC1-dependent phosphorylation of ULK1 and Atg13 (Hosokawa et al., 2009) result in the inactivation of ULK $1 / 2$ complex and down regulation of autophagy. Under stress, mTORC1 is inhibited and ULK1/2 complex dephosphorylated. ULK1/2 then phosphorylates itself, Atg13 and FIP200 and activate autophagy.

A class III phosphatidylinositol 3-kinase (PI3K) complex, including the lipid kinase VPS34 and the regulatory protein Beclin1, controls the membrane nucleation stage and initial phagophore formation. Phosphatidylinositol 3-phosphate (PtdIns3P) that is generated by PI3K activity serves as a landing pad for autophagy-related proteins containing PI3P-binding domains (e.g., FYVE-domains). Among them WIPI1-4 and DFCP1 were involved in the formation of a membrane structure called omegasome or cradle, a structure that creates a platform for the elongation of autophagosome precursor isolation membranes (Mauthe et al., 2011; Mercer et al., 2018).

Elongation of the isolation membrane depends on two ubiquitin-like conjugation systems. In the first system, autophagy-related gene 12 (ATG12) is covalently conjugated to the ATG5 protein through the action of ATG7 (E1-like) and ATG10 (E2-like) proteins. Then, recruitment of the ATG16L1 protein to ATG12-5 dimer results in the formation of a larger complex. Then forming ATG12-5-16L1 oligomers serve as E3 ligases that conjugate lipid molecules (such as phosphatidylethanolamine) to ATG8 orthologs MAP1LC3, GATE16, GABARAP (Mizushima et al., 2011; Shpilka et al., 2011; Tsuboyama et al., 2016). Lipid-conjugated ATG8 proteins are required for the elongation, expansion and closure of autophagosome membranes (Nakatogawa et al., 2007).

In order to acquire lytic capacity, autophagosomes fuse with late endosomes or lysosomes. In mammalian cells, fusion requires lysosomal integral membrane protein LAMP-2, several SNARE proteins (e.g., STX17 and WAMP8) and RAB proteins (e.g., RAB5 and RAB7) (Tanaka et al., 2000; Jager, 2004). Following fusion of the outer membrane of autophagosomes, materials contained in the inner membrane are degraded by the action of lysosomal hydrolases (Tanida et al., 2004). Building blocks (e.g., 


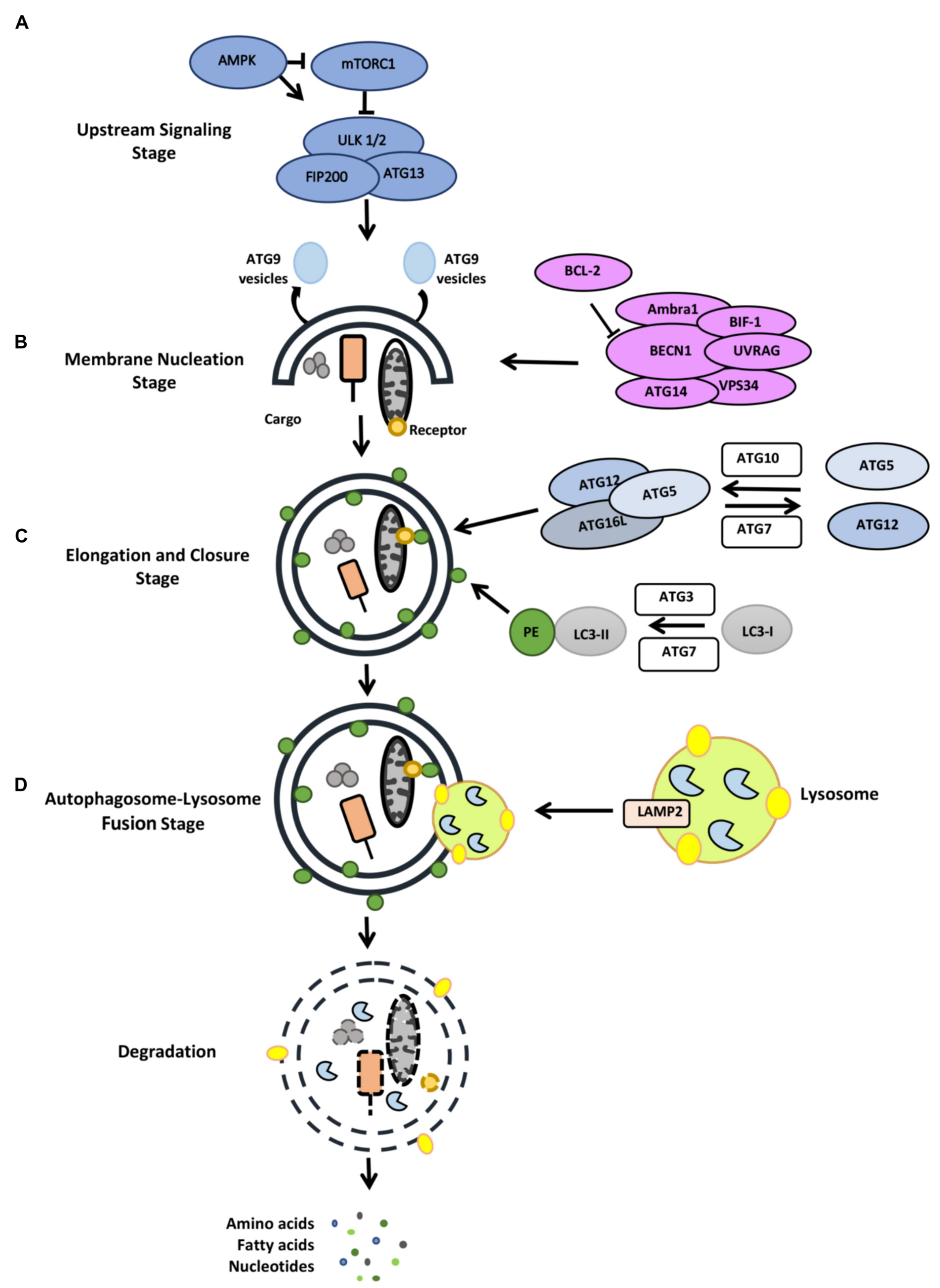

FIGURE 2 | Stages of the autophagy pathway (for detail, see the text). (A) Upstream signaling, (B) membrane nucleation stage, (C) elongation and closure stage, (D) autophagosome-lysosome fusion stage.

amino acids, fatty acids etc.) are then transported back to cytosol for reuse in the metabolic processes of the cells.

Autophagic vesicles engulf targets such as portions of cytoplasm and various cytoplasmic components in a non-selective manner. On the other hand, several selective forms of autophagy have been described (Kraft et al., 2010; Anding and Baehrecke, 2017). In most cases, ubiquitylation of the cargo constitutes a key step in the chain of events leading to its autophagic removal (Kirkin et al., 2009; Rogov et al., 2014). Selective targets include mitochondria (Okamoto 
et al., 2009), peroxisomes (Till et al., 2012), lysosomes (Hung et al., 2013), endoplasmic reticulum (ER) (Khaminets et al., 2015), ribosomes (An and Harper, 2018), cytoplasmic protein aggregates (Lamark and Johansen, 2012), pathogenic intracellular invaders (Wileman, 2013) and even certain free proteins and RNAs (Huang et al., 2015) were shown to be targets of selective autophagy. By this way, cells control number of the organelles, eliminate dysfunctional components and get rid of potentially harmful aggregates and invaders.

Selectivity is ensured by target-specific autophagy receptors that form a bridge between the ubiquitylated cargo and LC3 component of autophagic membranes. Selective autophagy relies on the recognition and binding capacity of autophagy receptors to various types of cargo, including mitochondria (OPTN, NDP52, Tax1BP1, NIX, FUNDC1) (Novak et al., 2010; Sarraf et al., 2013; Wong and Holzbaur, 2014; Lazarou et al., 2015; Chen et al., 2016), peroxisomes (NBR1) (Deosaran et al., 2013), lysosomes (galectin-3) (Hasegawa et al., 2015), ER (FAM134B, SEC62, RTN3, and CCPG1) (Khaminets et al., 2015; Fumagalli et al., 2016; Grumati et al., 2017; Smith et al., 2018) and intracellular ubiquitylated aggregates (p62, NBR1, OPTN, TOLLIP receptors) (Pankiv et al., 2007; Kirkin et al., 2009; Korac et al., 2013; Lu et al., 2014), bacterial invaders (p62, OPTN, NDP52 receptors) (Thurston, 2009; Zheng et al., 2009; Wild et al., 2011). LC3-interacting region (LIR) is the common motif which allows autophagy receptors to bind lipidated LC3. On the other hand, ubiquitin-associated domain (UBA domain) on autophagy receptors are responsible for the recognition of ubiquitin decorated cargos (Khaminets et al., 2016). Cargos that are wrapped and packed in autophagosomes are then ready for delivery and degradation in lysosomes.

\section{THE UPS-AUTOPHAGY CONNECTION}

The UPS and autophagy are the two major and evolutionarily conserved degradation and recycling systems in eukaryotes. Although their activities are not interdependent, recent studies show that connections and crosstalks exist between the two systems. Mitophagy constitutes a prominent example connecting these two degradative systems, yet several other examples exist. In this section, we will summarize biological events involving autophagy and the UPS, and discuss molecular details of the crosstalk mechanisms.

\section{Compensation Between the Two Degradative Pathways}

Initial observations about functional connections between the UPS and autophagy systems revealed that inhibition of one led to a compensatory upregulation of the other system. In order to maintain homeostasis, cellular materials that accumulate following inhibition of one degradative system needs to be cleared, at least in part, by the other system (Figure 3). Here, we will give examples of scenarios where these compensation mechanisms are operational.

Inhibition of the UPS using various compounds (e.g., MG132, bortezomib, lactacystine etc.) (Wu et al., 2008; Selimovic et al., 2013; Fan et al., 2018) or by genetic approaches (Demishtein et al., 2017) resulted in the upregulation of the autophagic activity in cells (Figure 3). For example, inhibition of proteasomal activity by the proteasome inhibitor and chemotherapy agent bortezomib led to an increase in the expression of autophagy genes ATG5 and ATG7, and induced autophagy. In fact, autophagy gene upregulation depended on an ER stress-dependent pathway that involved eukaryotic translation initiation factor-2 alpha (eIF2 $\alpha$ ) phosphorylation (Zhu et al., 2010). In another study, proteasome inhibition was associated with an increase in p62 and GABARAPL1 levels by Nrf1-dependent and -independent pathways prior to autophagy activation (Sha et al., 2018). In other contexts, MG132-mediated proteasome inhibition resulted in a decrease in cell proliferation, cell cycle arrest at G2/M phase and stimulation of autophagy through upregulation of Beclin1 and LC3 (Ge et al., 2009).

Autophagy induction following proteasome inhibition correlated with AMPK activation as well. A number of studies provided evidence that proteasomal inhibition is sensed by both AMPK and mTORC1, two major regulators of autophagy.
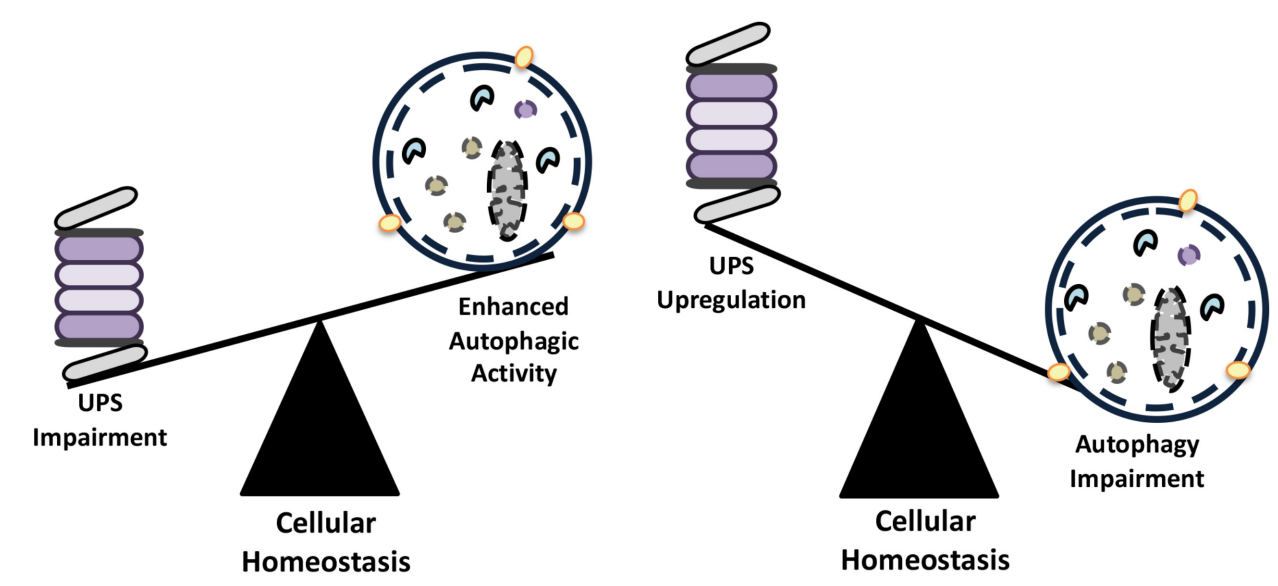

FIGURE 3 | The compensatory balance between the activities of autophagy and the UPS in order to maintain cellular homeostasis. 
For instance, in macrophages, epitelial and endothelial cells, proteasome inhibition using chemicals resulted in the activation of AMPK (Xu et al., 2012; Jiang et al., 2015). In some other cancer cell types, CaMKK $\beta$ and glycogen synthase kinase-3 $\beta$ (GSK-3 $\beta$ ) were identified as upstream regulators of AMPK activation, proteasome inhibition was linked to a decrease in GSK-3 $\beta$ activity and to the activation of AMPK and autophagy (Sun et al., 2016). On the other hand, Torin-1- or rapamycin-mediated inhibition of mTOR stimulated long-lived protein degradation through activation of both UPS and autophagy (Zhao et al., 2015; Zhao and Goldberg, 2016). In retinal pigment epithelial cells, inhibition of proteasome by lactacystin and epoxomicin was shown to block the AKT-mTOR pathway and induce autophagy (Tang et al., 2014). SiRNA-mediated knockdown of Psmb7 gene coding for the proteasome $\beta 2$ subunit, resulted in enhanced autophagic activity, and it was linked the mTOR activation status of cultured cardiomyocytes (Kyrychenko et al., 2013).

Similarly, impairment of autophagy correlated with the activation of the UPS. In colon cancer cells, chemical inhibition of autophagy and small RNA mediated knock down of ATG genes resulted in the upregulation of proteasomal subunit levels, including the catalytic proteasome $\beta 5$ subunit, PSMB5 and led to increased UPS activity (Wang et al., 2013). In another study, 3-MA-mediated autophagy inhibition in cultured neonatal rat ventricular myocytes (NRVMs) increased chymotrypsin-like activity of proteasomes (Tannous et al., 2008).

Since proteasomes were identified as autophagic degradation targets (proteaphagy), enhanced proteasome peptidase activity following autophagy inhibition might be associated with the accumulation of proteasomes (Cuervo et al., 1995; Marshall et al., 2015). Yet in several cases, autophagy inhibition correlated with the accumulation of ubiquitylated proteins. For instance in independent studies with ATG5 or ATG7 knockout mice, accumulation of ubiquitylated conjugates were observed, especially in the brain and the liver of the animals (Komatsu et al., 2005, 2006; Hara et al., 2006; Riley et al., 2010). Similar results were observed in other animal models such as Drosophila (Nezis et al., 2008). In line with these data, inhibition of autophagy through siRNA-mediated knockdown of ATG7 and ATG12 in HeLa cells resulted in the impairment of UPS, accumulation of ubiquitylated proteins as well as other important UPS substrates, including p53 and $\beta$-catenine (Korolchuk et al., 2009a). In above-cited papers, autophagy impairment followed by the autophagy receptor p62 accumulation in cells, and played a key role in the observed UPS defects.

Ubiquitylation was proposed to be a common component that directs substrates to the proper degradation system and even contribute to the UPS-autophagy crosstalk (Korolchuk et al., 2010; Dikic, 2017). According to this view, proteins that are predominantly linked to K48-based ubiquitin chains are generally directed for degradation through UPS. Conversely, aggregates that are linked to K63-based ubiquitin chains are directed for autophagic degradation. P62 binding capacity was introduced as the critical step in the choice between the UPS and autophagy. Although, p62 is able to attach both K48- and K63-linked ubiquitin chains through its UBA domain, binding affinity of the protein for K63-linked chains seems to be higher
(Long et al., 2008; Tan et al., 2008a; Wooten et al., 2008). Due to this dual ubiquitin binding ability, p62 might show UPS inhibitory effects in some contexts. A competition between p62 and p97/VCP (a ubiquitin binding ER-associated degradation protein) determined the fate of ubiquitylated proteins in cells (Korolchuk et al., 2009a,b). Over expression of p97/VCP protein prevented binding of p62 to ubiquitylated substrates, and directed them for degradation by the UPS. On the other hand, accumulation of p62 following autophagy inhibition led to the sequestration of proteins that were otherwise p97/VCP targets.

In summary, in the case of a defect in one of the two degradation systems, the other system is upregulated in order to eliminate ubiquitylated protein substrates. Yet, compensation does not always work and its success largely depends on cell types, cellular and environmental conditions and target protein load.

\section{Interplay Between the UPS-Autophagy in the Selective Clearance of Cytosolic Proteins}

Function of proteins depend on their proper folding and 3D structures. Various insults, including heat shock, organellar stress, oxidative stress etc., might lead to the accumulation of unfolded or misfolded proteins. Moreover several diseaserelated mutations were associated with folding problems. Failure to refold result in dysfunctional or malfunctional, hence toxic protein accumulations, activation of stress and even cell death pathways. In order to control toxic protein accumulations, an active process of protein aggregate formation comes into play. Additionally some proteins, including mutant proteins are already prone to form aggregates. Selective clearance of most cytosolic proteins require ubiquitylation. Depending on their solubility, ubiquitylated proteins and protein aggregates are then cleared by the UPS or autophagy.

Soluble fractions of proteins with a folding problem are recognized by the chaperone machinery and directed to the UPS for degradation. Hsp70 and Hsp90 chaperone interactor CHIP was identified as one of the E3 ligases that are responsible for K48-linked ubiquitin chain addition to unfolded/misfolded proteins. BAG family proteins, especially BAG1, interact with the Hsp70 complex and induce proteasomal degradation of client proteins.

On the other hand, clearance of insoluble aggregate-prone proteins require formation of aggresomes. Ubiquitylation by a number of different E3 ligases, including CHIP, Parkin, HRD1 and TRIM50 prime aggregate-prone proteins (Olzmann et al., 2007; Mishra et al., 2009; Zhang and Qian, 2011; Mao et al., 2017). HDAC6 is another protein that plays a key role in the process of aggresome formation. HDAC6 was shown to provide the link between K63-based ubiquitylated aggregates and microtubule motor protein dynein (Matthias et al., 2008; Olzmann et al., 2007). Then, dynein-mediated mechanism direct the aggregates toward microtubule organizing centers (MTOCs), resulting in their piling of as aggresomes (Johnston et al., 1998; Kopito, 2000) (Figure 4). Following aggresome formation, direct interaction of adaptor proteins p62 and NBR1 with ubiquitylated aggregates result in their delivery to autophagosomes (Ichimura et al., 2008; Lamark and Johansen, 2012). Another autophagy-related protein, ALFY, was also identified as a player in the selective autophagy 


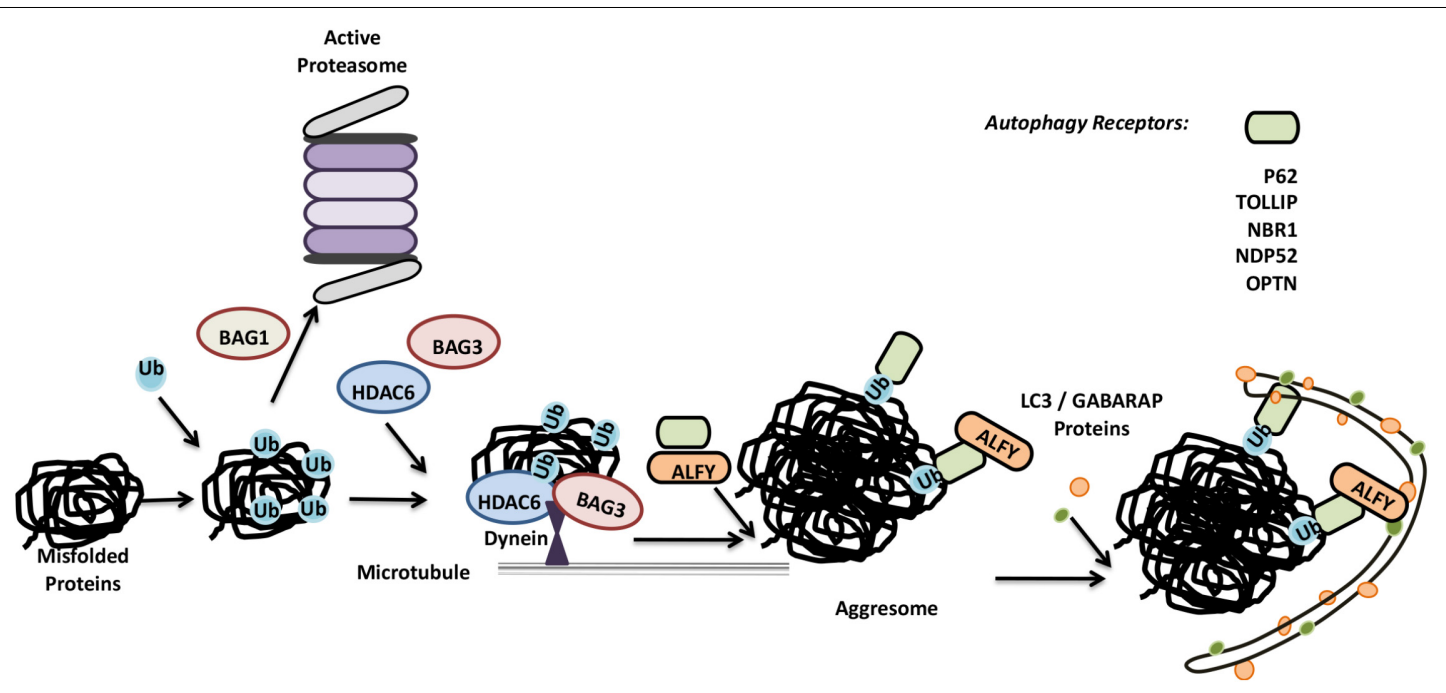

FIGURE 4 | Misfolded proteins can be eliminated by both the UPS and autophagy system. Misfolded proteins are ubiquitylated and based on the differences in ubiquitin linkages and ubiquitin binding proteins, they are directed for proteasomal degradation or further accumulated in aggresomes. Aggresomes are selectively cleared by autophagy.

and degradation of aggresomes (Clausen et al., 2010; Filimonenko et al., 2010).

An alternative pathway for aggresome formation require Hsp70 partner proteins BAG3 and CHIP (Zhang and Qian, 2011). Similar to HDAC6, BAG3 binds to dynein, and this directs Hsp70 substrates to aggresomes. However, BAG3-dependent aggresome formation was not dependent on the ubiquitylation of substrates as in the case of HDAC6, and CHIP E3 ligase activity was dispensible (Gamerdinger et al., 2011; Zhang and Qian, 2011). Yet, E3 ligases such as CHIP were required for BAG3-dependent aggresome clearance by autophagy (Klimek et al., 2017).

\section{Proteolytic Degradation of the UPS or Autophagy Components as a Mutual Control Mechanism}

Until so far, we focused on the UPS and autophagy as complementary but independent mechanisms. However, there are cases where components of one system were reported to be a proteolytic target of the other system. For example, a number of autophagy proteins were regulated through degradation by the UPS. On the other hand, even the whole proteasomes were shown be selective targets of autophagic degradation. Here, we will give examples of how mutual regulation through proteolysis contributes to the crosstalk and the interplay between the two systems.

\section{Control of the UPS by the Autophagic Activity}

Early studies indicated that proteasomes could be degraded in lysosomes (Cuervo et al., 1995). Later on, plant studies revealed that lysosomal degradation of $26 \mathrm{~S}$ proteasomes occurred by a specific form of selective autophagy, proteaphagy (Marshall et al., 2015). RPN10 protein was introduced as an ATG8 interacting plant proteaphagy receptor. Unlike the plant protein, yeast and mammalian RPN10 failed to interact with ATG8/LC3. Instead,
Cue5 protein in the yeast and its human ortholog TOLLIP, were introduced as selective receptors regulating proteasome clearance by autophagy (Lu et al., 2014). Moreover, p62 was also described as another proteaphagy receptor (Cohen-kaplan et al., 2016). For example, in mammals, amino acid starvation significantly upregulated ubiquitylation of $19 \mathrm{~S}$ proteasome cap components RPN1, RPN10, RPN13, and led to their p62-mediated recruitment to autophagosomes (Cohen-kaplan et al., 2016) (Figure 5). Interestingly during carbon or nitrogen starvation, plant and yeast proteasomes were shown to localize in proteasomal storage granules (PSGs), protecting them from autophagic degradation during stress (Peters et al., 2016; Marshall and Vierstra, 2018). Whether similar mechanisms exist in the mammals is currently an open question. These observations underline the importance of selective degradation of proteasome by autophagy in the control of proteasome numbers as well as overall UPS and lytic activity in cells.

\section{Control of Autophagy Components by the UPS}

Modulation of the half-life of some proteins in the autophagy pathway by the UPS serves as a means to control cellular autophagic activity. For instance, LC3 protein was shown to be processed in a stepwise manner by the $20 \mathrm{~S}$ proteasome, a process that was inhibited by p62 binding (Gao et al., 2010). On the other hand, E3 ligase NEDD4-mediated K11-linked ubiquitylation of Beclin1 prevented its binding to the lipid kinase VPS34, and led to its degradation (Platta et al., 2012). Another E3 ligase, RNF216 ubiquitylated Beclin1 adding K48linked ubiquitin chains on the protein (Xu et al., 2014). Beclin1 ubiquitylation resulted in autophagy blockage in both cases. Conversely, reversal of Beclin1 ubiquitylation by the DUB protein USP19 stabilized the protein under starvation conditions and promoted autophagy (Jin et al., 2016). USP10 and USP13 as well as USP9X were characterized as other DUBs that regulated 


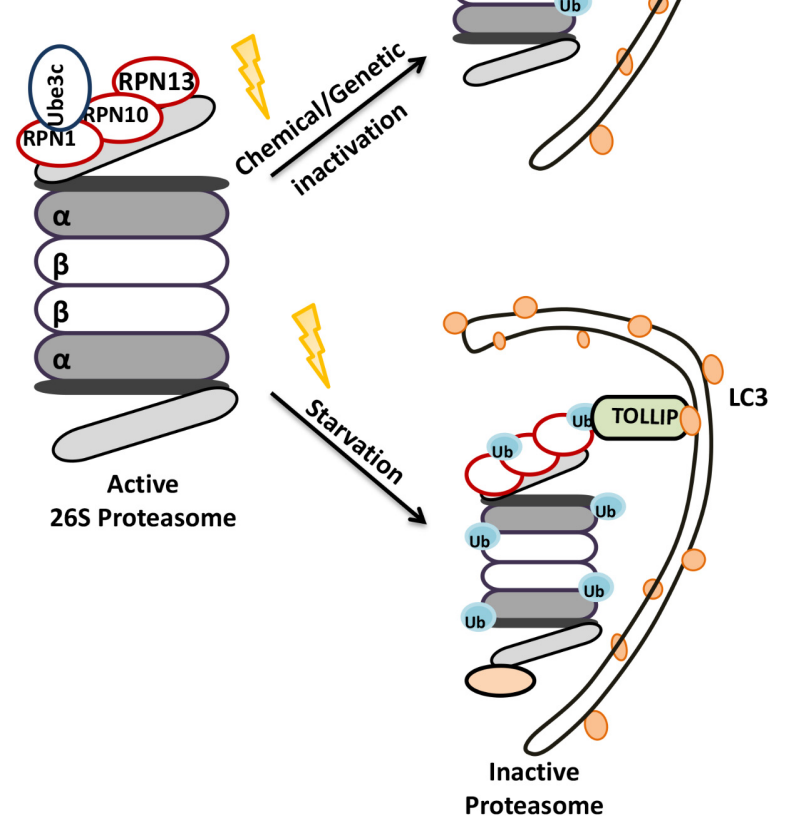

FIGURE 5 | Schematic representation of the selective degradation of proteasomes by autophagy. Upon starvation and functional defects proteasomes become ubiquitylated and degraded by autophagic machinery.

autophagy through control of Beclin1 stability (Liu et al., 2011; Jin et al., 2016).

Beclin 1 is not the only autophagy protein that is targeted by the UPS in a controlled manner. G-protein-coupled receptor (GPCR) ligands and agonists were reported to regulate cellular Atg14L levels, and therefore autophagy, through ZBTB16-mediated ubiquitylation of the protein (Zhang T. et al., 2015). Serum starvation increased GSK3 $\beta$-mediated phosphorylation of ZBTB16, leading to its degradation. Under these conditions, stabilization of Atg14L restored of autophagy. AMBRA1 is another UPS-controlled autophagy protein. Cullin-4 was identified as an E3 ligase that was responsible for the ubiquitylation of AMBRA1, dooming it for degradation under nutrient-rich conditions where autophagy should be inhibited (Antonioli et al., 2014). The PI3K complex subunit p85b is another example. Ubiquitylation of this autophagy signaling component by the E3 ligase SKP1 led to a decrease in its cellular levels and stimulated autophagic activity (Kuchay et al., 2013).

Ubiquitylation of some autophagy proteins did not result in their immediate proteasomal degradation, yet the post-translational modification provided an extra layer of control for the autophagy pathway. For instance, autophagy receptor
OPTN was ubiquitylated as a target of the E3 ligase HACE1, and K48-linked ubiquitylation regulated the interaction of the protein with p62 (Liu Z. et al., 2014). TRAF6, a central E3 ligase of the NF- $\kappa \mathrm{B}$ pathway, participated controlled ULK1 activity through K63-linked ubiquitylation. Under nutrient-rich conditions, mTOR phosphorylated AMBRA1 leading to its inactivation. When nutrients were limiting, mTOR inhibition resulted in AMBRA1 dephosphorylation and increased the interaction of the protein with TRAF6. This event facilitated ULK1 ubiquitylation by TRAF6 (Nazio et al., 2013). Ubiquitylation of ULK1 resulted in the stabilization of the protein, controlled its dimerization and regulated its kinase activity. Another ubiquitin-dependent regulation mechanism involved AMBRA1-Cullin-5 interaction in the regulation of mTOR complex component DEPTOR (Antonioli et al., 2014). Above-mentioned AMBRA1-Cullin-4 complex dissociated under autophagy-inducing conditions, allowing AMBRA1 to bind another E3 ligase, Cullin-5. This newly formed complex was shown to stabilize DEPTOR and induce mTOR inactivation, providing a negative feed-back loop in the control of autophagy (Antonioli et al., 2014).

In another study, TLR4 signaling triggered autophagy through Beclin1 ubiquitylation and stabilization. TLR4-associated TRAF6 protein was identified as the E3 ligase responsible for K63-linked ubiquitylation of Beclin1 at its $\mathrm{BH} 3$ domain. This modification blocked inhibitory BCL-2 binding to the protein, and free Beclin1 could activate autophagy (Shi and Kehrl, 2010). On the other hand, the deubiquitinating enzyme A20 reversed TRAF6-mediated ubiquitylation of Beclin1, resulting in autophagy inhibition (Shi and Kehrl, 2010). Another K63-linked ubiquitylation event on Beclin1 was promoted by AMBRA1 protein. In the same context, the WASH protein interacted with Beclin1, blocked AMBRA1-mediated Beclin1 ubiquitylation, and suppressed autophagy (Xia et al., 2013).

LC3 and p62 were also subjected to regulatory ubiquitylation. NEDD4 was identified as the E3 ligase in these reactions. NEDD4 was reported to interact with LC3 (Sun et al., 2017) and p62 (Lin et al., 2017), and LC3 binding to NEDD4 stimulated its ubiquitin ligase activity on the p62 protein (Sun et al., 2017). Moreover, NEDD4 deficient cells exhibited aberrant p62 containing inclusions, indicating the defect in aggresome clearance (Lin et al., 2017). Hence, NEDD4 is important for the regulation of p62 function and autophagy.

\section{Xenophagy: Removal of Intracellular Invaders}

Another essential function of autophagy is the clearance of intracellular pathogens. This special form of autophagy, called xenophagy, is a result of a cooperation between the ubiquitylation machinery and the autophagy pathway. Pathogens such as Streptococcus pyogenes, Mycobacterium tuberculosis, Listeria monocytogenes, and Shigella flexneri were identified as autophagy targets (Gutierrez et al., 2004; Kirkegaard et al., 2004; Ogawa et al., 2005). As a form of selective autophagy, xenophagy involves cargo labeling with ubiquitin, followed by the recognition by autophagy receptors (Figure 6). K48- and K63-linked and linear M1-linked ubiquitin chains were shown to mediate recognition 


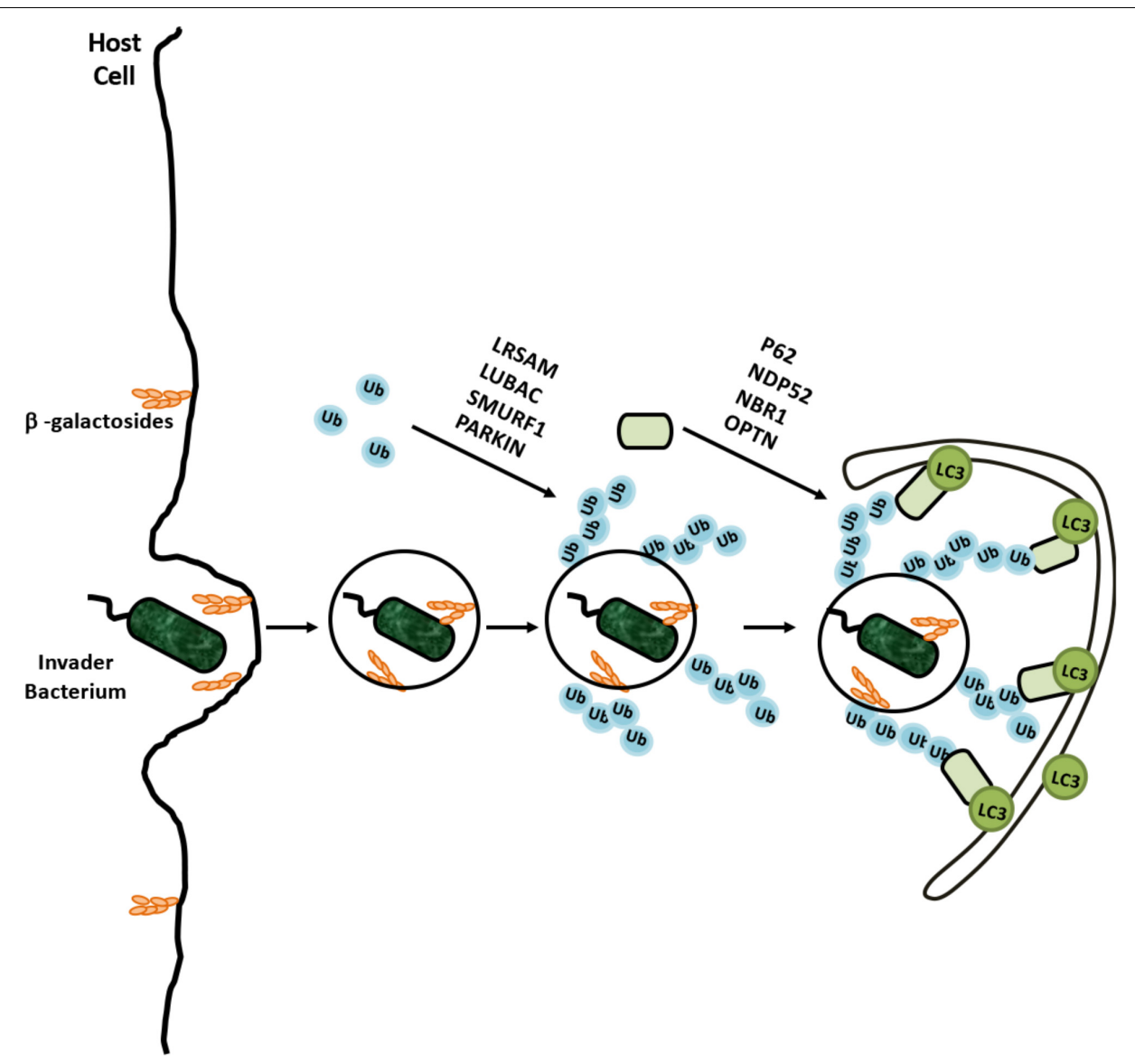

FIGURE 6 | Selective degradation of invaders by xenophagy is example of coregulation of the UPS and autophagy. Cellular degradation of invading bacterium was ubiquilated by various E3 ligases and recognized by adaptor proteins for recruitment autophagic membranes around bacterium.

of different pathogens by the xenophagy machinery (Collins et al., 2009; Randow and Youle, 2014).

Ubiquitylation frequently occurs on various cell penetrating parasites as well as on disrupted endosomes, providing an "eat me" signal for xenophagy. For example, Salmonella enterica serovar Typhimurium was heavily ubiquitylated in mammalian cells, and activation of xenophagy restricted intracellular bacteria numbers (Birmingham et al., 2006). Recent studies showed that, bacterial outer membrane-associated and integral membrane proteins were targets of ubiquitylation (Fiskin et al., 2016). A number of E3 ligases were involved in xenophagy, including Parkin, RNF166, ARIH1, HOIP, and LRSAM1 (Huett et al., 2012; Manzanillo et al., 2013; Heath et al., 2016; Franco et al., 2017; Lobato-Márquez and Mostowy, 2017).

For example, both K48- and K63-linked ubiquitylation were observed on Mycobacterium, and Parkin was identified as the E3 ligase catalyzing the K63-linked ubiquitylation (Collins et al., 2009; Manzanillo et al., 2013). Moreover endosome-free areas on the intracellular Salmonella Typhimurium contained a directly attached ubiquitin coat, and addition of linear M1-linked ubiquitin chains by the E3 ligase HOIP of the LUBAC on these ubiquitins contributed to the autophagy of the intracellular parasite (Noad et al., 2017). Xenophagy receptors that were described to date include p62, OPTN, NDP52, and NBR1 (Thurston, 2009; Zheng et al., 2009; Wild et al., 2011). These receptors were reported to bind pathogen- and/or endosome-associated ubiquitin, and directing the selective targets to autophagic membranes (Wild et al., 2011; Richter et al., 2016).

The interplay between ubiquitylation and autophagy achieves the important task of keeping host cells pathogen-free and providing an intracellular innate immune defense mechanism against invaders. In some reports, ubiquitylated bacteria were found to be surrounded by proteasomes as well (Perrin et al., 2004) and proteasomal activity might also be required for efficient killing of intracellular parasites (Iovino et al., 2014). Whether in the elimination of invading organisms, the crosstalk between the UPS and autophagy systems goes beyond ubiquitylation, needs further consideration. As discussed below, cellular mechanisms controlling commensal-turned ancient intracellular microorganisms, namely mitochondria, indeed rely on the function of both the UPS and autophagy.

\section{Mitophagy: Mitochondrial Turnover}

Mitochondria are vital organelles that form an intracellular dynamic network in the cytosol of eukaryotic cells. Through 
fusion and fission, they are constantly made and destroyed. Under steady state conditions, mitochondria might be eliminated by basal in a non-selective manner. On the other hand, elimination of damaged, dysfunctional or superfluous mitochondria requires a selective form of autophagy called mitophagy (Lemasters, 2005). Programmed elimination of mitochondria during development and differentiation (e.g., reticulocyte maturation to erythrocyte, in oocytes after fertilization, during lens formation in the eye) also relies on mitophagy (Schweers et al., 2007; Song et al., 2016; Esteban-Martínez et al., 2017). Recent studies showed that mitophagy is a biological phenomenon that involves both the UPS and autophagy. In this section, we will discuss mechanisms of mitophagy, and analyze connections between the UPS and autophagy in this context.

\section{PINK1/Parkin-Dependent Mitophagy}

Depending on the E3 ligase that ubiquitylates proteins on mitochondria, mitophagy can be divided into two major forms: Parkin-dependent and Parkin-independent mitophagy. The E3 ligase Parkin was first characterized as the product of the gene PARK2, mutations of which were linked to early-onset of Parkinson's Disease. Strikingly, Parkin recruitment to mitochondria was found to be necessary for mitophagy (Narendra et al., 2008). Further studies showed that Parkin, together with another familiar Parkinson's Disease-associated gene, PINK1 (PARK7), was responsible for priming mitochondria for autophagic degradation (Figure 7).

Under normal conditions, after being synthesized as precursor in the cytoplasm, PINK1 was imported to mitochondria by its N-terminal mitochondria targeting sequence (MTS). Then, PINK1 was post-translationally modified within mitochondria by resident proteases: MPP and PARL (Jin et al., 2010; Deas et al., 2011). Cleavage by PARL resulted in destabilization of the protein and its degradation by cytoplasmic proteasomes (Yamano and Youle, 2013). Under mitochondrial stress however, PINK1 cleavage did not occur and the protein accumulated on the outer mitochondrial membrane (OMM) (Lazarou et al., 2012; Hasson et al., 2013). Recruitment of cytoplasmic E3 ligase Parkin onto mitochondria required stabilization and the kinase activity of the PINK1 protein (Lazarou et al., 2012). Parkin itself was a substrate of PINK1 (Kondapalli et al., 2012; Shiba-Fukushima et al., 2012). Phosphorylation of Parkin by PINK1 resulted in a conformational change overcoming an

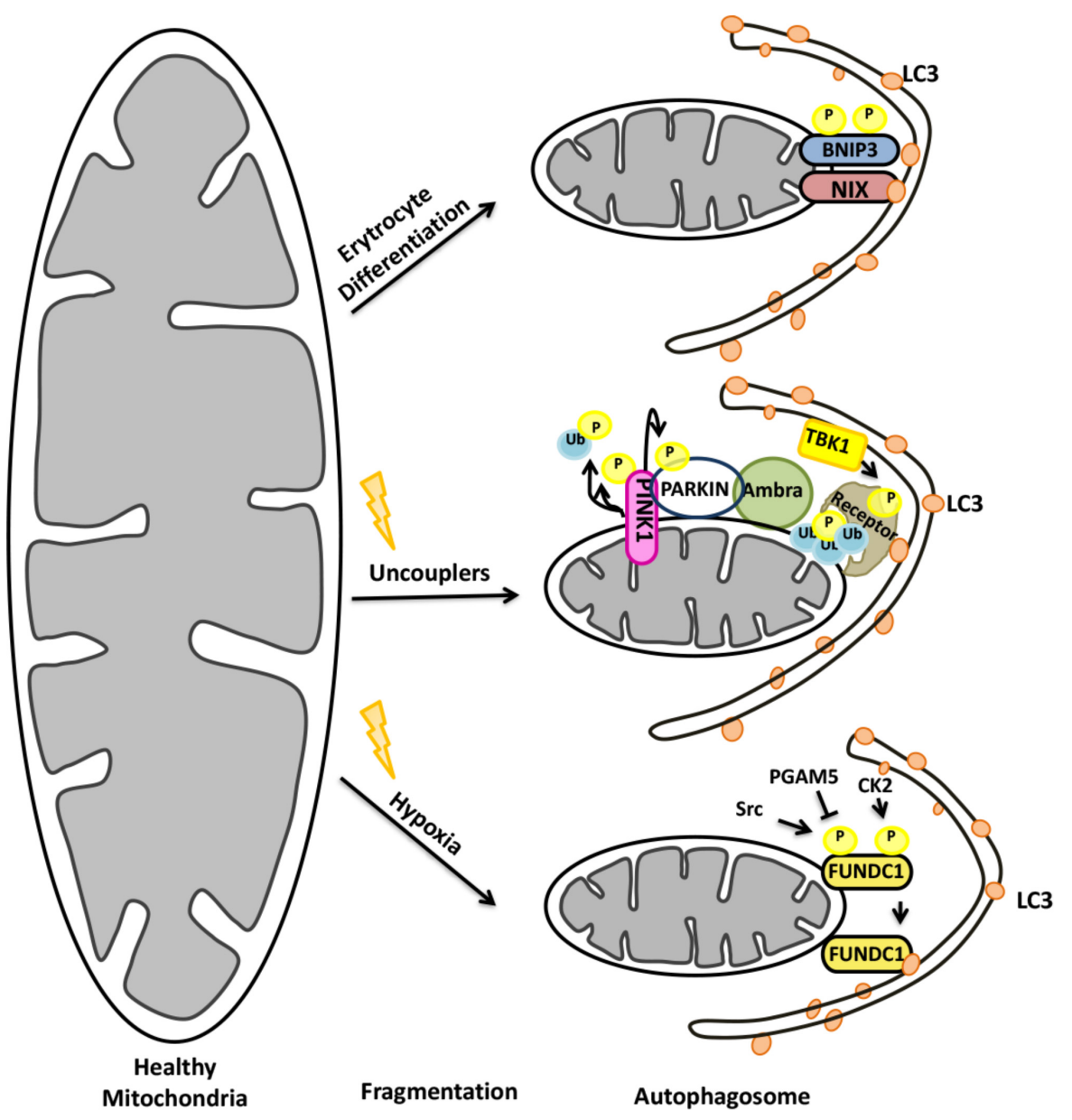

FIGURE 7 | Mitochondrial elimination by autophagy requires the activity of both the UPS and autophagy. 
autoinhibition, and stimulated its E3 ligase activity (Kondapalli et al., 2012; Shiba-Fukushima et al., 2012; Trempe et al., 2013; Wauer and Komander, 2013). Interestingly, PINK1 was shown to phosphorylate ubiquitin molecules on mitochondrial resident proteins as well. Ubiquitin phosphorylation correlated with an increase in the amount of mitochondria-localized Parkin, providing a feed-forward mechanism of Parkin recruitment (Kane et al., 2014; Kazlauskaite et al., 2014; Koyano et al., 2014; Shiba-Fukushima et al., 2014).

Several proteins on the mitochondrial outer membrane were identified as Parkin ubiquitylation substrates. The list includes VDAC, TOM proteins, mitofusins etc (Sarraf et al., 2013). Following ubiquitylation some of these targets were shown to be degraded by the proteasome (e.g., mitofusins) and some were not (e.g., VDAC). Degradation of proteins related to mitochondrial integrity promoted fission events that facilitate engulfment of mitochondrial portions by autophagosomes, whereas proteins that are not degraded upon ubiquitylation rather contributed to mitochondrial rearrangements (e.g., aggregation).

The UPS activity was a prerequisite in the preparation of mitochondria for autophagy. Ubiquitylation of mitochondrial targets preceeded the recruitment of the autophagic machinery onto mitochondria (Yoshii et al., 2011). Selective autophagy receptors were shown to bind ubiquitin-labeled proteins on mitochondria and recruit ATG8/LC3 proteins for mitophagy. Serial knock out of putative autophagy receptors showed that NDP52, optineurin (OPTN) and TAX1BP1 were functional mitophagy receptors, and a triple knockout of these proteins completely blocked mitophagy (Lazarou et al., 2015; Shi J. et al., 2015). On the other hand, the autophagy receptor p62 was essential for clustering of damaged mitochondria in perinuclear region of the cells, but not for mitophagy (Narendra et al., 2010; Okatsu et al., 2010).

Ubiquitin modifications on mitochondria might be reversed by the action of DUB proteins. Several DUBs were identified as positive or negative regulators of mitophagy (Dikic and Bremm, 2014; Wang et al., 2015). For example, deubiquitylation of mitochondrial targets by USP15, USP30, and USP35 prevented further progression of mitophagy in a number of cell lines and experimental models (Bingol et al., 2014; Cornelissen et al., 2014; Wang et al., 2015). DUB-mediated deubiquitylation of targets decreased Parkin recruitment onto mitochondria as well (Bingol et al., 2014). USP8-mediated removal of K6-linked ubiquitin chains from Parkin itself affected recruitment of the protein onto mitochondria and therefore mitophagy (Durcan et al., 2014; Durcan and Fon, 2015).

\section{Parkin-Independent Mitophagy}

Expression of Parkin is restricted to a few cell types, including dopaminergic neurons. Consequently, Parkin-null animals showed prominent mitophagy defects only in selected brain regions (Lee et al., 2018). Therefore in other cell types and tissues, mitophagy has to proceed in a Parkin-independent manner. Alternative E3 ligases were found to play a role in mitophagy in these contexts.

Mulan (MUL1) is an E3 ubiquitin ligase that resided on the OMM, and it was shown to play a role in
Parkin-independent mitophagy in different model organisms, including Caenorhabditis elegans, Drosophila and mammals (Ambivero et al., 2014; Yun et al., 2014). Mulan stabilized DRP1, led to degradation of MFN2, and interacted with ATG8 family member protein GABARAP (Braschi et al., 2009; Ambivero et al., 2014). Another E3 ligase that was associated with mitophagy was GP78 (Christianson et al., 2012). Over expression of GP78 induced MFN1 and 2 ubiquitylation and degradation, that was followed by mitochondrial fragmentation and mitophagy in cells lacking Parkin (Fu et al., 2013). Synphilin-1-dependent recruitment of the E3 ligase Siah1 to mitochondria resulted in mitochondrial protein ubiquitylation and mitophagy in a PINK1-dependent but Parkin-independent manner (Szargel et al., 2015). Conversely, another OMM E3 ligase, MITOL (MARCH5), was reported to ubiquitylate FIS1, DRP1 (Yonashiro et al., 2006) and MFN2 (Nakamura et al., 2006), yet inhibited hypoxia-induced and Parkinindependent mitophagy through ubiquitylation and degradation of FUNDC1 (Chen et al., 2017). All these findings underline the fact that mitophagy might proceed in cells which do not express Parkin. Further studies are required to unravel the molecular mechanisms of Parkin-independent mitophagy in different tissues and cell types, and reveal the details of the crosstalk between the UPS and autophagy under these conditions.

\section{A Special Type of Mitophagy During Reticulocyte Maturation}

During differentiation, in order to increase their capacity to load hemoglobin-bound oxygen, reticulocytes lose their organelles, including mitochondria, and become mature red blood cells (Dzierzak and Philipsen, 2013). During this process, a protein called NIX (also known as BNIP3L) is upregulated (Aerbajinai et al., 2003). NIX is a C-terminally anchored outer mitochondrial membrane $(\mathrm{OMM})$ protein that contains a LC3-interacting region (LIR) at its cytoplasmic $\mathrm{N}$-terminal part. Through its LIR domain, NIX interacted with LC3, enabling engulfment of mitochondria by autophagosomes in reticulocytes (Novak et al., 2010). Characterization of NIX-deficient mice showed that, NIX-deficient Erythrocytes failed to eliminate their mitochondria revealing a critical role for NIX in mitophagy (Schweers et al., 2007; Sandoval et al., 2008) (Figure 7). Although NIX-dependent mitophagy was predominantly studied in reticulocytes, NIX-dependent mitophagy might be important for other cell types as well [for example, see (Esteban-Martínez et al., 2017)].

A role for the UPS in NIX/BNIP3L-dependent mitophagy was revealed. NIX/BNIP3L was discovered to be ubiquitylated through a PINK1/Parkin-dependent mechanism. Ubiquitylated NIX/BNIP3L colocalized with selective autophagy receptors, and the process was necessary for mitochondrial stress-induced mitophagy (Ding et al., 2010; Gao et al., 2015; Palikaras et al., 2015). Therefore, the role of NIX/BNIP3L seems to be more general than previously thought and beyond the developmental context, and stress-induced mitochondrial elimination by autophagy might also require NIX/BNIP3L in different cell and organism types. 


\section{Pexophagy: Autophagic Removal of Peroxisomes}

Autophagy of peroxisomes, pexophagy, is a selective degradation process of peroxisomes during which the UPS and autophagy mechanisms work in collaboration. Peroxisomes are responsible of a number of cellular functions, including fatty acid oxidation, purine metabolism and phospholipid synthesis (Wanders et al., 2016). Several peroxisomal enzymes are involved in redox regulation due to their dual functions in the generation and scavenging of reactive oxygen and nitrogen species. Therefore, peroxisome biogenesis and degradation must be tightly regulated in order to control peroxisome size, number and function (Du et al., 2015; Honsho et al., 2016). Moreover under stress conditions such as hypoxia, oxidative stress, starvation or conditions causing UPS defects, pexophagy is upregulated.

During pexophagy, a number of peroxisomal membrane proteins, including peroxins and PMP70 become ubiquitylated (Kim et al., 2008). PEX2-PEX10-PEX12 complex serves as an E3 ligase at least for two well studied peroxisome proteins, PEX5 and PMP70. Ubiquitylation of peroxisome proteins result in the recruitment of p62 and/or NBR1 autophagy receptors, priming these organelles for autophagic degradation. For example, PEX2 overexpression or amino acid starvation activated the ubiquitylation of PEX5, and another peroxisomal membrane protein, PMP70, and led to peroxisome degradation (Sargent et al., 2016). Moreover in response to oxidative stress, ATM was recruited onto peroxisomes through physical interaction with PEX5 and promote its ubiquitylation. Inactivation of mTORC1 in a TSC2-dependent manner and stimulation of ULK1 phosphorylation by ATM, potentiated pexophagy (Zhang J. et al., 2015; Tripathi et al., 2016; Wang and Subramani, 2017). On the other hand, AAA ATPase complex (PEX1, PEX6, and PEX26) was shown to extract ubiquitylated PEX5 from peroxisomal membranes and regulate pexophagy (Carvalho et al., 2007; Okumoto et al., 2011; Law et al., 2017) (Figure 8). Both NBR1 and p62 were shown to be recruited onto peroxisomes during pexophagy. Yet, NBR1 was a major pexophagy receptor in a number of contexts, and p62 increased the efficiency of NBR1-dependent pexophagy through direct interaction with the latter (Deosaran et al., 2013; Zhang J. et al., 2015; Sargent et al., 2016). Altogether, these findings underline the importance of ubiquitylation for the selective degradation of peroxisomes by autophagy.

\section{Autophagic Removal of Ribosomes and Stress Granules}

In addition to major cellular organelles, autophagy was implicated in the clearance of ribosomes. Although ribosomes can be degraded in a non-specific manner during non-selective autophagy, a special form of selective autophagy is activated under various stress conditions, and the process is called ribosomal autophagy or ribophagy. On the other hand, mRNA protein complexes that are stalled during translation form stress granules, and their clearance requires both the UPS and autophagy.

Ribophagy was first described in the yeast during nutrient stress, and was shown to involve ubiquitylation of the $60 \mathrm{~S}$ ribosome protein $\mathrm{Rp} 25$ by the ubiquitin ligase Ltn1/Rkr1 (Kraft and Peter, 2008; Kraft et al., 2008; Ossareh-Nazari et al., 2014). In the mammalian system, in addition to mTOR inhibition, oxidative stress, induction of chromosomal mis-segregation, translation inhibition and stress granule formation were all shown to induce ribophagy (An and Harper, 2018). Ubiquitylation of ribosomes was observed under ER stress-inducing conditions (Higgins et al., 2015). P97/VCP that binds to ubiquitylated proteins and that functions in the delivery of these substrates to proteasome was necessary for ribophagy both in yeast and mammalian cells (Verma et al., 2013; An and Harper, 2018). Yet, individual ribosomal proteins were indeed shown to be a target of the UPS (Wyant et al., 2018). NUFIP1-ZNHIT3 proteins were identified as novel ribophagy receptors that directly connected ribosomes to LC3 and autophagy, yet whether ubiquitylation is a prerequisite for ribophagy needs to be clarified by future studies (Wyant et al., 2018) (Figure 9).

Stress granules are composed of actively accumulated non-translating mRNA ribonucleoprotein complexes (Protter and Parker, 2016). Proteins that accumulated in the stress granules, include stalled $40 \mathrm{~S}$ ribosomal units and various translation initiation factors [e.g., eIF4E, eIF4G, eIF3, eIF2 and poly(A)-binding protein (PABP)] and regulators such as eIF2$\alpha$ and GCN2 (Kedersha et al., 2005; Mazroui et al., 2007; Farny et al., 2009; Reineke and Lloyd, 2013). G3BP1 and TIA1 are also among the proteins that contribute to stress granule formation (Kedersha et al., 2000; Tourrière et al., 2003; Waris et al., 2014). Moreover, an interplay between G3BP1 and Caprin1 proteins and the DUB protein USP10 was shown to regulate

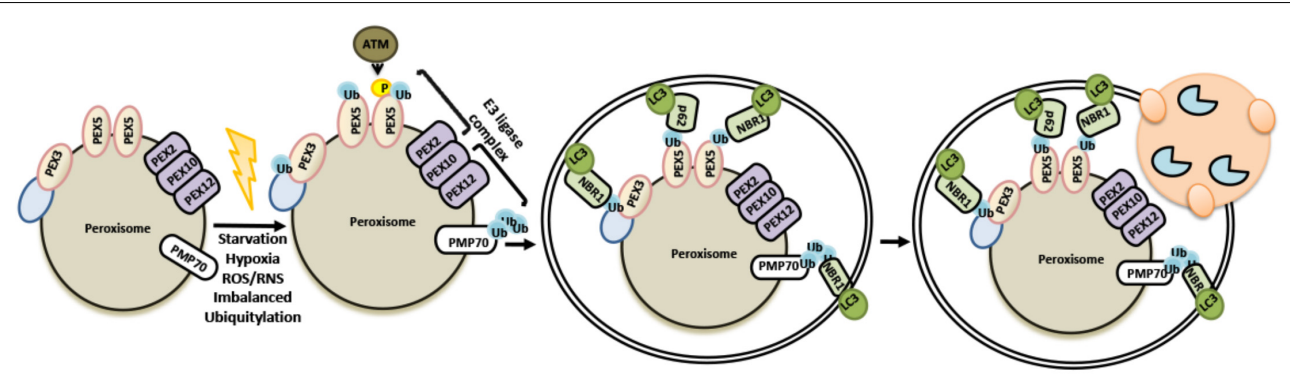

FIGURE 8 | Selective removal of peroxisomes by autophagy utilizes ubiquitylation as signal. 


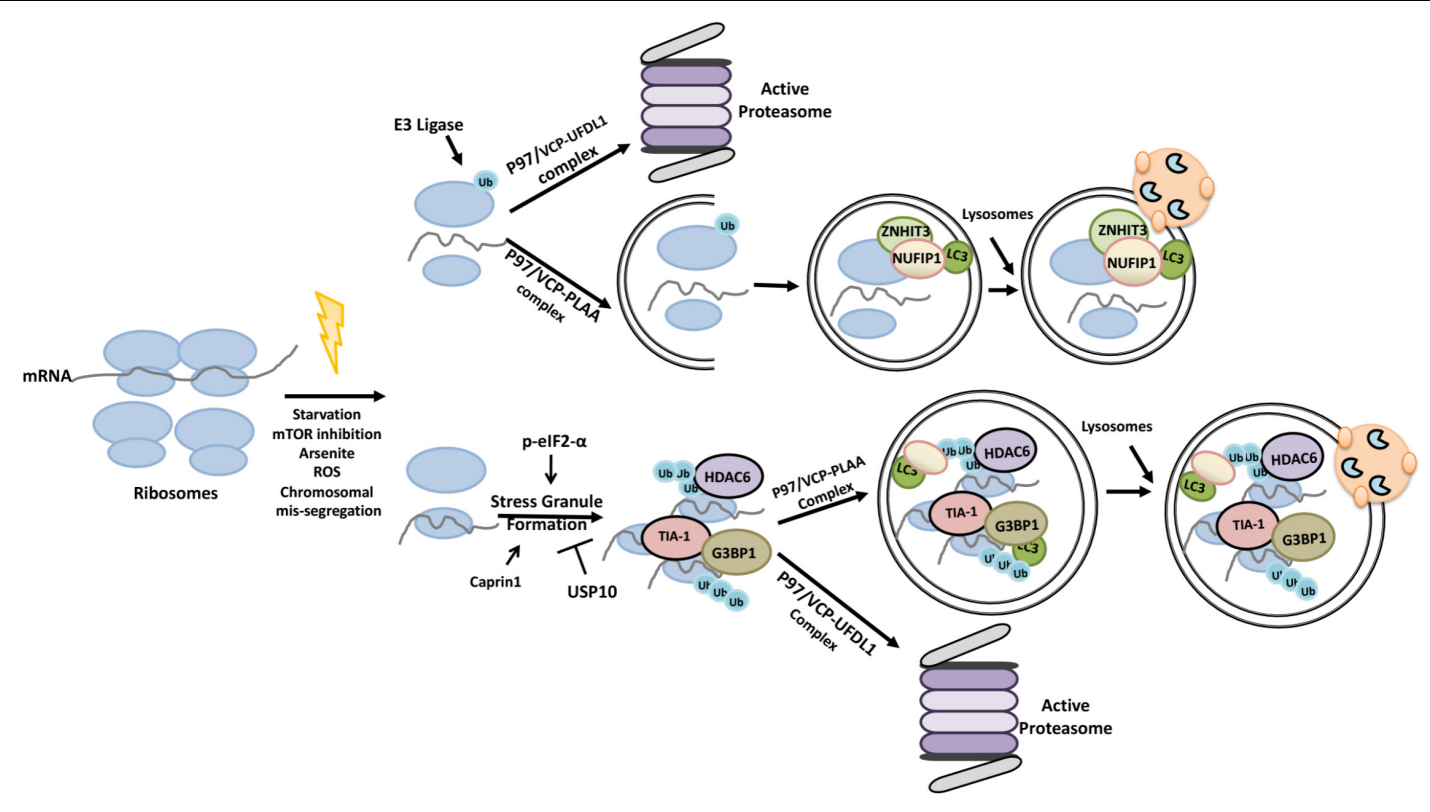

FIGURE 9 | Ubiquitylation primes ribosomes and stress granules for proteasomal degradation and autophagic elimination.

stress granule formation (Kedersha et al., 2016). HDAC6 protein was a component of stress granules as well (Seguin et al., 2014).

Accumulating data indicate that both the UPS and autophagy play a role in stress granüle control and elimination, and the p97/VCP protein was a key component in these processes. For example, inhibition of autophagy or p97/VCP deficiency was linked to decreased stress granule removal (Buchan et al., 2013). Co-factors of p97/VCP determined target selectivity of the protein. In this context, while the association of p97/VCP with the co-factor UFD1L led to the degradation of defective ribosomal products and dysfunctional 60S ribosomes by the UPS (Ju et al., 2008; Fujii et al., 2012; Verma et al., 2013), HDAC6 containing p97/VCP and PLAA associated granules were made a target of ribophagy (Ossareh-Nazari et al., 2010). Therefore depending on the co-factor of choice, $\mathrm{p} 97 / \mathrm{VCP}$ has a decisive role in the choice of the degradative pathway through which ribonuclear substrates are eliminated.

\section{Cross Talk Between UPS and Autophagy During Endoplasmic Reticulum Stress}

Endoplasmic reticulum (ER) stress is one of the conditions under which both the UPS and autophagy pathways are being activated. Abnormalities in calcium homeostasis, oxidative stress and conditions leading to protein glycosylation or folding defects etc. may result in the accumulation of misfolded and/or unfolded proteins in the ER lumen, a condition known as ER stress. ER stress might be very destructive for cells, therefore ER-specific stress response pathways such as the unfolded protein response (UPR) and the ER-associated degradation (ERAD) pathways were evolved. Both pathways are directly or indirectly connected to the UPS and autophagy.
In mammalian cells, accumulation of unfolded proteins in the lumen of the ER result in the activation of stress responses. Following protein accumulation in the ER, the chaperone protein GRP78/BiP dissociates from the lumen-facing parts of the transmembrane proteins IRE1, ATF-6, and PERK and bind to unfolded proteins in order to assist their refolding. GRP78/BiP release triggers activation of these stress proteins (Bertolotti et al., 2000; Shen et al., 2002). PERK activation leads to the phosphorylation of the $\alpha$ subunit of the translation initiation factor, eIF $2 \alpha$, which inhibits the assembly of the $80 \mathrm{~S}$ ribosome and cap-dependent protein synthesis, while allowing cap-independent translation of the stress response genes such as ATF4. Activation of IRE1 and ATF6 promotes transcription of other stress response genes. IRE1-mediated processing generates a splice-form of the XBP1 mRNA, resulting in the production of a transcription factor that upregulates chaperones and other relevant genes. GRP78/BiP dissociation results in the transfer of ATF6 to Golgi where cleavage of the protein by S1P and S2P proteases creates an N-terminal ATF6 fragment possessing a transcriptional activity (Figure 10). Due to a decrease in the protein load in the ER and an increased folding capacity, the UPR facilitates recovery from stress. In case of failure, the UPR sensitizes cells to programmed death mechanisms.

Components of the UPR were subject to active regulation by the UPS. For example, SCF component E3 ligase $\beta \operatorname{TrCP}$ was shown to lead to the ubiquitylation ATF4 following its phosphorylation (Lassot et al., 2001). On one other hand, persistent ER stress induced transcription of E3 ligase Siah1/2 following PERK-ATF4 and IRE1-XBP1 activation. On the other hand, by targeting prolyl hydroxylase PHD3, Siah1/2 was shown to regulate ATF4 hydroxylation and activity (Scortegagna et al., 2014). CHOP stability was regulated by the UPS and p300 and cIAP were responsible for $\mathrm{CHOP}$ ubiquitylation and degradation 


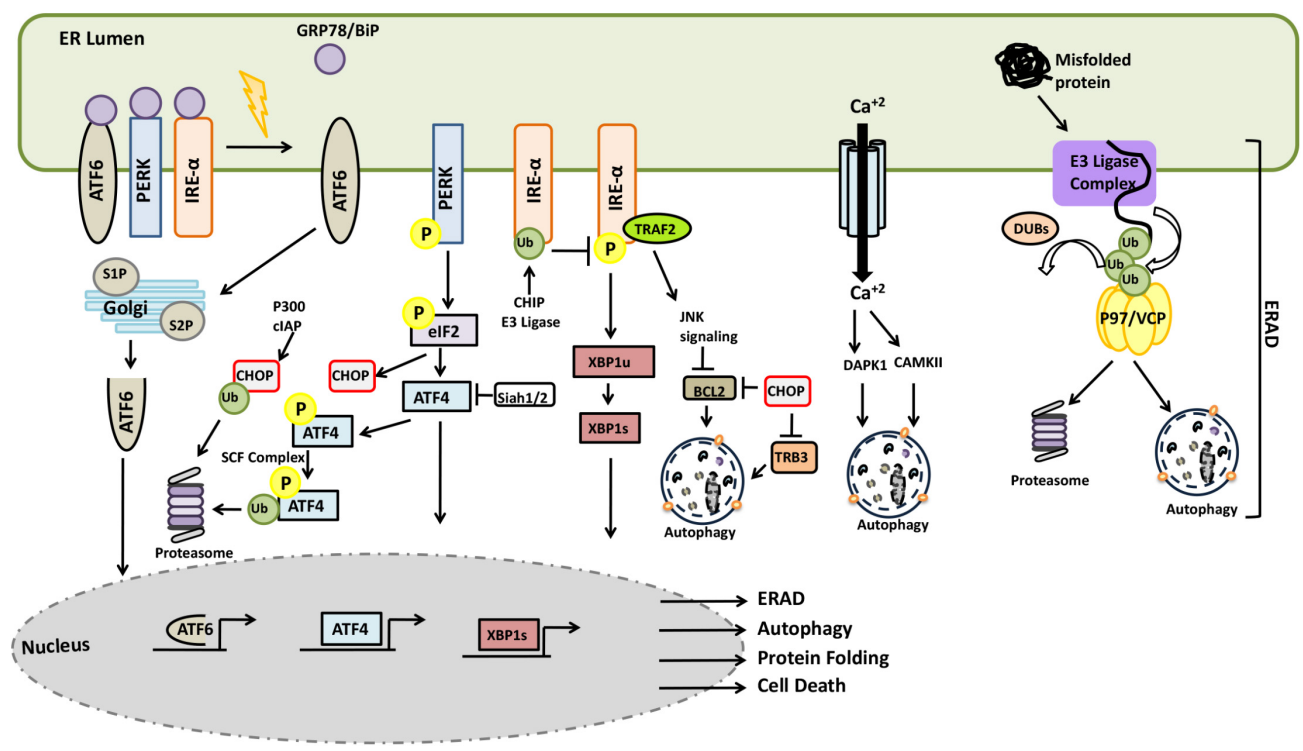

FIGURE 10 | Crosstalk between the UPS and autophagy systems during ER stress and ERAD.

counterbalancing its upregulation during ER stress (Qi and Xia, 2012; Jeong et al., 2014). Another UPR component, IRE1 was identified as a ubiquitylation target of the E3 ligase CHIP during ER stress. Ubiquitylation IRE1 inhibited its phosphorylation, perturbed its interaction with TRAF2, and attenuating JNK signaling (Zhu et al., 2014). Under stress conditions, translation of XIAP, an E3 ligase protein and an inhibitor of apoptosis was downregulated in a PERK-eIF2 $\alpha$-dependent manner. In the same context, ATF4 may promote ubiquitylation and degradation of XIAP, leading to sensitization of cells to ER stress-related cell death (Hiramatsu et al., 2014). Conversely, activation of PERK-eIF2 $\alpha$ axis might also show opposing effects through induction of other IAP proteins, cIAP1 and cIAP2, and counter balance cell death induction signals (Hamanaka et al., 2009).

Endoplasmic reticulum stress was shown to trigger autophagy, and ER-related stress response mechanisms were involved in the process. PERK-mediated phosphorylation of eIF2 $\alpha$ and resulting ATF4 and $\mathrm{CHOP}$ activation, were associated with the transcription of genes such as ATG5, ATG12, Beclin1, ATG16L1, LC3, p62 and TSC2 activator, hence mTOR inhibitor REDD1 (Whitney et al., 2009; B'Chir et al., 2013). Moreover, CHOP downregulated BCL2 binding (Mccullough et al., 2001). TRB3, an AKT inhibitor protein, was also described as a target of CHOP (Ohoka et al., 2005). In addition, IRE1 activation resulted in the recruitment of ASK1 by the adaptor TRAF2 and the outcome was the activation of JNK and p38 kinases (Nishitoh et al., 2002). BCL2 is one of the targets of JNK, its phosphorylation by the kinase resulted in destabilization the inhibitory BCL2-Beclin1 complex, stimulating autophagy (Bassik et al., 2004). On the other hand, in its unspliced form, IRE1 splicing target XBP1, in its unspliced form was shown to target the autophagy activator FOXO1 for degradation by the UPS (Vidal et al., 2012; Xiong et al., 2012).
Endoplasmic reticulum is a major calcium store in cells, and calcium release to cytosol was observed during ER stress. In addition to problems with SERCA refill pumps and leakiness of membranes during stress, upregulation of ERO1- $\alpha$ by CHOP resulted in an IP3-mediated calcium release (Li et al., 2009). Calcium binding protein calmodulin senses the cytosolic increase in the concentration of the ion, and bind to calmodulin-regulated kinases such as CaMKII and DAPK1, modulating their activity. Activated CaMKII was shown to stimulate autophagy through AMPK phosphorylation and activation (Høyer-Hansen et al., 2007). In addition, calmodulin-binding and PP2A-mediated dephosphorylation was necessary for the activation of the autophagy-related kinase DAPK1 (Gozuacik et al., 2008). DAPK1 could directly phosphorylate Beclin1 on the BH3-domain, resulting in the dissociation of Beclin1 from the BCL2-Beclin1 complex and allowing it to stimulate autophagy (Zalckvar et al., 2009).

Proteins that accumulate in the ER are degraded by the ER-associated degradation (ERAD) system. ERAD mediates transport, extraction and ubiquitylation of proteins that cannot be salvaged and target them for degradation in proteasomes. In mammalian cells, ER membrane-resident complexes containing E3 ligases such as HRD1 and GP78, and other regulatory components such as EDEM1, SEL1L, ERManI, and HERP control the ERAD pathway. P97/VCP protein and its co-factors also play a role in the pathway (DeLaBarre et al., 2006; Nowis et al., 2006). Unfolded/misfolded proteins are recognized in the lumen of the ER by chaperone proteins, including BiP/GRP78 and EDEM1, and are then subsequently targeted them to the ERAD pathway. During retrotranslocation of client proteins to cytosol, ubiquitylation is followed by a p97/VCP-assisted extraction. P97/VCP also assists in the delivery of proteins to proteasomes for degradation. DUB proteins, including YOD1, USP13, USP19, and Ataxin-3 were implicated in the control of client protein 
ubiquitylation and ERAD substrate modulation (Zhong and Pittman, 2006; Bernardi et al., 2013; Liu Y. et al., 2014; Harada et al., 2016).

ER-associated degradation regulators and therefore ERAD might be controlled by the UPS and autophagy pathways. For example, E3 ligase Smurf1 was found to be downregulated during ER stress, resulting in the accumulation of its direct ubiquitylation target WFS, which is a stabilizer ER-related E3 ligase HRD1 (Guo et al., 2011). Smurf1 was also involved in selective bacterial autophagy (Franco et al., 2017). On the other hand, while the ERAD complex component HERP protein was degraded by the UPS (Hori et al., 2004), EDEM1 and ERManI proteins were eliminated by the autophagy machinery (Le Fourn et al., 2013; Park et al., 2014; Benyair et al., 2015). An ER-localized E3 ligase synoviolin protein was shown to ubiquitylate HERP protein and control its degradation by proteasome (Maeda et al., 2018). Yet, other ERAD-related components, EDEM1 and Derlin2 as well as ubiquitylated EDEM1 proteins colocalized with cytoplasmic aggregates and autophagy receptors p62 and NBR1, they were degraded by selective autophagy (Le Fourn et al., 2013; Park et al., 2014). ERManI, a mannosidase that is responsible for priming ERresident glycosylated proteins for degradation, was described as an accelerator of the ERAD pathway and clearance of clients by the UPS. But, following proteasome inhibition and subsequent ER stress, ERManI colocalized with LC3 and degraded in an autophagy-dependent manner (Benyair et al., 2015).

All these findings point out to the presence of important junctions and coregulation nodes between the UPS and autophagy in the context of ER stress. Additionally, ERphagy, the autophagy of portions of the ER, was implicated in the recovery from ER stress and control of ER size, but this mechanism was so far described as a ubiquitin-independent process (Schuck et al., 2014).

\section{Transcriptional Mechanisms Connecting the UPS and Autophagy}

Several transcription factors that are regulated by the UPS, including $\mathrm{p} 53$, NFкB, HIF $1 \alpha$, and FOXO, have been implicated in the control of autophagy. In general, these factors were shown to directly activate transcription of key autophagy genes under stress conditions. Some autophagy proteins such as LC3 are consumed in the lysosome following delivery, and during prolonged stress, cellular levels of these proteins are sustained by mechanisms, including transcription. On the other hand, regulation of the transcriptional activity NRF2 involves a special crosstalk between the two systems. In this section, we will summarize molecular details of transcription regulation by the UPS and autophagy.

P53, a guardian of the genome, is one of the well-known transcriptonal regulators that has a dual role in autophagy depending on its intracellular localization. In the absence of stress, cellular p53 levels are controlled by the E3 ligase HDM2/MDM2 and the UPS. Under stress conditions, p14/p19/ARF protein binds, sequesters and inactivates HDM2/MDM2, stabilizing p53. Accumulating p53 protein activates transcription of several stress- and death-related genes, including autophagy-related genes PRKAB1, PRKAB2, TSC2, ATG2, ATG4, ATG7, ATG10,ULK1, BNIP3, DRAM1, and SESN2 (Crighton et al., 2006; Feng et al., 2007; Budanov and Karin, 2009; Kenzelmann Broz et al., 2013). On the other hand, a cytosolic form of p53 was shown to inhibit AMPK and activate the mTOR pathway. In this context, non-genotoxic stress by autophagy-inducing agents such as rapamycin, tunicamycin and nutrient deprivation favored HMD2/MDM2-dependent p53 degradation by the UPS (Tasdemir et al., 2008a,b). Interestingly, HMD2/MDM2 stability and activity were also regulated by E3 ligases SMURF1/2 which in turn affected the stability of p53. SMURF1/2-mediated ubiquitylation was shown to increase MDM2-MDMX heterodimerization, decreasing autoubiquitylation of MDM2, therefore stabilized the protein (Nie et al., 2010). Additionally, another E3 ligase, NEDD4-1 was shown to control MDM2 stability and p53 activation (Xu et al., 2015). In addition to MDM2, another E3 ligase, PIRH2, was able to ubiquitylate p53 to control its cellular stability (Shloush et al., 2011).

NF- $\kappa \mathrm{B}$ is a well studied transcriptional regulator of autophagy. As a result of its association with IКB, NF- $\kappa \mathrm{B}$ is found in an inactive state in the cytosol. In response to agonists, IкB was reported to be ubiquitylated and subsequently degraded by the UPS. Regulation of NF- $\mathrm{B}$ by external signals involved phosphorylation of IKB by upstream kinases of the IKK complex (IKK $\alpha$, IKK $\beta$, and IKK $\gamma / \mathrm{NEMO}$ ). Phosphorylated IкB recruits the E3 ligase SCF- $\beta$ TRCP, followed by its degradation in the

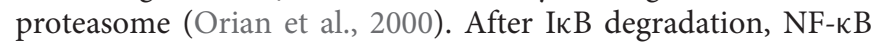
was then free to migrate to the nucleus of the cell, and induce transcription of target genes, including Beclin1 and p62, and induce autophagy (Copetti et al., 2009; Ling et al., 2012).

Another level of regulation involved TNF- $\alpha$ receptor-associated protein complexes. Binding of TNF- $\alpha$ to TNFR1 led to the recruitment of TRADD and RIPK1 to the receptor, promoting TRAF- and cIAP-mediated K63 and/or K11 linked ubiquitylation of the RIPK1. Ubiquitylated RIPK1 could recruit NEMO and TAB-TAK1 complex for IKK activation and hence NF- $\mathrm{BB}$ stimulation. Additionally, RIPK1 could also be modified by A20 through addition of K48-linked poly-ubiquitin chains, sending the kinase for proteasomal degradation (Kravtsova-ivantsiv et al., 2015).

However, in some contexts, TNF- $\alpha$-induced NF- $\kappa$ B activation was reported to inhibit autophagy (Djavaheri-Mergny et al., 2006). TNF- $\alpha$-induced activation of IKK $\alpha$ or IKK $\beta$ could stimulate phosphorylation of TSC1/2 and activate mTOR, leading to a similar inhibitory outcome (Lee et al., 2007; Dan and Baldwin, 2008). Furthermore in some contexts, RIPK1 silencing activated autophagy under both basal and stress conditions (Yonekawa et al., 2015). On the other hand, RIPK1 itself was reported to be a target of p62-mediated selective autophagy (Goodall et al., 2016). Moreover, autophagy was responsible for the degradation of NF- $\mathrm{BB}$ activator NIK and IKK complex subunits, indicating the presence of a tight cross-regulation of the NF-кB pathway by the UPS and autophagy (Qing et al., 2007).

Another transcription factor that was controlling the autophagic outcome was HIF1 $\alpha$. Hypoxia induced HIF1 $\alpha$ transcriptionally regulated various hypoxia response genes, 
including GLUT1 (Chen et al., 2001), NOX2 (Yuan et al., 2011), and PDK1 (Kim et al., 2006) as well as autophagy genes, including BNIP3, BNIP3L, ATG5, and BECN1 to stimulate autophagy, mitophagy, and pexophagy (Zhang et al., 2008; Bellot et al., 2009; Walter et al., 2014). HIF1 $\alpha$ itself was regulated in a UPS-dependent manner. Under normoxia, hydroxylation of HIF1 $\alpha$ specific prolyl hydroxylases (PHDs) hydroxylated HIF1 $\alpha$ (Jaakkola et al., 2014) served as a recognition signal for $\mathrm{UbcH5}$, an E2 enzyme and von Hippel-Lindau protein (the pVHL), E3 ligase complex containing Elongin B and C, Cullin-2, and Rbx1 allowing K48 linked ubiquitination of HIF1 $\alpha$ and its proteasomal degradation (Ohh et al., 2000; Lee et al., 2015). In contrast, during hypoxia, PHDs were inhibited and HIF1 $\alpha$ stabilized. SCF E3 ligase complex was also a regulator of HIF1 $\alpha$ stability in response to GSK3 $\beta$-mediated phosphorylation of the protein (Cassavaugh et al., 2011; Flugel et al., 2012). Another E3 ligase facilitating HIF1 $\alpha$ degradation was HAF (also known as SART $1_{800}$ ). Unlike pVHL, HAF-mediated ubiquitylation of HIF $1 \alpha$ was not depending on the oxygen levels, providing an alternative HIF1 $\alpha$ regulation mechanism (Koh et al., 2008). Stability of PHD proteins were also controlled by the UPS. For example, SIAH1/2 was shown to direct PHDs for proteasomal degradation under hypoxic stress (Nakayama et al., 2004). Moreover several DUBs were implicated in HIF1 $\alpha$ regulation, including USP20 (Li et al., 2002b), USP28 (Flugel et al., 2012), and USP33 (Li et al., 2002a).

FOXO family of transcription factors (FOXOs) were associated with various cellular pathways, including autophagy (Zhao et al., 2007). The activity of FOXOs were regulated by their phosphorylation status and following activation, FOXOs translocated to the nucleus and triggered the expression of a number of genes associated with different stages of the autophagy pathway, including ATG4, ATG12, BECN1, ULK1, PIK3C3, MAP1LC3, and GABARAP (Mammucari et al., 2007; Zhao et al., 2007; Sanchez et al., 2012). There are several connections between FOXOs and autophagy. Activation of the AKT pathway inhibited FOXO3 activity, led to a decrease in LC3 and BNIP3 expression, therefore blocked autophagy (Stitt et al., 2004; Mammucari et al., 2007). On the other hand, AMPK activation led to the phosphorylation of FOXO3a and ULK1, inducing MAP1LC3, GABARAP, and BECN1 expression and subsequent autophagy activation (Sanchez et al., 2012). Another FOXO family protein FOXK1/2, a negative regulator of FOXO3, was associated with a decrease in autophagy by removing $\operatorname{Sin} 3 \mathrm{~A} / \mathrm{HDAC}$ complex from histone $\mathrm{H} 4$ to diminish its acetylation. In this context, nuclear localization of FOXK1/2 was mTOR-dependent and showed an inhibitory effect on autophagy gene expression under basal conditions (Bowman et al., 2014). Moreover, JNK deficiency in neurons increased autophagic activity through FOXO1-mediated BNIP3 upregulation and Beclin1 disassociation from BCL-XL (Xu et al., 2011). Another example of a link between FOXOs autophagy involved ATG14. Liver specific knockout of FOXOs resulted in the downregulation of ATG14 and this event was associated with high levels of triglycerides in the liver and serum of mice (Xiong et al., 2012). Additionally, GATA-1 shown to directly regulate FOXO3-mediated activation of LC3 genes to facilitate autophagic activity (Kang et al., 2012).
Phosphorylation of FOXO proteins by various protein kinases, including AKT, IKK, and ERK, affected their ubiquitylation by E3 ligases and their stability (Huang and Tindall, 2011). For instance, AKT-mediated phosphorylation of FOXO1 provided a signal for its recognition by the SKP protein, an SCF E3 ligase complex component, followed by FOXO1 ubiquitylation and degradation (Huang et al., 2005). COP1 was also identified as an E3 ligase that regulated FOXO protein stability. COP1 ubiquitylated FOXO1 and promoted its proteasomal degradation. This type of regulation might be important in the glucose metabolism of hepatocytes, and possibly in autophagy modulation under this conditions (Kato et al., 2008). Another FOXO regulating E3 ligase was MDM2 that was reported to be responsible for FOXO1 and FOXO3A ubiquitylation and degradation (Fu et al., 2009). MDM2-mediated ubiquitylation was activated by the phosphorylation of FOXOs by AKT. Due to its role in p53 regulation, MDM2 could be part of a more complex regulatory mechanism which might link the UPS, transcriptional regulation and autophagic activity.

NRF2-KEAP1-P62 pathway was defined as another major oxidative stress response mechanism involving an interplay between the UPS and autophagy. NRF2 is a transcription factor, and when activated, is upregulated antioxidant and metabolic enzymes, including TXNRD1 (Suvorova et al., 2009), HMOX1 (Reichard et al., 2007), GPX2 (Banning et al., 2005), GBE1, PHK1 (Banning et al., 2005), and downregulated proinflammation-related genes such as IL6, IL1B (Kobayashi et al., 2016). KEAP1 is an adaptor protein of the E3 ligase Cullin-3 and plays a role in substrate recognition. Under normal conditions, transcription factor NRF2 was found in association with KEAP1-Cullin-3 E3 ligase complex, that catalyzed its ubiquitylation, rendering it a substrate for proteasomal elimination by selective autophagy (Ishimura et al., 2014). Competition resulted in the migration of free NRF2 to the nucleus and transactivation of stress-related cytoprotective genes (Kobayashi et al., 2004; Komatsu et al., 2010). Additionally, the NRF2-KEAP1 pathway provides a positive feedback loop for autophagy. P62 was characterized as a direct transcriptional target of activated NRF2 (Jain et al., 2010). Moreover, KEAP1 regulation by p62 was modulated by the E3 ligase TRIM21. NRF2 activation was negatively affected by TRIM21-mediated K63-linked ubiquitylation of p62 (Pan et al., 2016).

\section{Autophagy-UPS Crosstalk in Diseases}

Crosstalk between autophagy and the UPS may change character under disease conditions, contribute to the pathogenesis of diseases and even affect their outcome. Degenerative diseases and cancer are examples of diseases that illustrate the interplay between the UPS and autophagy in the clearance of misfolded abnormal proteins (Juenemann et al., 2013).

For example, Huntington Disease is caused by poly-glutamine extensions in a protein called Huntingtin (Htt), leading to abnormal organization and eventual aggregation of the protein. Htt protein was shown to be ubiquitylated via K48- or K63-linked ubiquitin chains (Bhat et al., 2014). Mutant Htt clearance depended on both the UPS and autophagy in different experimental settings. Mutant $\mathrm{Htt}$ aggregates were largely cleared 
by K63-dependent autophagy mechanisms (Renna et al., 2010; Menzies et al., 2015). On the other hand, overexpression of K48-specific E3 ligase Ube3a, resulted in a UPS-dependent degradation of mutant proteins. Yet, cellular levels of E3 ligase was shown to decline in an age-dependent manner. Therefore, in elderly people, accumulation of K63-linked polyubiquitylated proteins might tip the balance toward clearance of protein aggregates by autophagy. A similar UPS switch was also observed in a CHIP-dependent manner (Jana et al., 2005; Bhat et al., 2014).

Another example involves the ERAD protein p97/VCP. Mutant forms of the protein were associated with a rare syndrome that mainly affects muscles, bones and the brain (Inclusion Body Myopathy with the Paget's Disease of Bone and frontotemporal Dementia, IBMPFD). Moreover, p97/VCP mutations were detected in a fraction of patients suffering from familial forms of Parkinson's Disease or from Amyotrophic Lateral Sclerosis (ALS) (Johnson et al., 2010). As mentioned in the previous sections, p97/VCP is important for the extraction of misfolded ER proteins as well as their delivery to proteasomes. Moreover, p97/VCP was proposed to play a role in autophagosome maturation and autolysosome formation (Tresse et al., 2010). We recently showed that some of the diseaserelated mutations of $\mathrm{p} 97 / \mathrm{VCP}$ (namely P137L and G157R) resulted in the aggregation of the protein itself. Mutant p97/VCP proteins formed complexes with wild-type counterparts and led to further accumulation of ubiquitylated proteins upon ER stress, indicating that the ERAD system was negatively affected by the mutant (Bayraktar et al., 2016). Indeed, ERAD cofactor and ubiquitin binding capacity of the mutant p97/VCP was decreased (Erzurumlu et al., 2013). Yet, autophagy was still functional under these conditions, and could significantly eliminate these aggregates (Bayraktar et al., 2016). Therefore, preferential elimination of mutant proteins by autophagy might tip the balance in favor of wild-type proteins and restore disease-related loss of cellular functions including UPS-related mechanisms.

The role of the crosstalk between the two systems is also prominent in the cancer context. For example, the P53-regulated and cancer-related protein EI24, was introduced as a critical link between the UPS and autophagy (Devkota et al., 2012). EI24 controlled the stability of E3 ligases TRIM41, TRIM2, and TRIM28 by the regulation of their autophagic degradation (Devkota et al., 2016; Nam et al., 2017). Cellular levels of other E3 ligases, namely MDM2 and TRAF2, were also regulated by EI24-controlled degradation, modulating p53 and mTOR pathways, respectively, and influencing cancer formation and progression (Devkota et al., 2016).

Deregulation and/or mutations of proteins that function in the autophagy and/or the UPS were observed in some cancer types, resulting in the modification of individual pathways and possibly affecting the crosstalk between the two systems. Changes include, modulation of levels of E3 ligases such as MDM2 (Haupt et al., 2017), SMURF1 (Fukunaga et al., 2008; Kwon et al., 2013), SCF components (e.g., $\beta$ TrCP), point mutations of NEDD4 (Amodio et al., 2010), COP1 (Marine, 2012), FBXW7 (Korphaisarn et al., 2017), and mutations in autophagy related proteins Beclin1 (Laddha et al., 2014), LKB1 (Ji et al., 2007),
ATG5 (Takamura et al., 2011), ATG4C (Marino et al., 2007) as well as deletions of genes of proteins, such as Beclin1 (Liang et al., 1999; Qu et al., 2003), AMPK (Li et al., 2015) and UVRAG (He et al., 2015). Under these circumstances, dynamic and complex changes in the regulation of the degradative pathways should have dramatic effects that contribute to cancer-related alterations in the proteomic landscape of cells.

Autophagy-UPS crosstalk emerges as a critical factor that determines the success of disease treatment, chemotherapy is one striking example. For instance, proteasome inhibition by the chemotherapy agent bortezomib resulted in the accumulation of misfolded proteins and induced compensatory autophagy in cancer cells (Obeng et al., 2006). Under these circumstances, autophagic activity protected cancer cells from bortezomibinduced cell death, and inhibition of autophagy improved the outcome of chemotherapy. These dual autophagy-UPS targeting approaches also gave promising results in clinical trials (Vogl et al., 2014).

Several companies are now developing drugs that modulate the UPS or autophagy [for example, (Huang and Dixit, 2016)]. Concepts and data that were discussed above and elsewhere indicate that, depending on the disease type and treatment strategy, the crosstalk between the UPS and autophagy should definitely be taken into account in these efforts.

\section{CONCLUSION AND PERSPECTIVES}

Autophagy and the ubiquitin proteasome systems are major degradation systems in mammalian cells that allow recycling of cellular contents ranging from soluble proteins to intracellular organelles. Although their mode of action and their requirements for substrate recognition are different, there are several overlaps and interconnections between the UPS and autophagy pathways.

A prominent component of the crosstalk is the ubiquitin protein itself and ubiquitylation. Indeed, ubiquitin is a common signal for both the UPS and autophagy. It was proposed that, ubiquitin chain type could determine the pathway of choice for protein degradation. K48-linked ubiquitylation was introduced to be a signal for the UPS, whereas K63-linked ubiquitylation directed proteins for autophagosomal degradation (Herhaus and Dikic, 2015). Yet, a number of independent studies provided evidence that both ubiquitylation types could lead to autophagic degradation of substrates (Wandel et al., 2017). Moreover, recent studies underline the importance of ubiquitin phosphorylation as an event that increased the affinity of autophagy receptors for their targets during selective autophagy (Kane et al., 2014; Koyano et al., 2014). Additionally, non-ubiquitin modifications (e.g., acetylation, sumoylation, neddylation etc.) were shown to affect protein degradation as well (Hwang and Lee, 2017). Therefore, a barcode of ubiquitin and other modifications seem to prime proteins for one or the other degradation pathway and determine their fate. As another level of regulation, deconjugating enzymes such as DUBs may counteract or redirect proteins for different degradation systems.

E3 ligases emerged as important components of the UPS-autophagy switches. For example, Cullin-3 
(Pintard et al., 2004), SMURF1 (Ebisawa et al., 2001), MDM2 (Shi and Gu, 2012) E3 ligases directed proteins to degradation by the UPS, whereas the role of Parkin (Chan et al., 2011), LRSAM1 (Huett et al., 2012), and CHIP (Shin et al., 2005) in priming proteins for autophagic degradation was observed in several studies. On the other hand, the same E3 ligase that might be able to generate different ubiquitin linkages under different conditions and on different substrates (Chan et al., 2011), the switch between degradative pathways being controlled by specific E3 ligase adaptors, post-translational modifications on target proteins as well as other unknown factors. A prominent example is the Parkin protein. During mitophagy although some of the proteins that are ubiquitylated by Parkin are degraded, other ubiquitylated proteins contribute to mitochondrial clustering and recognition by autophagy receptors. To date, factors or modifications that determine the substrate selectivity of Parkin are unknown.

Another example of UPS-autophagy switch involves the p97/VCP protein. While binding of the co-factor PLAA to p97/VCP resulted in the autophagic degradation of ubiquitylated clients of the protein, binding of UFDL1 as a co-factor favored degradation by the UPS. Moreover, p97/VCP was also associated with aggregate formation in collaboration with some autophagy receptors.

Signaling switches involved in the regulated activation of one or the other system was shown to modify cellular responses to stress. For example, NRF2 degradation by the UPS was controlled through p62-mediated KEAP1 elimination by autophagy (Jain et al., 2010). Prevention of HIF1 $\alpha$ degradation by the UPS, resulted in the expression of stress response genes, including autophagy genes, led to autophagy activation. In another example, the UPS activity was required for NF- $\mathrm{B}$ activation and NF- $\kappa B$-mediated autophagy gene upregulation. Yet, autophagic degradation of NF- $\mathrm{KB}$ activators NIK and IKKs provided a negative feedback loop in the control in this context (Qing et al., 2007). Therefore, modification of cellular signaling pathways by degradative systems might modulate upstream signals that control autophagy and/or the UPS, and affect their activation and amplitude.

Degradation of the components or regulators of one system by the other system was also reported. For example, proteasomes were defined as substrates of selective autophagy (Marshall et al., 2015). Conversely, various autophagy proteins were ubiquitylated and degraded by the UPS in a regulated manner. Therefore, checks and balances between the two systems exist, and these control mechanisms possibly allow remodeling of the cellular proteome under different conditions.

Compensation mechanisms are also operational between the two systems. Inhibition of the UPS generally upregulated autophagy, whereas failures in the autophagy system were associated with increased UPS activity, although inefficient compensation and failure in both systems were also observed under certain conditions (Korolchuk et al., 2009a,b). Moreover, alternative protein degradation pathways, such as CMA and microautophagy might come into play under these conditions as well. Nevertheless, depending on the character of the target to be degraded, compensation mechanisms were less or more effective. For example, large aggregates and whole organelles should be cleared by autophagy, but defective ribosomal products that could not be accumulated in stress granules were shown to be directed for proteasomal degradation. Therefore for cellular homeostasis and for proper functioning of cells, ideally both systems should be fully operational.

Data obtained so far demonstrate that crosstalk and communication between autophagy and the UPS generally rely on non-specialized and even indirect links. Yet, there might exist so far unknown specialized proteins providing coordination and co-regulation of the two systems. Furthermore, regulation through direct protein-protein interactions between known system components is another possibility. Therefore, dedicated communication proteins or pathways between the degradation mechanisms may be present, allowing better and faster coordination in case of need. Further studies are required to unveil the nature of these putative proteins, interactions and pathways.

An emerging theme in the regulation and coordination of autophagy and the UPS involves non-coding RNAs and their intricate networks. A growing list of microRNAs as well as long non-coding RNAs were implicated in the control of autophagy (Tekirdag et al., 2016) as well as the UPS (Wu and Pfeffer, 2016; Chang et al., 2018). MicroRNAs have the advantage of affecting the level of multiple proteins at once, and they are able to rapidly reshape cellular signaling mechanisms and pathways. Therefore, non-coding RNA networks possibly contribute to the co-regulation of these degradative systems. Intriguingly, deregulation of non-coding RNA levels contribute to the progression of diseases such as cancer. Future studies on non-coding RNAs will reveal their relevance in the autophagyUPS crosstalk under physiological and pathological conditions.

Overall, coordination, interconnection and crosstalk mechanisms between the UPS and autophagy exist at various levels. In addition to ubiquitin and ubiquitylation, several proteins and signaling pathways were implicated in the communication and mutual regulation of the two systems. Considering the importance of protein catabolism for cellular and organismal homeostasis and health, a better understanding of individual systems as well as the interconnections and crosstalks between them will be most rewarding from both a basic science perspective and with regards to clinical management of diseases involving protein quality control problems.

\section{AUTHOR CONTRIBUTIONS}

NK and DG wrote the manuscript and did critical reading. NK prepared the illustrations in the manuscript.

\section{FUNDING}

This work was supported by the Scientific and Technological Research Council of Turkey (TÜBİTAK) 1001 Grant Project Number 110T405 and Sabanci University. NK was supported by TUBITAK-BIDEB 2211-A Ph.D. Scholarship during Ph.D. studies. 


\section{REFERENCES}

Aerbajinai, W., Giattina, M., Lee, Y. T., Raffeld, M., and Miller, J. L. (2003). The proapoptotic factor Nix is coexpressed with Bcl-xL during terminal erythroid differentiation. Blood 102, 712-717. doi: 10.1182/blood-2002-11-3324

Altieri, D. C. (2010). Survivin and IAP proteins in cell-death mechanisms. Biochem. J. 430, 199-205. doi: 10.1042/BJ20100814

Ambivero, C. T., Cilenti, L., Main, S., and Zervos, A. S. (2014). Mulan E3 ubiquitin ligase interacts with multiple E2 conjugating enzymes and participates in mitophagy by recruiting GABARAP. Cell. Signal. 26, 2921-2929. doi: 10.1016/j. cellsig.2014.09.004

Amodio, N., Scrima, M., Palaia, L., Salman, A. N., Quintiero, A., Franco, R., et al. (2010). Oncogenic role of the E3 ubiquitin ligase NEDD4-1, a PTEN negative regulator, in non-small-cell lung carcinomas. Am. J. Pathol. 177, 2622-2634. doi: 10.2353/ajpath.2010.091075

An, H., and Harper, J. W. (2018). Systematic analysis of ribophagy in human cells reveals bystander flux during selective autophagy. Nat. Cell Biol. 20, 135-143. doi: 10.1038/s41556-017-0007-x

Anding, A. L., and Baehrecke, E. H. (2017). Cleaning house: selective autophagy of organelles. Dev. Cell 41, 10-22. doi: 10.1016/j.devcel.2017.02.016

Antonioli, M., Di Rienzo, M., Piacentini, M., Fimia, G. M., Albiero, F., Nazio, F., et al. (2014). AMBRA1 interplay with cullin E3 Ubiquitin ligases regulates autophagy dynamics. Dev. Cell 31, 734-746. doi: 10.1016/j.devcel.2014.11.013

Arora, V., Cheung, H. H., Plenchette, S., Micali, O. C., Liston, P., and Korneluk, R. G. (2007). Degradation of survivin by the X-linked Inhibitor of Apoptosis (XIAP)-XAF1 complex. J. Biol. Chem. 282, 26202-26209. doi: 10.1074/jbc. M700776200

Banning, A., Deubel, S., Kluth, D., Zhou, Z., and Brigelius-Flohe, R. (2005). The GI-GPx gene is a target for Nrf2. Mol. Cell. Biol. 25, 4914-4923. doi: 10.1128/ MCB.25.12.4914-4923.2005

Bassik, M. C., Scorrano, L., Oakes, S. A., Pozzan, T., and Korsmeyer, S. J. (2004). Phosphorylation of BCL-2 regulates $\mathrm{ER} \mathrm{Ca} 2^{+}$homeostasis and apoptosis. EMBO J. 23, 1207-1216. doi: 10.1038/sj.emboj.7600104

Bayraktar, O., Oral, O., Kocaturk, N. M., Akkoc, Y., Eberhart, K., Kosar, A., et al. (2016). IBMPFD disease-causing mutant $\mathrm{VCP} / \mathrm{p} 97$ proteins are targets of autophagic-lysosomal degradation. PLoS One 11:e0164864. doi: 10.1371/ journal.pone.0164864

B'Chir, W., Maurin, A. C., Carraro, V., Averous, J., Jousse, C., Muranishi, Y., et al. (2013). The eIF2 $\alpha / A T F 4$ pathway is essential for stress-induced autophagy gene expression. Nucleic Acids Res. 41, 7683-7699. doi: 10.1093/nar/gkt563

Behrends, C., and Harper, J. W. (2011). Constructing and decoding unconventional ubiquitin chains. Nat. Struct. Mol. Biol. 18, 520-528. doi: 10.1038/nsmb.2066

Bellot, G., Garcia-Medina, R., Gounon, P., Chiche, J., Roux, D., Pouyssegur, J., et al. (2009). Hypoxia-induced autophagy is mediated through hypoxia-inducible factor induction of BNIP3 and BNIP3L via their BH3 domains. Mol. Cell. Biol. 29, 2570-2581. doi: 10.1128/MCB.00166-09

Benanti, J. A. (2012). Coordination of cell growth and division by the ubiquitinproteasome system. Semin. Cell Dev. Biol. 23, 492-498. doi: 10.1016/j.semcdb. 2012.04.005

Benyair, R., Ogen-Shtern, N., Mazkereth, N., Shai, B., Ehrlich, M., and Lederkremer, G. Z. (2015). Mammalian ER mannosidase I resides in quality control vesicles, where it encounters its glycoprotein substrates. Mol. Biol. Cell 26, 172-184. doi: 10.1091/mbc.E14-06-1152

Bernardi, K. M., Williams, J. M., Inoue, T., Schultz, A., and Tsai, B. (2013). A deubiquitinase negatively regulates retro-translocation of nonubiquitinated substrates. Mol. Biol. Cell 24, 3545-3556. doi: 10.1091/mbc.E13-06-0332

Bertolotti, A., Zhang, Y., Hendershot, L. M., Harding, H. P., and Ron, D. (2000). Dynamic interaction of BiP and ER stress transducers in the unfolded-protein response. Nat. Cell Biol. 2, 326-332. doi: 10.1038/35014014

Bhat, K. P., Yan, S., Wang, C.-E., Li, S., and Li, X.-J. (2014). Differential ubiquitination and degradation of huntingtin fragments modulated by ubiquitin-protein ligase E3A. Proc. Natl. Acad. Sci. U.S.A. 111, 5706-5711. doi: 10.1073/pnas.1402215111

Bingol, B., Tea, J. S., Phu, L., Reichelt, M., Bakalarski, C. E., Song, Q., et al. (2014). The mitochondrial deubiquitinase USP30 opposes parkin-mediated mitophagy. Nature 510, 370-375. doi: 10.1038/nature13418

Birmingham, C. L., Smith, A. C., Bakowski, M. A., Yoshimori, T., and Brumell, J. H. (2006). Autophagy controls Salmonella infection in response to damage to the Salmonella-containing vacuole. J. Biol. Chem. 281, 11374-11383. doi: 10.1074/jbc.M509157200

Bowman, C. J., Ayer, D. E., and Dynlacht, B. D. (2014). Foxk proteins repress the initiation of starvation-induced atrophy and autophagy programs. Nat. Cell Biol. 16, 1202-1214. doi: 10.1038/ncb3062

Braschi, E., Zunino, R., and McBride, H. M. (2009). MAPL is a new mitochondrial SUMO E3 ligase that regulates mitochondrial fission. EMBO Rep. 10, 748-754. doi: 10.1038/embor.2009.86

Buchan, J. R., Kolaitis, R. M., Taylor, J. P., and Parker, R. (2013). Eukaryotic stress granules are cleared by autophagy and Cdc48/VCP function. Cell 153, 1461-1474. doi: 10.1016/j.cell.2013.05.037

Budanov, A. V., and Karin, M. (2009). The p53-regulated Sestrin gene products inhibit mTOR signaling. Cell 134, 451-460. doi: 10.1016/j.cell.2008.06.028. The

Carvalho, A. F., Pinto, M. P., Grou, C. P., Alencastre, I. S., Fransen, M., Sá-Miranda, C., et al. (2007). Ubiquitination of mammalian Pex5p, the peroxisomal import receptor. J. Biol. Chem. 282, 31267-31272. doi: 10.1074/ jbc.M706325200

Cassavaugh, J. M., Hale, S. A., Wellman, T. L., Howe, A. K., Wong, C., and Lounsbury, K. M. (2011). Negative regulation of HIF-1 $\alpha$ by an FBW7-mediated degradation pathway during hypoxia. J. Cell. Biochem. 112, 3882-3890. doi: $10.1002 /$ jcb. 23321

Chan, N. C., Salazar, A. M., Pham, A. H., Sweredoski, M. J., Kolawa, N. J., Graham, R. L. J., et al. (2011). Broad activation of the ubiquitin-proteasome system by Parkin is critical for mitophagy. Hum. Mol. Genet. 20, 1726-1737. doi: 10.1093/ hmg/ddr048

Chang, H., Liu, Y., Wang, L., Wang, J., Zhao, Z., Qu, J., et al. (2018). MiR-182 promotes cell proliferation by suppressing FBXW7 and FBXW11 in non-small cell lung cancer. Am. J. Transl. Res. 10, 1131-1142.

Chen, C., Pore, N., Behrooz, A., Ismail-Beigi, F., and Maity, A. (2001). Regulation of glut1 mRNA by hypoxia-inducible factor-1: interaction between H-ras and hypoxia. J. Biol. Chem. 276, 9519-9525. doi: 10.1074/jbc.M01014 4200

Chen, M., Chen, Z., Wang, Y., Tan, Z., Zhu, C., Li, Y., et al. (2016). Mitophagy receptor FUNDC1 regulates mitochondrial dynamics and mitophagy. Autophagy 12, 689-702. doi: 10.1080/15548627.2016.115 1580

Chen, Z., Liu, L., Cheng, Q., Li, Y., Wu, H., Zhang, W., et al. (2017). Mitochondrial E3 ligase MARCH5 regulates FUNDC1 to fine-tune hypoxic mitophagy. EMBO Rep. 18, 495-509. doi: 10.15252/embr.201643309

Christianson, J. C., Olzmann, J. A., Shaler, T. A., Sowa, M. E., Bennett, E. J., Richter, C. M., et al. (2012). Defining human ERAD networks through an integrative mapping strategy. Nat. Cell Biol. 14, 93-105. doi: 10.1038/ncb2383

Clague, M. J., Heride, C., and Urbé, S. (2015). The demographics of the ubiquitin system. Trends Cell Biol. 25, 417-426. doi: 10.1016/j.tcb.2015.03.002

Clausen, T. H., Lamark, T., Isakson, P., Finley, K., Larsen, K. B., Brech, A., et al. (2010). p62/SQSTM1 and ALFY interact to facilitate the formation of p62 bodies/ALIS and their degradation by autophagy. Autophagy 6, 330-344. doi: 10.4161/auto.6.3.11226

Cohen-kaplan, V., Livneh, I., Avni, N., Fabre, B., Ziv, T., and Tae, Y. (2016). p62- and ubiquitin-dependent stress-induced autophagy of the mammalian 26S proteasome. Proc. Natl. Acad. Sci. U.S.A. 113, E7490-E7499. doi: 10.1073/pnas. 1615455113

Collins, C. A., De Mazière, A., Van Dijk, S., Carlsson, F., Klumperman, J., and Brown, E. J. (2009). Atg5-independent sequestration of ubiquitinated mycobacteria. PLoS Pathog. 5:e1000430. doi: 10.1371/journal.ppat.100 0430

Collins, G. A., and Goldberg, A. L. (2017). The logic of the $26 \mathrm{~S}$ proteasome. Cell 169, 792-806. doi: 10.1016/j.cell.2017.04.023

Copetti, T., Bertoli, C., Dalla, E., Demarchi, F., and Schneider, C. (2009). p65/RelA modulates BECN1 transcription and autophagy. Mol. Cell. Biol. 29, 2594-2608. doi: 10.1128/MCB.01396-08

Cornelissen, T., Haddad, D., Wauters, F., Van Humbeeck, C., Mandemakers, W., Koentjoro, B., et al. (2014). The deubiquitinase USP15 antagonizes Parkinmediated mitochondrial ubiquitination and mitophagy. Hum. Mol. Genet. 23, 5227-5242. doi: 10.1093/hmg/ddu244

Crighton, D., Wilkinson, S., O’Prey, J., Syed, N., Smith, P., Harrison, P. R., et al. (2006). DRAM, a p53-induced modulator of autophagy. Is critical for apoptosis. Cell 126, 121-134. doi: 10.1016/j.cell.2006.05.034 
Cuervo, A. M., Palmer, A., Rivett, A. J., and Knecht, E. (1995). Degradation of proteasomes by lysosomes in rat liver. Eur. J. Biochem. 227, 792-800. doi: 10.1111/j.1432-1033.1995.0792p.x

Dan, H. C., and Baldwin, A. S. (2008). Differential involvement of I B kinases and in cytokine- and insulin-induced mammalian target of rapamycin activation determined by akt. J. Immunol. 180, 7582-7589. doi: 10.4049/jimmunol.180.11. 7582

Deas, E., Plun-Favreau, H., Gandhi, S., Desmond, H., Kjaer, S., Loh, S. H. Y., et al. (2011). PINK1 cleavage at position A103 by the mitochondrial protease PARL. Hum. Mol. Genet. 20, 867-879. doi: 10.1093/hmg/ddq526

DeLaBarre, B., Christianson, J. C., Kopito, R. R., and Brunger, A. T. (2006). Central pore residues mediate the p97/VCP activity required for ERAD. Mol. Cell 22, 451-462. doi: 10.1016/j.molcel.2006.03.036

Delgado, M. E., Dyck, L., Laussmann, M. A., and Rehm, M. (2014). Modulation of apoptosis sensitivity through the interplay with autophagic and proteasomal degradation pathways. Cell Death Dis. 5, e1011-e1018. doi: 10.1038/cddis. 2013.520

Demishtein, A., Fraiberg, M., Berko, D., Tirosh, B., Elazar, Z., and Navon, A. (2017). SQSTM1 / p62-mediated autophagy compensates for loss of proteasome polyubiquitin recruiting capacity. Autophagy 13, 1697-1708. doi: 10.1080/ 15548627.2017.1356549

Deosaran, E., Larsen, K. B., Hua, R., Sargent, G., Wang, Y., Kim, S., et al. (2013). NBR1 acts as an autophagy receptor for peroxisomes. J. Cell Sci. 126, 939-952. doi: $10.1242 /$ jcs. 114819

Devkota, S., Jeong, H., Kim, Y., Ali, M., Roh, J. L., Hwang, D. et al. (2016). Functional characterization of EI24-induced autophagy in the degradation of RING-domain E3 ligases. Autophagy 12, 2038-2053. doi: 10.1080/15548627. 2016.1217371

Devkota, S., Sung, Y. H., Choi, J. M., Lee, J., Ha, N. Y., Kim, H., et al. (2012). Ei24deficiency attenuates protein kinase $\mathrm{C} \alpha$ signaling and skin carcinogenesis in mice. Int. J. Biochem. Cell Biol. 44, 1887-1896. doi: 10.1016/j.biocel.2012.06.034

Dikic, I. (2017). Proteasomal and autophagic degradation systems. Annu. Rev. Biochem. 86, 193-224. doi: 10.1146/annurev-biochem-061516-044908

Dikic, I., and Bremm, A. (2014). DUBs counteract parkin for efficient mitophagy. EMBO J. 33, 2442-2443. doi: 10.15252/embj.201490101

Ding, W.-X., Ni, H.-M., Li, M., Liao, Y., Chen, X., Stolz, D. B., et al. (2010), Nix is critical to two distinct phases of mitophagy: reactive oxygen species (ROS)-mediated autophagy induction and Parkin-ubiqutin-p62-mediated mitochondria priming. J. Biol. Chem. 285, 27879-27890. doi: 10.1074/jbc.M110. 119537

Djavaheri-Mergny, M., Amelotti, M., Mathieu, J., Besançon, F., Bauvy, C., Souquère, S., et al. (2006). NF-kB activation represses tumor necrosis factor$\alpha$-induced autophagy. J. Biol. Chem. 281, 30373-30382. doi: 10.1074/jbc. M602097200

Du, H., Kim, S., Hur, Y.-S., Lee, M.-S., Lee, S.-H., and Cheon, C.-I. (2015). A cytosolic thioredoxin acts as a molecular chaperone for peroxisome matrix proteins as well as antioxidant in peroxisome. Mol. Cells 38, 187-194. doi: 10.14348/molcells.2015.2277

Durcan, T. M., and Fon, E. A. (2015). USP8 and PARK2/parkin-mediated mitophagy. Autophagy 11, 428-429. doi: 10.1080/15548627.2015.1009794

Durcan, T. M., Tang, M. Y., Perusse, J. R., Dashti, E. A., Aguileta, M. A., McLelland, G.-L., et al. (2014). USP8 regulates mitophagy by removing K6-linked ubiquitin conjugates from parkin. EMBO J. 33, 2473-2491. doi: 10.15252/embj.201489729

Dzierzak, E., and Philipsen, S. (2013). Erythropoiesis?: development and differentiation. Cold Spring Harb. Perspect. Med. 3:a011601.

Ebisawa, T., Fukuchi, M., Murakami, G., Chiba, T., Tanaka, K., Imamura, T., et al. (2001). Smurf1 interacts with transforming growth factor- $\beta$ type I receptor through Smad7 and induces receptor degradation. J. Biol. Chem. 276, 12477-12480. doi: 10.1074/jbc.C100008200

Erzurumlu, Y., Kose, F. A., Gozen, O., Gozuacik, D., Toth, E. A., and Ballar, P. (2013). A unique IBMPFD-related P97/VCP mutation with differential binding pattern and subcellular localization. Int. J. Biochem. Cell Biol. 45, 773-782. doi: 10.1016/j.biocel.2013.01.006

Esteban-Martínez, L., Sierra-Filardi, E., McGreal, R. S., Salazar-Roa, M., Mariño, G., Seco, E., et al. (2017). Programmed mitophagy is essential for the glycolytic switch during cell differentiation. EMBO J. 36, 1688-1706. doi: $10.15252 / \mathrm{embj} .201695916$
Fan, T., Huang, Z., Wang, W., Zhang, B., Xu, Y., Mao, Z., et al. (2018). Proteasome inhibition promotes autophagy and protects from endoplasmic reticulum stress in rat alveolar macrophages exposed to hypoxiareoxygenation injury. J. Cell Physiol. 233, 6748-6758. doi: 10.1002/jcp. 26516

Farny, N. G., Kedersha, N. L., and Silver, P. A. (2009). Metazoan stress granule assembly is mediated by P-eIF2a-dependent and -independent mechanisms. RNA 15, 1814-1821. doi: 10.1261/rna.1684009

Feng, Z., Hu, W., De Stanchina, E., Teresky, A. K., Jin, S., Lowe, S., et al. (2007). The regulation of AMPK $\beta 1$, TSC2, and PTEN expression by p53: stress, cell and tissue specificity, and the role of these gene products in modulating the IGF-1-AKT-mTOR pathways. Cancer Res. 67, 3043-3053. doi: 10.1158/00085472.CAN-06-4149

Filimonenko, M., Isakson, P., Finley, K. D., Anderson, M., Jeong, H., Melia, T. J., et al. (2010). The selective macroautophagic degradation of aggregated proteins requires the PI3P-binding protein alfy. Mol. Cell 38, 265-279. doi: 10.1016/j. molcel.2010.04.007

Finley, D. (2009). Recognition and processing of ubiquitin-protein conjugates by the proteasome. Annu. Rev. Biochem. 78, 477-513. doi: 10.1146/annurev. biochem.78.081507.101607

Fiskin, E., Bionda, T., Dikic, I., and Behrends, C. (2016). Global analysis of host and bacterial ubiquitinome in response to Salmonella typhimurium infection. Mol. Cell 62, 967-981. doi: 10.1016/j.molcel.2016.04.015

Flugel, D., Gorlach, A., and Kietzmann, T. (2012). GSK-3beta regulates cell growth, migration, and angiogenesis via Fbw7 and USP28-dependent degradation of HIF-1alpha. Blood 119, 1292-1301.

Franco, L. H., Nair, V. R., Scharn, C. R., Xavier, R. J., Torrealba, J. R., Shiloh, M. U., et al. (2017). The ubiquitin ligase smurfl functions in selective autophagy of Mycobacterium tuberculosis and anti-tuberculous host defense. Cell Host Microbe 21, 59-72. doi: 10.1016/j.chom.2016.11.002

Fu, M., St-Pierre, P., Shankar, J., Wang, P. T. C., Joshi, B., and Nabi, I. R. (2013). Regulation of mitophagy by the Gp78 E3 ubiquitin ligase. Mol. Biol. Cell 24, 1153-1162. doi: 10.1091/mbc.E12-08-0607

Fu, W., Ma, Q., Chen, L., Li, P., Zhang, M., Ramamoorthy, S., et al. (2009). MDM2 acts downstream of p53 as an E3 ligase to promote FOXO ubiquitination and degradation. J. Biol. Chem. 284, 13987-14000. doi: 10.1074/jbc.M90175 8200

Fujii, K., Kitabatake, M., Sakata, T., and Ohno, M. (2012). 40S subunit dissociation and proteasome-dependent RNA degradation in nonfunctional 25S rRNA decay. EMBO J. 31, 2579-2589. doi: 10.1038/emboj.2012.85

Fukunaga, E., Inoue, Y., Komiya, S., Horiguchi, K., Goto, K., Saitoh, M., et al. (2008). Smurf2 induces ubiquitin-dependent degradation of Smurf1 to prevent migration of breast cancer cells. J. Biol. Chem. 283, 35660-35667. doi: 10.1074/ jbc.M710496200

Fumagalli, F., Noack, J., Bergmann, T. J., Presmanes, E. C., Pisoni, G. B., Fasana, E. et al. (2016). Translocon component Sec62 acts in endoplasmic reticulum turnover during stress recovery. Nat. Cell Biol. 18, 1173-1184. doi: 10.1038/ ncb3423

Gamerdinger, M., Kaya, A. M., Wolfrum, U., Clement, A. M., and Behl, C. (2011). BAG3 mediates chaperone-based aggresome-targeting and selective autophagy of misfolded proteins. EMBO Rep. 12, 149-156. doi: 10.1038/embor. 2010.203

Gao, F., Chen, D., Si, J., Hu, Q., Qin, Z., Fang, M., et al. (2015). The mitochondrial protein BNIP3L is the substrate of PARK2 and mediates mitophagy in PINK1/PARK2 pathway. Hum. Mol. Genet. 24, 2528-2538. doi: 10.1093/hmg/ ddv017

Gao, Z., Gammoh, N., Wong, P. M., Erdjument-Bromage, H., Tempst, P., and Jiang, X. (2010). Processing of autophagic protein LC3 by the 20 S proteasome. Autophagy 6, 126-137. doi: 10.4161/auto.6.1.10928

Ge, P., Zhang, J., Wang, X., Meng, F., Li, W., Luan, Y., et al. (2009). Inhibition of autophagy induced by proteasome inhibition increases cell death in human SHG-44 glioma cells. Acta Pharmacol. Sin. 30, 1046-1052. doi: 10.1038/aps. 2009.71

Glotzer, M., Murray, A. W., and Kirschner, M. W. (1991). Cyclin is degraded by the ubiquitin pathway. Nature $349,132-138$. doi: 10.1038/349132a0

Goodall, M. L., Fitzwalter, B. E., Zahedi, S., Wu, M., Rodriguez, D., Mulcahy-Levy, J. M., et al. (2016). The autophagy machinery controls cell death switching 
between apoptosis and necroptosis. Dev. Cell 37, 337-349. doi: 10.1016/j.devcel. 2016.04.018

Gozuacik, D., Bialik, S., Raveh, T., Mitou, G., Shohat, G., Sabanay, H., et al. (2008). DAP-kinase is a mediator of endoplasmic reticulum stress-induced caspase activation and autophagic cell death. Cell Death Differ. 15, 1875-1886. doi: 10.1038/cdd.2008.121

Groll, M., and Huber, R. (2003). Substrate access and processing by the $20 \mathrm{~S}$ proteasome core particle. Int. J. Biochem. Cell Biol. 35, 606-616. doi: 10.1016/ S1357-2725(02)00390-4

Groll, M., and Huber, R. (2004). Inhibitors of the eukaryotic 20 s proteasome core particle: a structural approach. Biochim. Biophys. Acta 1695, 33-44. doi: 10.1016/j.bbamcr.2004.09.025

Grou, C. P., Pinto, M. P., Mendes, A. V., Domingues, P., and Azevedo, J. E. (2015). The de novo synthesis of ubiquitin: identification of deubiquitinases acting on ubiquitin precursors. Sci. Rep. 5:12836. doi: 10.1038/srep12836

Grumati, P., Morozzi, G., Hölper, S., Mari, M., Harwardt, M. L. I. E., Yan, R., et al. (2017). Full length RTN3 regulates turnover of tubular endoplasmic reticulum via selective autophagy. eLife 6:e25555. doi: 10.7554/eLife.25555

Guo, X., Shen, S., Song, S., He, S., Cui, Y., Xing, G., et al. (2011). The E3 ligase Smurf1 regulates Wolfram syndrome protein stability at the endoplasmic reticulum. J. Biol. Chem. 286, 18037-18047. doi: 10.1074/jbc.M111.225615

Gutierrez, M. G., Master, S. S., Singh, S. B., Taylor, G. A., Colombo, M. I., and Deretic, V. (2004). Autophagy is a defense mechanism inhibiting BCG and Mycobacterium tuberculosis survival in infected macrophages. Cell 119, 753-766. doi: 10.1016/j.cell.2004.11.038

Hamanaka, R. B., Bobrovnikova-Marjon, E., Ji, X., Liebhaber, S. A., and Diehl, J. A. (2009). PERK-dependent regulation of IAP translation during ER stress. Oncogene 28, 910-920. doi: 10.1038/onc.2008.428

Hara, T., Nakamura, K., Matsui, M., Yamamoto, A., Nakahara, Y., SuzukiMigishima, R., et al. (2006). Suppression of basal autophagy in neural cells causes neurodegenerative disease in mice. Nature 441, 885-889. doi: 10.1038/ nature 04724

Harada, K., Kato, M., and Nakamura, N. (2016). USP19-mediated deubiquitination facilitates the stabilization of HRD1 ubiquitin ligase. Int. J. Mol. Sci. 17:E1829. doi: $10.3390 / \mathrm{ijms} 17111829$

Hasegawa, J., Maejima, I., Iwamoto, R., and Yoshimori, T. (2015). Selective autophagy: lysophagy. Methods 75, 128-132. doi: 10.1016/j.ymeth.2014.12.014

Hasson, S. A., Kane, L. A., Yamano, K., Huang, C. H., Sliter, D. A., Buehler, E., et al. (2013). High-content genome-wide RNAi screens identify regulators of parkin upstream of mitophagy. Nature 504, 291-295. doi: 10.1038/nature12748

Haupt, S., Vijayakumaran, R., Miranda, P. J., Burgess, A., Lim, E., and Haupt, Y. (2017). The role of MDM2 and MDM4 in breast cancer development and prevention. J. Mol. Cell Biol. 9, 53-61. doi: 10.1093/jmcb/mjx007

He, M., Zhou, Z., Shah, A. A., Zou, H., Tao, J., Chen, Q., et al. (2016). The emerging role of deubiquitinating enzymes in genomic integrity, diseases, and therapeutics. Cell Biosci. 6:62. doi: 10.1186/s13578-016-0127-1

He, S., Zhao, Z., Yang, Y., O'Connell, D., Zhang, X., Oh, S., et al. (2015). Truncating mutation in the autophagy gene UVRAG confers oncogenic properties and chemosensitivity in colorectal cancers. Nat. Commun. 6:7839. doi: 10.1038/ ncomms 8839

Heath, R. J., Goel, G., Baxt, L. A., Rush, J. S., Mohanan, V., Paulus, G. L. C., et al. (2016). RNF166 determines recruitment of adaptor proteins during antibacterial autophagy. Cell Rep. 17, 2183-2194. doi: 10.1016/j.celrep.2016. 11.005

Heinemeyer, W., Ramos, P. C., and Dohmen, R. J. (2004). Ubiquitinproteasome system. Cell. Mol. Life Sci. 31, 137-155. doi: 10.1007/s00018-004$4130-\mathrm{z}$

Herhaus, L., and Dikic, I. (2015). Expanding the ubiquitin code through posttranslational modification. EMBO Rep. 16, 1071-1083. doi: 10.15252/embr. 201540891

Hershko, A. (1983). Ubiquitin: roles in protein modification and breakdown. Cell 34, 11-12. doi: 10.1016/0092-8674(83)90131-9

Hershko, A. (2005). The ubiquitin system for protein degradation and some of its roles in the control of the cell-division cycle (Nobel Lecture). Angew. Chem. Int. Ed. 44, 5932-5943. doi: 10.1002/anie.200501724

Hershko, A., and Ciechanover, A. (1998). The ubiquitin system. Annu. Rev. Biochem. 67, 425-479. doi: 10.1146/annurev.biochem.67.1.425
Higgins, R., Gendron, J. M., Rising, L., Mak, R., Webb, K., Kaiser, S. E., et al. (2015). The unfolded protein response triggers site-specific regulatory ubiquitylation of 40S ribosomal proteins. Mol. Cell 59, 35-49. doi: 10.1016/j.molcel.2015.04.026

Hiramatsu, N., Messah, C., Han, J., LaVail, M. M., Kaufman, R. J., and Lin, J. H. (2014). Translational and posttranslational regulation of XIAP by eIF2 and ATF4 promotes ER stress-induced cell death during the unfolded protein response. Mol. Biol. Cell 25, 1411-1420. doi: 10.1091/mbc.E13-110664

Honsho, M., Yamashita, S., and Fujiki, Y. (2016). Peroxisome homeostasis: mechanisms of division and selective degradation of peroxisomes in mammals. Biochim. Biophys. Acta 1863, 984-991. doi: 10.1016/j.bbamcr.2015. 09.032

Hori, O., Ichinoda, F., Yamaguchi, A., Tamatani, T., Taniguchi, M., Koyama, Y., et al. (2004). Role of Herp in the endoplasmic reticulum stress response. Genes Cells 9, 457-469. doi: 10.1111/j.1356-9597.2004.00735.x

Hosokawa, N., Hara, T., Kaizuka, T., Kishi, C., Takamura, A., Miura, Y., et al. (2009). Nutrient-dependent mTORC1 association with the ULK1 - Atg13 FIP200 complex required for autophagy. Mol. Biol. Cell 20, 1981-1991. doi: $10.1091 / \mathrm{mbc} . \mathrm{E} 08$

Høyer-Hansen, M., Bastholm, L., Szyniarowski, P., Campanella, M., Szabadkai, G., Farkas, T., et al. (2007). Control of macroautophagy by calcium, calmodulindependent kinase kinase- $\beta$, and Bcl-2. Mol. Cell 25, 193-205. doi: 10.1016/j. molcel.2006.12.009

Huang, H., Kawamata, T., Horie, T., Tsugawa, H., Nakayama, Y., Ohsumi, Y., et al. (2015). Bulk RNA degradation by nitrogen starvation-induced autophagy in yeast. EMBO J. 34, 154-168. doi: 10.15252/embj.201489083

Huang, H., Regan, K. M., Wang, F., Wang, D., Smith, D. I., van Deursen, J. M. A., et al. (2005). Skp2 inhibits FOXO1 in tumor suppression through ubiquitinmediated degradation. Proc. Natl. Acad. Sci. U.S.A. 102, 1649-1654. doi: 10. 1073/pnas.0406789102

Huang, H., and Tindall, D. J. (2011). Regulation of FOXO protein stability via ubiquitination and proteasome degradation. Biochim. Biophys. Acta 1813, 1961-1964. doi: 10.1016/j.bbamcr.2011.01.007

Huang, X., and Dixit, V. M. (2016). Drugging the undruggables: exploring the ubiquitin system for drug development. Cell Res. 26, 484-498. doi: 10.1038/cr. 2016.31

Huett, A., Heath, R. J., Begun, J., Sassi, S. O., Baxt, L. A., Vyas, J. M., et al. (2012). The LRR and RING domain protein LRSAM1 is an E3 ligase crucial for ubiquitin-dependent autophagy of intracellular Salmonella typhimurium. Cell Host Microbe 12, 778-790. doi: 10.1016/j.chom.2012.10.019

Hung, Y. H., Chen, L. M. W., Yang, J. Y., and Yuan Yang, W. (2013). Spatiotemporally controlled induction of autophagy-mediated lysosome turnover. Nat. Commun. 4:2111. doi: 10.1038/ncomms3111

Hwang, S. P., and Lee, D. H. (2017). Autophagy mediates SUMO-induced degradation of a polyglutamine protein ataxin-3. Anim. Cells Syst. 21, 169-176. doi: 10.1080/19768354.2017.1330765

Ichimura, Y., Kumanomidou, T., Sou, Y. S., Mizushima, T., Ezaki, J., Ueno, T., et al. (2008). Structural basis for sorting mechanism of p62 in selective autophagy. J. Biol. Chem. 283, 22847-22857. doi: 10.1074/jbc.M802182200

Iovino, F., Gradstedt, H., and Bijlsma, J. J. (2014). The proteasome-ubiquitin system is required for efficient killing of intracellular Streptococcus pneumoniae by brain endothelial cells. mBio 5:e00984-14. doi: 10.1128/mBio.00984- 14

Ishimura, R., Tanaka, K., and Komatsu, M. (2014). Dissection of the role of p62/Sqstm1 in activation of Nrf2 during xenophagy. FEBS Lett. 588, 822-828. doi: 10.1016/j.febslet.2014.01.045

Jaakkola, P., Jaakkola, P., Mole, D. R., Tian, Y., Kriegsheim, A., Von, et al. (2014). Targeting of HIF- $\alpha$ to the von hippel-lindau ubiquitylation complex by $\mathrm{O}_{2}$ regulated prolyl hydroxylation. Science 292, 468-472. doi: 10.1126/science. 1059796

Jager, S. (2004). Role for Rab7 in maturation of late autophagic vacuoles. J. Cell Sci. 117, 4837-4848. doi: $10.1242 /$ jcs. 01370

Jain, A., Lamark, T., Sjøttem, E., Larsen, K. B., Awuh, J. A., Øvervatn, A., et al. (2010). p62/SQSTM1 is a target gene for transcription factor NRF2 and creates a positive feedback loop by inducing antioxidant response element-driven gene transcription. J. Biol. Chem. 285, 22576-22591. doi: 10.1074/jbc.M110.118976

Jana, N. R., Dikshit, P., Goswami, A., Kotliarova, S., Murata, S., Tanaka, K., et al. (2005). Co-chaperone CHIP associates with expanded polyglutamine 
protein and promotes their degradation by proteasomes. J. Biol. Chem. 280, 11635-11640. doi: 10.1074/jbc.M412042200

Jeong, K., Kim, H., Kim, K., Kim, S. J., Hahn, B. S., Jahng, G. H., et al. (2014). Cyclophilin B is involved in p300-mediated degradation of CHOP in tumor cell adaptation to hypoxia. Cell Death Differ. 21, 438-450. doi: 10.1038/cdd.20 13.164

Ji, H., Ramsey, M. R., Hayes, D. N., Fan, C., McNamara, K., Kozlowski, P., et al. (2007). LKB1 modulates lung cancer differentiation and metastasis. Nature 448, 807-810. doi: 10.1038/nature06030

Jiang, S., Park, D. W., Gao, Y., Ravi, S., Darley-Usmar, V., Abraham, E., et al. (2015). Participation of proteasome-ubiquitin protein degradation in autophagy and the activation of AMP-activated protein kinase. Cell. Signal. 27, 1186-1197. doi: 10.1016/j.cellsig.2015.02.024

Jin, S., Tian, S., Chen, Y., Zhang, C., Xie, W., Xia, X., et al. (2016). USP19 modulates autophagy and antiviral immune responses by deubiquitinating Beclin-1. EMBO J. 35, 866-880. doi: 10.15252/embj.201593596

Jin, S. M., Lazarou, M., Wang, C., Kane, L. A., Narendra, D. P., and Youle, R. J. (2010). Mitochondrial membrane potential regulates PINK1 import and proteolytic destabilization by PARL. J. Cell Biol. 191, 933-942. doi: 10.1083/jcb. 201008084

Johnson, J. O., Mandrioli, J., Benatar, M., Abramzon, Y., Van Deerlin, V. M., Trojanowski, J. Q., et al. (2010). Exome sequencing reveals VCP mutations as a cause of familial ALS. Neuron 68, 857-864. doi: 10.1016/j.neuron.2010.11.036

Johnston, J. A., Ward, C. L., and Kopito, R. R. (1998). Aggresomes: a cellular response to misfolded proteins. J.? Cell Biol. 143, 1883-1898. doi: 10.1083/jcb. 143.7.1883

Ju, J. S., Miller, S. E., Hanson, P. I., and Weihl, C. C. (2008). Impaired protein aggregate handling and clearance underlie the pathogenesis of p97/VCP-associated disease. J. Biol. Chem. 283, 30289-30299. doi: 10.1074/jbc. M805517200

Juenemann, K., Schipper-Krom, S., Wiemhoefer, A., Kloss, A., Sanz, A. S., and Reits, E. A. J. (2013). Expanded polyglutamine-containing N-terminal huntingtin fragments are entirely degraded by mammalian proteasomes. J. Biol. Chem. 288, 27068-27084. doi: 10.1074/jbc.M113.486076

Kane, L. A., Lazarou, M., Fogel, A. I., Li, Y., Yamano, K., Sarraf, S. A., et al. (2014). PINK1 phosphorylates ubiquitin to activate parkin E3 ubiquitin ligase activity. J. Cell Biol. 205, 143-153. doi: 10.1083/jcb.201402104

Kang, Y.-A., Sanalkumar, R., O'Geen, H., Linnemann, A. K., Chang, C.J., Bouhassira, E. E., et al. (2012). Autophagy driven by a master regulator of hematopoiesis. Mol. Cell. Biol. 32, 226-239. doi: 10.1128/MCB. 06166-11

Kato, S., Ding, J., Pisck, E., Jhala, U. S., and Du, K. (2008). COP1 functions as a FoxO1 ubiquitin E3 ligase to regulate FoxO1-mediated gene expression. J. Biol. Chem. 283, 35464-35473. doi: 10.1074/jbc.M801011200

Kaushik, S., and Cuervo, A. M. (2018). The coming of age of chaperone-mediated autophagy. Nat. Rev. Mol. Cell Biol. 19, 365-381. doi: 10.1038/s41580-0180001-6

Kazlauskaite, A., Kondapalli, C., Gourlay, R., Campbell, D. G., Ritorto, M. S., Hofmann, K., et al. (2014). Parkin is activated by PINK1-dependent phosphorylation of ubiquitin at Ser 65. Biochem. J. 460, 127-141. doi: 10.1042/ BJ20140334

Kedersha, N., Cho, M. R., Li, W., Yacono, P. W., Chen, S., Gilks, N., et al. (2000). Dynamic shuttling of TIA-1 accompanies the recruitment of mRNA to mammalian stress granules. J. Cell Biol. 151, 1257-1268. doi: 10.1083/jcb.151.6. 1257

Kedersha, N., Panas, M. D., Achorn, C. A., Lyons, S., Tisdale, S., Hickman, T., et al. (2016). G3BP-Caprin1-USP10 complexes mediate stress granule condensation and associate with 40 S subunits. J. Cell Biol. 212, 845-860. doi: 10.1083/jcb. 201508028

Kedersha, N., Stoecklin, G., Ayodele, M., Yacono, P., Lykke-Andersen, J., Fitzler, M. J., et al. (2005). Stress granules and processing bodies are dynamically linked sites of mRNP remodeling. J. Cell Biol. 169, 871-884. doi: 10.1083/jcb. 200502088

Kenzelmann Broz, D., Mello, S. S., Bieging, K. T., Jiang, D., Dusek, R. L., Brady, C. A., et al. (2013). Global genomic profiling reveals an extensive p53regulated autophagy program contributing to key 533 responses. Genes Dev. 27, 1016-1031. doi: 10.1101/gad.212282.112
Khaminets, A., Behl, C., and Dikic, I. (2016). Ubiquitin-dependent and independent signals in selective autophagy. Trends Cell Biol. 26, 6-16. doi: 10.1016/j.tcb.2015.08.010

Khaminets, A., Heinrich, T., Mari, M., Grumati, P., Huebner, A. K., Akutsu, M., et al. (2015). Regulation of endoplasmic reticulum turnover by selective autophagy. Nature 522, 354-358. doi: 10.1038/nature14498

Kim, J. W., Tchernyshyov, I., Semenza, G. L., and Dang, C. V. (2006). HIF-1mediated expression of pyruvate dehydrogenase kinase: a metabolic switch required for cellular adaptation to hypoxia. Cell Metab. 3, 177-185. doi: 10. 1016/j.cmet.2006.02.002

Kim, P. K., Hailey, D. W., Mullen, R. T., and Lippincott-Schwartz, J. (2008). Ubiquitin signals autophagic degradation of cytosolic proteins and peroxisomes. Proc. Natl. Acad. Sci. U.S.A. 105, 20567-20574. doi: 10.1073/pnas. 0810611105

Kirkegaard, K., Taylor, M. P., and Jackson, W. T. (2004). Cellular autophagy: surrender, avoidance and subversion by microorganisms. Nat. Rev. Microbiol. 2, 301-314. doi: 10.1038/nrmicro865

Kirkin, V., McEwan, D. G., Novak, I., and Dikic, I. (2009). A role for ubiquitin in selective autophagy. Mol. Cell 34, 259-269. doi: 10.1016/j.molcel.2009.04.026

Klimek, C., Kathage, B., Wördehoff, J., and Höhfeld, J. (2017). BAG3-mediated proteostasis at a glance. J. Cell Sci. 130, 2781-2788. doi: 10.1242/jcs.203679

Klionsky, D. J. (2007). Autophagy: from phenomenology to molecular understanding in less than a decade. Nat. Rev. Mol. Cell Biol. 8, 931-937. doi: $10.1038 / \mathrm{nrm} 2245$

Kobayashi, A., Kang, M., Okawa, H., Zenke, Y., Chiba, T., Igarashi, K., et al. (2004). Oxidative stress sensor Keap1 functions as an adaptor for Cul3-based E3 ligase to regulate proteasomal degradation of Nrf2. Mol. Cell. Biol. 24, 7130-7139. doi: 10.1128/MCB.24.16.7130

Kobayashi, E. H., Suzuki, T., Funayama, R., Nagashima, T., Hayashi, M., Sekine, H., et al. (2016). Nrf2 suppresses macrophage inflammatory response by blocking proinflammatory cytokine transcription. Nat. Commun. 7:11624. doi: 10.1038/ ncomms11624

Koh, M. Y., Darnay, B. G., and Powis, G. (2008). Hypoxia-associated factor, a novel E3-ubiquitin ligase, binds and ubiquitinates hypoxia-inducible factor 1, leading to its oxygen-independent degradation. Mol. Cell. Biol. 28, 7081-7095. doi: 10.1128/MCB.00773-08

Komander, D., Clague, M. J., and Urbé, S. (2009). Breaking the chains: structure and function of the deubiquitinases. Nat. Rev. Mol. Cell Biol. 10, 550-563. doi: $10.1038 / \mathrm{nrm} 2731$

Komatsu, M., Kurokawa, H., Waguri, S., Taguchi, K., Kobayashi, A., Ichimura, Y., et al. (2010). The selective autophagy substrate p62 activates the stress responsive transcription factor Nrf2 through inactivation of Keap1. Nat. Cell Biol. 12, 213-223. doi: 10.1038/ncb2021

Komatsu, M., Waguri, S., Chiba, T., Murata, S., Iwata, J. I., Tanida, I., et al. (2006). Loss of autophagy in the central nervous system causes neurodegeneration in mice. Nature 441, 880-884. doi: 10.1038/nature04723

Komatsu, M., Waguri, S., Ueno, T., Iwata, J., Murata, S., Tanida, I., et al. (2005). Impairment of starvation-induced and constitutive autophagy in Atg7-deficient mice. J. Cell Biol. 169, 425-434. doi: 10.1083/jcb.200412022

Kondapalli, C., Kazlauskaite, A., Zhang, N., Woodroof, H. I., Campbell, D. G., Gourlay, R., et al. (2012). PINK1 is activated by mitochondrial membrane potential depolarization and stimulates Parkin E3 ligase activity by phosphorylating Serine 65. Open Biol. 2:120080. doi: 10.1098/rsob.120080

Kopito, R. R. (2000). Aggresomes, inclusion bodies and protein aggregation. Trends Cell Biol. 10, 524-530. doi: 10.1016/S0962-8924(00)01852-3

Korac, J., Schaeffer, V., Kovacevic, I., Clement, A. M., Jungblut, B., Behl, C., et al. (2013). Ubiquitin-independent function of optineurin in autophagic clearance of protein aggregates. J. Cell Sci. 126, 580-592. doi: 10.1242/jcs.114926

Korolchuk, V. I., Mansilla, A., Menzies, F. M., and Rubinsztein, D. C. (2009a). Autophagy inhibition compromises degradation of ubiquitin-proteasome pathway substrates. Mol. Cell 33, 517-527. doi: 10.1016/j.molcel.2009.01.021

Korolchuk, V. I., Menzies, F. M., and Rubinsztein, D. C. (2009b). A novel link between autophagy and the ubiquitin-proteasome system. Autophagy 5, 862-863. doi: 10.4161/auto.8840

Korolchuk, V. I., Menzies, F. M., and Rubinsztein, D. C. (2010). Mechanisms of cross-talk between the ubiquitin-proteasome and autophagy-lysosome systems. FEBS Lett. 584, 1393-1398. doi: 10.1016/j.febslet.2009.12.047 
Korphaisarn, K., Morris, V., Overman, M., Fogelman, D. R., Kee, B. K., Raghav, K. P. S., et al. (2017). FBXW7 missense mutation: a novel negative prognostic factor in metastatic colorectal adenocarcinoma. Oncotarget 8, 39268-39279. doi: 10.18632/oncotarget.16848

Koyano, F., Okatsu, K., Kosako, H., Tamura, Y., Go, E., Kimura, M., et al. (2014). Ubiquitin is phosphorylated by PINK1 to activate parkin. Nature 510, 162-166. doi: 10.1038/nature13392

Kraft, C., Deplazes, A., Sohrmann, M., and Peter, M. (2008). Mature ribosomes are selectively degraded upon starvation by an autophagy pathway requiring the Ubp3p/Bre5p ubiquitin protease. Nat. Cell Biol. 10, 602-610. doi: 10.1038/ ncb 1723

Kraft, C., and Peter, M. (2008). Is the Rsp5 ubiquitin ligase involved in the regulation of ribophagy? Autophagy 4, 838-840. doi: 10.4161/auto.6603

Kraft, C., Peter, M., and Hofmann, K. (2010). Selective autophagy: ubiquitinmediated recognition and beyond. Nat. Cell Biol. 12, 836-841. doi: 10.1038/ ncb0910-836

Kravtsova-ivantsiv, Y., Ciechanover, A., Kravtsova-ivantsiv, Y., and Ciechanover, A. (2015). The ubiquitin-proteasome system and activation of NF- $\kappa$ B: involvement of the ubiquitin ligase $\mathrm{KPC1}$ in p105 processing and tumor suppression. Mol. Cell. Oncol. 2:e1054552. doi: 10.1080/23723556.2015.1054552

Kuchay, S., Duan, S., Schenkein, E., Peschiaroli, A., Saraf, A., Florens, L., et al. (2013). FBXL2- and PTPL1-mediated degradation of $\mathrm{p} 110$-free $\mathrm{p} 85 \beta$ regulatory subunit controls the PI(3)K signalling cascade. Nat. Cell Biol. 15, 472-480. doi: $10.1038 / \mathrm{ncb} 2731$

Kwon, A., Lee, H.-L., Woo, K. M., Ryoo, H.-M., and Baek, J.-H. (2013). SMURF1 Plays a role in EGF-induced breast cancer cell migration and invasion. Mol. Cells 36, 548-555. doi: 10.1007/s10059-013-0233-4

Kwon, Y. T., and Ciechanover, A. (2017). The ubiquitin code in the ubiquitinproteasome system and autophagy. Trends Biochem. Sci. 42, 873-886. doi: 10. 1016/j.tibs.2017.09.002

Kyrychenko, V. O., Nagibin, V. S., Tumanovska, L. V., Pashevin, D. O., Gurianova, V. L., Moibenko, A. A., et al. (2013). Knockdown of PSMB7 induces autophagy in cardiomyocyte cultures: possible role in endoplasmic reticulum stress. Pathobiology 81, 8-14. doi: 10.1159/000350704

Laddha, S. V., Ganesan, S., Chan, C. S., and White, E. (2014). Mutational landscape of the essential autophagy gene BECN1 in human cancers. Mol. Cancer Res. 12, 485-490. doi: 10.1158/1541-7786.MCR-13-0614

Lamark, T., and Johansen, T. (2012). Aggrephagy: selective disposal of protein aggregates by macroautophagy. Int. J. Cell Biol. 2012:736905. doi: 10.1155/2012/ 736905

Lamb, C. A., Yoshimori, T., and Tooze, S. A. (2013). The autophagosome: origins unknown, biogenesis complex. Nat. Rev. Mol. Cell Biol. 14, 759-774. doi: 10. 1038/nrm3696

Lander, G. C., Estrin, E., Matyskiela, M. E., Bashore, C., Nogales, E., and Martin, A. (2012). Complete subunit architecture of the proteasome regulatory particle. Nature 482, 186-191. doi: 10.1038/nature10774

Lassot, I., Segeral, E., Berlioz-Torrent, C., Durand, H., Groussin, L., Hai, T., et al. (2001). ATF4 degradation relies on a phosphorylation-dependent interaction with the SCF TrCP ubiquitin ligase. Mol. Cell. Biol. 21, 2192-2202. doi: 10.1128/ MCB.21.6.2192-2202.2001

Law, K. B., Bronte-tinkew, D., Pietro, E., Di, Snowden, A., Jones, O., et al. (2017). The peroxisomal AAA ATPase complex prevents pexophagy and development of peroxisome biogenesis disorders. Autophagy 13, 868-884. doi: 10.1080/ 15548627.2017.1291470

Lazarou, M., Jin, S. M., Kane, L. A., and Youle, R. J. (2012). Role of PINK1 binding to the TOM complex and alternate intracellular membranes in recruitment and activation of the E3 ligase parkin. Dev. Cell 22, 320-333. doi: 10.1016/j.devcel. 2011.12.014

Lazarou, M., Sliter, D. A., Kane, L. A., Sarraf, S. A., Wang, C., Burman, J. L., et al. (2015). The ubiquitin kinase PINK1 recruits autophagy receptors to induce mitophagy. Nature 524, 309-314. doi: 10.1038/nature14893

Le Fourn, V., Park, S., Jang, I., Gaplovska-Kysela, K., Guhl, B., Lee, Y., et al. (2013). Large protein complexes retained in the ER are dislocated by non-COPII vesicles and degraded by selective autophagy. Cell. Mol. Life Sci. 70, 1985-2002. doi: 10.1007/s00018-012-1236-6

Lee, D. F., Kuo, H. P., Chen, C., Te, Hsu, J. M., Chou, C. K., et al. (2007). IKK $\beta$ suppression of TSC1 links inflammation and tumor angiogenesis via the mTOR pathway. Cell 130, 440-455. doi: 10.1016/j.cell.2007.05.058
Lee, J. H., Elly, C., Park, Y., and Liu, Y. C. (2015). E3 ubiquitin ligase VHL regulates hypoxia-inducible factor- $1 \alpha$ to maintain regulatory $\mathrm{T}$ Cell Stability and Suppressive Capacity. Immunity 42, 1062-1074. doi: 10.1016/j.immuni. 2015.05.016

Lee, J. J., Sanchez-Martinez, A., Zarate, A. M., Benincá, C., Mayor, U., Clague, M. J., et al. (2018). Basal mitophagy is widespread in Drosophila but minimally affected by loss of Pink1 or parkin. J. Cell Biol. 217, 1613-1622. doi: 10.1083/jcb. 201801044

Lee, M. J., Lee, B.-H., Hanna, J., King, R. W., and Finley, D. (2011). Trimming of ubiquitin chains by proteasome-associated deubiquitinating enzymes. Mol. Cell. Proteomics 10:R110.003871. doi: 10.1074/mcp.R110.003871

Lemasters, J. J. (2005). Selective mitochondrial autophagy, or mitophagy, as a targeted defense against oxidative stress, mitochondrial dysfunction, and aging. Rejuvenation Res. 8, 3-5. doi: 10.1089/rej.2005.8.3

Li, G., Mongillo, M., Chin, K. T., Harding, H., Ron, D., Marks, A. R., et al. (2009). Role of ERO1- $\alpha$-mediated stimulation of inositol 1,4,5-triphosphate receptor activity in endoplasmic reticulum stress-induced apoptosis. J. Cell Biol. 186, 783-792. doi: $10.1083 /$ jcb. 200904060

Li, W., Saud, S. M., Young, M. R., Chen, G., and Hua, B. (2015). Targeting AMPK for cancer prevention and treatment. Oncotarget 6, 7365-7378. doi: 10.18632/ oncotarget.3629

Li, Z., Na, X., Wang, D., Schoen, S. R., Messing, E. M., and Wu, G. (2002a). Ubiquitination of a novel deubiquitinating enzyme requires direct binding to von Hippel-Lindau tumor suppressor protein. J. Biol. Chem. 277, 4656-4662. doi: 10.1074/jbc.M108269200

Li, Z., Wang, D., Na, X., Schoen, S. R., Messing, E. M., and Wu, G. (2002b). Identification of a deubiquitinating enzyme subfamily as substrates of the von Hippel-Lindau tumor suppressor. Biochem. Biophys. Res. Commun. 294, 700-709. doi: 10.1016/S0006-291X(02)00534-X

Liang, X. H., Jackson, S., Seaman, M., Brown, K., Kempkes, B., Hibshoosh, H., et al. (1999). Induction of autophagy and inhibition of tumorigenesis by beclin 1 . Nature 402, 672-676. doi: 10.1038/45257

Lin, Q., Dai, Q., Meng, H., Sun, A., Wei, J., Peng, K., et al. (2017). The HECT E3 ubiquitin ligase NEDD4 interacts with and ubiquitylates SQSTM1 for inclusion body autophagy. J. Cell Sci. 130, 3839-3850. doi: 10.1242/jcs.207068

Ling, J., Kang, Y., Zhao, R., Xia, Q., Lee, D. F., Chang, Z., et al. (2012). Kras G12D-induced IKK2/ $\beta /$ NF- $\kappa$ B activation by IL- $1 \alpha$ and $p 62$ feedforward loops is required for development of pancreatic ductal adenocarcinoma. Cancer Cell 21, 105-120. doi: 10.1016/j.ccr.2011.12.006

Liu, J., Xia, H., Kim, M., Xu, L., Li, Y., Zhang, L., et al. (2011). Beclin1 controls the levels of p53 by regulating the deubiquitination activity of USP10 and USP13. Cell 147, 223-234. doi: 10.1016/j.cell.2011.08.037

Liu, Y., Soetandyo, N., Lee, J. G., Liu, L., Xu, Y., Clemons, W. M., et al. (2014). USP13 antagonizes gp78 to maintain functionality of a chaperone in ERassociated degradation. eLife 3:e01369. doi: 10.7554/eLife.01369.001

Liu, Z., Chen, P., Gao, H., Gu, Y., Yang, J., Peng, H., et al. (2014). Ubiquitylation of autophagy receptor optineurin by HACE1 activates selective autophagy for tumor suppression. Cancer Cell 26, 106-120. doi: 10.1016/j.ccr.2014. 05.015

Lobato-Márquez, D., and Mostowy, S. (2017). Salmonella ubiquitination: ARIH1 enters the fray. EMBO Rep. 18, 1476-1477. doi: 10.15252/embr.201744672

Long, J., Gallagher, T. R. A., Cavey, J. R., Sheppard, P. W., Ralston, S. H., Layfield, R., et al. (2008). Ubiquitin recognition by the ubiquitin-associated domain of p62 involves a novel conformational switch. J. Biol. Chem. 283, 5427-5440. doi: 10.1074/jbc.M704973200

Lu, K., Psakhye, I., and Jentsch, S. (2014). Autophagic clearance of PolyQ proteins mediated by ubiquitin-Atg8 adaptors of the conserved CUET protein family. Cell 158, 549-563. doi: 10.1016/j.cell.2014.05.048

Maeda, T., Yu, F., Tababe-Furjimura, C., Zou, K., Liu, J., Liu, S., et al. (2018). An E3 ubiquitin ligase, Synoviolin, is involved in the degradation of homocysteineinducible ER protein. Biol. Pharm. Bull. 41, 915-919. doi: 10.1074/jbc. M307453200

Mammucari, C., Milan, G., Romanello, V., Masiero, E., Rudolf, R., Del Piccolo, P., et al. (2007). FoxO3 controls autophagy in skeletal muscle in vivo. Cell Metab. 6, 458-471. doi: 10.1016/j.cmet.2007.11.001

Manzanillo, P. S., Ayres, J. S., Watson, R. O., Collins, A. C., Souza, G., Rae, C. S., et al. (2013). The ubiquitin ligase parkin mediates resistance to intracellular pathogens. Nature 501, 512-516. doi: 10.1038/nature12566 
Mao, J., Xia, Q., Liu, C., Ying, Z., Wang, H., and Wang, G. (2017). A critical role of Hrd1 in the regulation of optineurin degradation and aggresome formation. Hum. Mol. Genet. 26, 1877-1889. doi: 10.1093/hmg/ddx096

Marine, J. (2012). Spotlight on the role of COP1 in tumorigenesis. Nat. Rev. Cancer 12, 455-464. doi: 10.1038/nrc3271

Marino, G., Salvador-Montoliu, N., Fueyo, A., Knecht, E., Mizushima, N., and López-Otín, C. (2007). Tissue-specific autophagy alterations and increased tumorigenesis in mice deficient in Atg4C/autophagin-3. J. Biol. Chem. 282, 18573-18583. doi: 10.1074/jbc.M701194200

Marshall, R. S., Li, F., Gemperline, D. C., Book, A. J., and Vierstra, R. D. (2015). Autophagic degradation of the 26s proteasome is mediated by the dual ATG8/ubiquitin receptor RPN10 in Arabidopsis. Mol. Cell 58, 1053-1066. doi: 10.1016/j.molcel.2015.04.023

Marshall, R. S., and Vierstra, R. D. (2018). Proteasome storage granules protect proteasomes from autophagic degradation upon carbon starvation. elife 7:e34532. doi: 10.7554/eLife.34532

Matthias, P., Yoshida, M., and Khochbin, S. (2008). HDAC6 a new cellular stress surveillance factor. Cell Cycle 7, 7-10. doi: 10.4161/cc.7.1.5186

Mauthe, M., Jacob, A., Freiberger, S., Hentschel, K., Stierhof, Y. D., Codogno, P., et al. (2011). Resveratrol-mediated autophagy requires WIPI-1-regulated LC3 lipidation in the absence of induced phagophore formation. Autophagy 7, 1448-1461. doi: 10.4161/auto.7.12.17802

Mazroui, R., Di Marco, S., Kaufman, R. J., and Gallouzi, I.-E. (2007). Inhibition of the ubiquitin-proteasome system induces stress granule formation. Mol. Biol. Cell 18, 2603-2618. doi: 10.1091/mbc.E06

Mccullough, K. D., Martindale, J. L., Aw, T., Holbrook, N. J., Cullough, K. D. M. C., and Klotz, L. (2001). Gadd153 sensitizes cells to endoplasmic reticulum stress by down-regulating $\mathrm{Bcl} 2$ and perturbing the cellular redox state. Mol. Cell. Biol. 21, 1249-1259. doi: 10.1128/MCB.21.4.1249

Menzies, F. M., Garcia-Arencibia, M., Imarisio, S., O'Sullivan, N. C., Ricketts, T., Kent, B. A., et al. (2015). Calpain inhibition mediates autophagy-dependent protection against polyglutamine toxicity. Cell Death Differ. 22, 433-444. doi: $10.1038 /$ cdd.2014.151

Mercer, T. J., Gubas, A., and Tooze, S. A. (2018). A molecular perspective of mammalian autophagosome biogenesis. J. Biol. Chem. 293, 5386-5395. doi: $10.1074 /$ jbc.R117.810366

Minina, E. A., Moschou, P. N., and Bozhkov, P. V. (2017). Limited and digestive proteolysis: crosstalk between evolutionary conserved pathways. New Phytol. 215, 958-964. doi: 10.1111/nph.14627

Mishra, A., Godavarthi, S. K., Maheshwari, M., Goswami, A., and Jana, N. R. (2009). The ubiquitin ligase E6-AP is induced and recruited to aggresomes in response to proteasome inhibition and may be involved in the ubiquitination of Hsp70bound misfolded proteins. J. Biol. Chem. 284, 10537-10545. doi: 10.1074/jbc. M806804200

Mizushima, N. (2010). Autophagy. FEBS Lett. 584, 1279-1279. doi: 10.1016/j. febslet.2010.02.053

Mizushima, N. (2018). A brief history of autophagy from cell biology to physiology and disease. Nat. Cell Biol. 20, 521-527. doi: 10.1038/s41556-018-0092-5

Mizushima, N., Yoshimori, T., and Ohsumi, Y. (2011). The role of atg proteins in autophagosome formation. Annu. Rev. Cell Dev. Biol. 27, 107-132. doi: 10.1146/annurev-cellbio-092910-154005

Nakamura, N., Kimura, Y., Tokuda, M., Honda, S., and Hirose, S. (2006). MARCH-V is a novel mitofusin 2- and Drp1-binding protein able to change mitochondrial morphology. EMBO Rep. 7, 1019-1022. doi: 10.1038/sj.embor. 7400790

Nakatogawa, H., Ichimura, Y., and Ohsumi, Y. (2007). Atg8, a ubiquitin-like protein required for autophagosome formation, mediates membrane tethering and hemifusion. Cell 130, 165-178. doi: 10.1016/j.cell.2007.05.021

Nakayama, K., Frew, I. J., Hagensen, M., Skals, M., Habelhah, H., Bhoumik, A., et al. (2004). Siah2 regulates stability of prolyl-hydroxylases, controls HIF1 $\alpha$ abundance, and modulates physiological responses to hypoxia. Cell 117, 941-952. doi: 10.1016/j.cell.2004.06.001

Nam, T., Han, J. H., Devkota, S., and Lee, H.-W. (2017). Emerging paradigm of crosstalk between autophagy and the ubiquitin-proteasome system. Mol. Cells 40, 897-905. doi: 10.14348/MOLCELLS.2017.0226

Narendra, D., Tanaka, A., Suen, D. F., and Youle, R. J. (2008). Parkin is recruited selectively to impaired mitochondria and promotes their autophagy. J. Cell Biol. 183, 795-803. doi: 10.1083/jcb.200809125
Narendra, D. P., Kane, L. A., Hauser, D. N., Fearnley, I. M., and Youle, R. J. (2010). p62/SQSTM1 is required for Parkin-induced mitochondrial clustering but not mitophagy; VDAC1 is dispensable for both. Autophagy 6, 1090-1106. doi: 10.4161/auto.6.8.13426

Nazio, F., Strappazzon, F., Antonioli, M., Bielli, P., Cianfanelli, V., Bordi, M., et al. (2013). MTOR inhibits autophagy by controlling ULK1 ubiquitylation, selfassociation and function through AMBRA1 and TRAF6. Nat. Cell Biol. 15, 406-416. doi: 10.1038/ncb2708

Nezis, I. P., Simonsen, A., Sagona, A. P., Finley, K., Gaumer, S., Contamine, D., et al. (2008). Ref(2)P, the Drosophila melanogaster homologue of mammalian p62, is required for the formation of protein aggregates in adult brain. J. Cell Biol. 180, 1065-1071. doi: 10.1083/jcb.200711108

Nie, J., Xie, P., Liu, L., Xing, G., Chang, Z., Yin, Y., et al. (2010). Smad ubiquitylation regulatory factor $1 / 2($ Smurf1/2) promotes $\mathrm{p} 53$ degradation by stabilizing the E3 ligase MDM2. J. Biol. Chem. 285, 22818-22830. doi: 10.1074/jbc.M110.126920

Nishitoh, H., Matsuzawa, A., Tobiume, K., Saegusa, K., Takeda, K., Inoue, K., et al. (2002). ASK1 is essential for endoplasmic reticulum stress-induced neuronal cell death triggered by expanded polyglutamine repeats. Genes Dev. 16, 1345-1355. doi: 10.1101/gad.992302

Noad, J., Von Der, Malsburg, A., Pathe, C., Michel, M. A., Komander, D., et al. (2017). LUBAC-synthesized linear ubiquitin chains restrict cytosol-invading bacteria by activating autophagy and NF-кB. Nat. Microbiol. 2:17063. doi: 10. 1038/nmicrobiol.2017.63

Novak, I., Kirkin, V., McEwan, D. G., Zhang, J., Wild, P., Rozenknop, A., et al. (2010). Nix is a selective autophagy receptor for mitochondrial clearance. EMBO Rep. 11, 45-51. doi: 10.1038/embor.2009.256

Nowis, D., McConnell, E., and Wójcik, C. (2006). Destabilization of the VCP-Ufd1Npl4 complex is associated with decreased levels of ERAD substrates. Exp. Cell Res. 312, 2921-2932. doi: 10.1016/j.yexcr.2006.05.013

Obeng, E. A., Carlson, L. M., Gutman, D. M., Harrington, W. J., Lee, K. P., and Boise, L. H. (2006). Proteasome inhibitors induce a terminal unfolded protein response in multiple myeloma cells. Blood 107, 4907-4916. doi: 10.1182/blood2005-08-3531

Ogawa, M., Yoshimori, T., Suzuki, T., Sagara, H., Mizushima, N., and Sasakawa, C. (2005). Escape of intracellular Shigella from autophagy. Science 307, 727-731. doi: $10.1126 /$ science. 1106036

Ohh, M., Park, C. W., Ivan, M., Hoffman, M. A., Kim, T., Huang, L. E., et al. (2000). Ubiquitination of hypoxia-inducible factor requires direct binding to the $\beta$-domain of the von Hippel-Lindau protein. Nat. Cell Biol. 2, 423-427.

Ohoka, N., Yoshii, S., Hattori, T., Onozaki, K., and Hayashi, H. (2005). TRB3, a novel ER stress-inducible gene, is induced via ATF4-CHOP pathway and is involved in cell death. EMBO J. 24, 1243-1255. doi: 10.1038/sj.emboj.7600596

Okamoto, K., Kondo-Okamoto, N., and Ohsumi, Y. (2009). Mitochondriaanchored receptor Atg32 mediates degradation of mitochondria via selective autophagy. Dev. Cell 17, 87-97. doi: 10.1016/j.devcel.2009.06.013

Okatsu, K., Saisho, K., Shimanuki, M., Nakada, K., Shitara, H., Sou, Y. S., et al. (2010). P62/SQSTM1 cooperates with Parkin for perinuclear clustering of depolarized mitochondria. Genes Cells 15, 887-900. doi: 10.1111/j.1365-2443. 2010.01426.x

Oku, M., and Sakai, Y. (2018). Three distinct types of microautophagy based on membrane dynamics and molecular machineries. Bioessays 40:e1800008. doi: 10.1002/bies.201800008

Okumoto, K., Misono, S., Miyata, N., Matsumoto, Y., Mukai, S., and Fujiki, Y. (2011). Cysteine ubiquitination of PTS1 receptor Pex5p regulates Pex5p recycling. Traffic 12, 1067-1083. doi: 10.1111/j.1600-0854.2011.01217.x

Olzmann, J. A., Li, A., Chudaev, M. V., Chen, J., Perez, F. A., Palmiter, R. D., et al. (2007). Parkin-mediated K63-linked polyubiquitination targets misfolded DJ-1 to aggresomes via binding to HDAC6. J. Cell Biol. 178, 1025-1038. doi: $10.1083 /$ jcb. 200611128

Orian, A., Gonen, H., Bercovich, B., Fajerman, I., Eytan, E., Israe, A., et al. (2000). SCF b -TrCP ubiquitin ligase-mediated processing of NF- k B p105 requires phosphorylation of its C-terminus by I k B kinase. EMBO J. 19, 2580-2591.

Ossareh-Nazari, B., Bonizec, M., Cohen, M., Dokudovskaya, S., Delalande, F., Schaeffer, C., et al. (2010). Cdc48 and Ufd3, new partners of the ubiquitin protease Ubp3, are required for ribophagy. EMBO Rep. 11, 548-554. doi: 10. 1038/embor.2010.74

Ossareh-Nazari, B., Niño, C. A., Bengtson, M. H., Lee, J. W., Joazeiro, C. A. P., and Dargemont, C. (2014). Ubiquitylation by the Ltn1 E3 ligase protects 
60 S ribosomes from starvation-induced selective autophagy. J. Cell Biol. 204, 909-917. doi: 10.1083/jcb.201308139

Palikaras, K., Lionaki, E., and Tavernarakis, N. (2015). Coordination of mitophagy and mitochondrial biogenesis during ageing in C. elegans. Nature 521, 525-528. doi: $10.1038 /$ nature 14300

Pan, J. A., Sun, Y., Jiang, Y. P., Bott, A. J., Jaber, N., Dou, Z., et al. (2016). TRIM21 ubiquitylates SQSTM1/p62 and suppresses protein sequestration to regulate redox homeostasis. Mol. Cell 61, 720-733. doi: 10.1016/j.molcel.2016. 02.007

Pankiv, S., Clausen, T. H., Lamark, T., Brech, A., Bruun, J. A., Outzen, H., et al. (2007). p62/SQSTM1 binds directly to Atg8/LC3 to facilitate degradation of ubiquitinated protein aggregates by autophagy*[S]. J. Biol. Chem. 282, 24131-24145. doi: 10.1074/jbc.M702824200

Park, S., Jang, I., Zuber, C., Lee, Y., Cho, J. W., Matsuo, I., et al. (2014). ERADication of EDEM1 occurs by selective autophagy and requires deglycosylation by cytoplasmic peptide N-glycanase. Histochem. Cell Biol. 142, 153-169. doi: 10. 1007/s00418-014-1204-3

Perrin, A. J., Jiang, X., Birmingham, C. L., So, N. S. Y., and Brumell, J. H. (2004). Recognition of bacteria in the cytosol of mammalian cells by the ubiquitin system. Curr. Biol. 14, 806-811. doi: 10.1016/j.cub.2004.04.033

Peters, L. Z., Karmon, O., Miodownik, S., and Ben-Aroya, S. (2016). Proteasome storage granules are transiently associated with the insoluble protein deposit in Saccharomyces cerevisiae. J. Cell Sci. 129, 1190-1197. doi: 10.1242/jcs.179648

Pickart, C. M., and Eddins, M. J. (2004). Ubiquitin: structures, functions, mechanisms. Biochim. Biophys. Acta 1695, 55-72. doi: 10.1016/j.bbamcr.2004. 09.019

Pintard, L., Willems, A., and Peter, M. (2004). Cullin-based ubiquitin ligases: Cul3BTB complexes join the family. EMBO J. 23, 1681-1687. doi: 10.1038/sj.emboj. 7600186

Pinto-Fernandez, A., and Kessler, B. M. (2016). DUBbing cancer: deubiquitylating enzymes involved in epigenetics, DNA damage and the cell cycle as therapeutic targets. Front. Genet. 7:133. doi: 10.3389/fgene.2016.00133

Platta, H. W., Abrahamsen, H., Thoresen, S. B., and Stenmark, H. (2012). Nedd4dependent lysine-11-linked polyubiquitination of the tumour suppressor Beclin 1. Biochem. J. 441, 399-406. doi: 10.1042/BJ20111424

Protter, D. S. W., and Parker, R. (2016). Principles and properties of stress granules. Trends Cell Biol. 26, 668-679. doi: 10.1016/j.tcb.2016.05.004

Qi, Y., and Xia, P. (2012). Cellular inhibitor of apoptosis protein-1 (cIAP1) plays a critical role in $\beta$-cell survival under endoplasmic reticulum stress: promoting ubiquitination and degradation of C/EBP homologous protein (CHOP). J. Biol. Chem. 287, 32236-32245. doi: 10.1074/jbc.M112.362160

Qing, G., Yan, P., Qu, Z., Liu, H., and Xiao, G. (2007). Hsp90 regulates processing of NF-kB2 p100 involving protection of NF-kB-inducing kinase (NIK) from autophagy-mediated degradation. Cell Res. 17, 520-530. doi: 10.1038/cr. 2007.47

Qu, X., Yu, J., Bhagat, G., Furuya, N., Hibshoosh, H., Troxel, A., et al. (2003). Promotion of tumorigenesis by heterozygous disruption of the beclin 1 autophagy gene. J. Clin. Invest. 112, 1809-1820. doi: 10.1172/JCI20039

Randow, F., and Youle, R. J. (2014). Self and nonself: how autophagy targets mitochondria and bacteria. Cell Host Microbe 15, 403-411. doi: 10.1016/j.chom. 2014.03.012

Reichard, J. F., Motz, G. T., and Puga, A. (2007). Heme oxygenase-1 induction by NRF2 requires inactivation of the transcriptional repressor BACH1. Nucleic Acids Res. 35, 7074-7086. doi: 10.1093/nar/gkm638

Reineke, L. C., and Lloyd, R. E. (2013). Diversion of stress granules and P-bodies during viral infection. Virology 436, 255-267. doi: 10.1016/j.virol.2012.11.017

Renna, M., Jimenez-Sanchez, M., Sarkar, S., and Rubinsztein, D. C. (2010). Chemical inducers of autophagy that enhance the clearance of mutant proteins in neurodegenerative diseases. J. Biol. Chem. 285, 11061-11067. doi: 10.1074/ jbc.R109.072181

Reyes-Turcu, F. E., Ventii, K. H., and Wilkinson, K. D. (2009). Regulation and cellular roles of ubiquitin-specific deubiquitinating enzymes. Annu. Rev. Biochem. 78, 363-397. doi: 10.1146/annurev.biochem.78.082307.091526

Richter, B., Sliter, D. A., Herhaus, L., Stolz, A., Wang, C., Beli, P., et al. (2016). Phosphorylation of OPTN by TBK1 enhances its binding to Ub chains and promotes selective autophagy of damaged mitochondria. Proc. Natl. Acad. Sci. U.S.A. 113, 4039-4044. doi: 10.1073/pnas.1523926113
Riley, B. E., Kaiser, S. E., Shaler, T. A., Ng, A. C. Y., Hara, T., Hipp, M. S., et al. (2010). Ubiquitin accumulation in autophagy-deficient mice is dependent on the Nrf2-mediated stress response pathway: a potential role for protein aggregation in autophagic substrate selection. J. Cell Biol. 191, 537-552. doi: $10.1083 /$ jcb.201005012

Rogov, V., Dötsch, V., Johansen, T., and Kirkin, V. (2014). Interactions between autophagy receptors and ubiquitin-like proteins form the molecular basis for selective autophagy. Mol. Cell 53, 167-178. doi: 10.1016/j.molcel.2013. 12.014

Sabatini, D. M. (2017). Twenty-five years of mTOR: uncovering the link from nutrients to growth. Proc. Natl. Acad. Sci. U.S.A. 114, 11818-11825. doi: $10.1073 /$ pnas. 1716173114

Sanchez, A. M. J., Csibi, A., Raibon, A., Cornille, K., Gay, S., Bernardi, H., et al. (2012). AMPK promotes skeletal muscle autophagy through activation of forkhead FoxO3a and interaction with Ulk1. J. Cell. Biochem. 113, 695-710. doi: $10.1002 /$ jcb.23399

Sandoval, H., Thiagarajan, P., Dasgupta, S. K., Schumacher, A., Prchal, J. T., Chen, M., et al. (2008). Essential role for Nix in autophagic maturation of erythroid cells. Nature 454, 232-235. doi: 10.1038/nature07006

Sargent, G., Zutphen, T., Van, Shatseva, T., Zhang, L., Giovanni, V., et al. (2016). PEX2 is the E3 ubiquitin ligase required for pexophagy during starvation. J. Cell Biol. 214, 677-690. doi: 10.1083/jcb.201511034

Sarraf, S. A., Raman, M., Guarani-Pereira, V., Sowa, M. E., Huttlin, E. L., Gygi, S. P., et al. (2013). Landscape of the PARKIN-dependent ubiquitylome in response to mitochondrial depolarization. Nature 496, 372-376. doi: 10.1038/nature 12043

Saxton, R. A., and Sabatini, D. M. (2017). mTOR signaling in growth, metabolism, and disease. Cell 168, 960-976. doi: 10.1016/j.cell.2017.02.004

Schuck, S., Gallagher, C. M., and Walter, P. (2014). ER-phagy mediates selective degradation of endoplasmic reticulum independently of the core autophagy machinery. J. Cell Sci. 127(Pt 18), 4078-4088. doi: 10.1242/jcs.154716

Schwartz, A. L., and Ciechanover, A. (2009). Targeting proteins for destruction by the ubiquitin system: implications for human pathobiology. Annu. Rev. Pharmacol. Toxicol. 49, 73-96. doi: 10.1146/annurev.pharmtox.051208.165340

Schweers, R. L., Zhang, J., Randall, M. S., Loyd, M. R., Li, W., Dorsey, F. C., et al. (2007). NIX is required for programmed mitochondrial clearance during reticulocyte maturation. Proc. Natl. Acad. Sci. U.S.A. 104, 19500-19505. doi: 10.1073/pnas.0708818104

Scortegagna, M., Kim, H., Li, J. L., Yao, H., Brill, L. M., Han, J., et al. (2014). Fine tuning of the UPR by the ubiquitin ligases Siah1/2. PLoS Genet. 10:e1004348. doi: 10.1371/journal.pgen.1004348

Seguin, S. J., Morelli, F. F., Vinet, J., Amore, D., De Biasi, S., Poletti, A., et al. (2014). Inhibition of autophagy, lysosome and VCP function impairs stress granule assembly. Cell Death Differ. 21, 1838-1851. doi: 10.1038/cdd.2014.103

Selimovic, D., Porzig, B. B. O. W., El-Khattouti, A., Badura, H. E., Ahmad, M., Ghanjati, F., et al. (2013). Bortezomib/proteasome inhibitor triggers both apoptosis and autophagy-dependent pathways in melanoma cells. Cell. Signal. 25, 308-318. doi: 10.1016/j.cellsig.2012.10.004

Sha, Z., Schnell, H. M., Ruoff, K., and Goldberg, A. (2018). Rapid induction of p62 and GABARAPL1 upon proteasome inhibition promotes survival before autophagy activation. J. Cell Biol. 217, 1757-1776. doi: 10.1083/jcb.201708168

Shen, J., Chen, X., Hendershot, L., and Prywes, R. (2002). ER stress regulation of ATF6 localization by dissociation of BiP/GRP78 binding and unmasking of golgi localization signals. Dev. Cell 3, 99-111. doi: 10.1016/S1534-5807(02) 00203-4

Shi, C. S., and Kehrl, J. H. (2010). TRAF6 and A20 regulate lysine 63-linked ubiquitination of Beclin-1 to control TLR4-induced autophagy. Sci. Signal. 3:ra42. doi: 10.1126/scisignal.2000751

Shi, D., and Gu, W. (2012). Dual roles of MDM2 in the regulation of p53: ubiquitination dependent and ubiquitination independent mechanisms of MDM2 repression of p53 activity. Genes Cancer 3, 240-248. doi: 10.1177/ 1947601912455199

Shi, J., Fung, G., Deng, H., Zhang, J., Fiesel, F. C., Springer, W., et al. (2015). NBR1 is dispensable for PARK2-mediated mitophagy regardless of the presence or absence of SQSTM1. Cell Death Dis. 6:e1943. doi: 10.1038/cddis.2015.278

Shiba-Fukushima, K., Arano, T., Matsumoto, G., Inoshita, T., Yoshida, S., Ishihama, Y., et al. (2014). Phosphorylation of mitochondrial polyubiquitin 
by PINK1 promotes parkin mitochondrial tethering. PLoS Genet. 10:e1004861. doi: 10.1371/journal.pgen.1004861

Shiba-Fukushima, K., Imai, Y., Yoshida, S., Ishihama, Y., Kanao, T., Sato, S., et al. (2012). PINK1-mediated phosphorylation of the Parkin ubiquitin-like domain primes mitochondrial translocation of Parkin and regulates mitophagy. Sci. Rep. 2:1002. doi: 10.1038/srep01002

Shin, Y., Klucken, J., Patterson, C., Hyman, B. T., and McLean, P. J. (2005). The Cochaperone carboxyl terminus of Hsp70-interacting protein (CHIP) mediates $\alpha$ synuclein degradation decisions between proteasomal and lysosomal pathways. J. Biol. Chem. 280, 23727-23734. doi: 10.1074/jbc.M503326200

Shloush, J., Vlassov, J. E., Engson, I., Duan, S., Saridakis, V., Dhe-paganon, S., et al. (2011). Structural and functional comparison of the RING domains of two p53 E3 ligases, Mdm2 and Pirh2. J. Biol. Chem. 286, 4796-4808. doi: 10.1074/jbc. M110.157669

Shpilka, T., Weidberg, H., Pietrokovski, S., and Elazar, Z. (2011). Atg8: an autophagy-related ubiquitin-like protein family. Genome Biol. 12:226. doi: 10. 1186/gb-2011-12-7-226

Smith, M. D., Harley, M. E., Kemp, A. J., Wills, J., Lee, M., Arends, M., et al. (2018). CCPG1 is a Non-canonical autophagy cargo receptor essential for ER-phagy and pancreatic ER proteostasis. Dev. Cell 44, 217-232.e11. doi: 10.1016/j.devcel. 2017.11.024

Song, W.-H., Yi, Y.-J., Sutovsky, M., Meyers, S., and Sutovsky, P. (2016). Autophagy and ubiquitin-proteasome system contribute to sperm mitophagy after mammalian fertilization. Proc. Natl. Acad. Sci. U.S.A. 113, E5261-E5270. doi: 10.1073/pnas.1605844113

Stitt, T. N., Drujan, D., Clarke, B. A., Panaro, F., Timofeyva, Y., Kline, W. O., et al. (2004). The IGF-1/PI3K/Akt pathway prevents expression of muscle atrophyinduced ubiquitin ligases by inhibiting FOXO transcription factors. Mol. Cell 14, 395-403. doi: 10.1016/S1097-2765(04)00211-4

Sun, A., Li, C., Chen, R., Huang, Y., Chen, Q., Cui, X., et al. (2016). GSK-3 $\beta$ controls autophagy by modulating LKB1-AMPK pathway in prostate cancer cells. Prostate 76, 172-183. doi: 10.1002/pros. 23106

Sun, A., Wei, J., Childress, C., Shaw, J. H., Peng, K., Shao, G., et al. (2017). The E3 ubiquitin ligase NEDD4 is an LC3-interactive protein and regulates autophagy. Autophagy 13, 522-537. doi: 10.1080/15548627.2016.126 8301

Suvorova, E. S., Lucas, O., Weisend, C. M., Rollins, M. C. F., Merrill, G. F., Capecchi, M. R., et al. (2009). Cytoprotective Nrf2 pathway is induced in chronically Txnrd 1-deficient hepatocytes. PLoS One 4:e6158. doi: 10.1371/ journal.pone. 0006158

Szargel, R., Shani, V., Elghani, F. A., Mekies, L. N., Liani, E., Rott, R., et al. (2015). The PINK1, synphilin-1 and SIAH-1 complex constitutes a novel mitophagy pathway. Hum. Mol. Genet. 25, 3476-3490. doi: 10.1093/hmg/ddw189

Takamura, A., Komatsu, M., Hara, T., Sakamoto, A., Kishi, C., Waguri, S., et al. (2011). Autophagy-deficient mice develop multiple liver tumors. Genes Dev. 25, 795-800. doi: 10.1101/gad.2016211

Tan, J. M. M., Wong, E. S. P., Dawson, V. L., Dawson, T. M., and Lim, K. L. (2008a). Lysine 63-linked polyubiquitin potentially partners with p62 to promote the clearance of protein inclusions by autophagy. Autophagy 4, 251-253. doi: 10. 4161/auto.5444

Tan, J. M. M., Wong, E. S. P., Kirkpatrick, D. S., Pletnikova, O., Ko, H. S., Tay, S. P., et al. (2008b). Lysine 63-linked ubiquitination promotes the formation and autophagic clearance of protein inclusions associated with neurodegenerative diseases. Hum. Mol. Genet. 17, 431-439. doi: 10.1093/hmg/ $\operatorname{ddm} 320$

Tanaka, Y., Guhde, G., Suter, A., Eskelinen, E. L., Hartmann, D., Lüllmann-Rauch, R., et al. (2000). Accumulation of autophagic vacuoles and cardiomyopathy LAMP-2-deficient mice. Nature 406, 902-906. doi: $10.1038 / 35022595$

Tang, B., Cai, J., Sun, L., Li, Y., Qu, J., Snider, B. J., et al. (2014). Proteasome inhibitors activate autophagy involving inhibition of PI3K-Akt-mTOR pathway as an anti-oxidation defense in human RPE cells. PLoS One 9:e103364. doi: 10.1371 /journal.pone. 0103364

Tanida, I., Ueno, T., and Kominami, E. (2004). Human light chain 3/MAP1LC3B Is cleaved at its carboxyl-terminal Met 121 to expose Gly120 for lipidation and targeting to autophagosomal membranes. J. Biol. Chem. 279, 47704-47710. doi: $10.1074 /$ jbc.M407016200
Tannous, P., Zhu, H., Nemchenko, A., Berry, J. M., Johnstone, J. L., Shelton, J. M., et al. (2008). Intracellular protein aggregation is a proximal trigger of cardiomyocyte autophagy. Circulation 117, 3070-3078. doi: 10.1161/ CIRCULATIONAHA.107.763870

Tasdemir, E., Maiuri, M. C., Galluzzi, L., Vitale, I., Djavaheri-Mergny, M., D'Amelio, M., et al. (2008a). Regulation of autophagy by cytoplasmic p53. Nat. Cell Biol. 10, 676-687. doi: 10.1038/ncb1730

Tasdemir, E., Maiuri, M. C., Morselli, E., Criollo, A., D’Amelio, M., DjavaheriMergny, M., et al. (2008b). A dual role of p53 in the control of autophagy. Autophagy 4, 810-814. doi: 10.4161/auto.6486

Tekirdag, K. A., Akkoc, Y., Kosar, A., and Gozuacik, D. (2016). MIR376 family and cancer. Histol. Histopathol. 31, 841-855. doi: 10.14670/HH-11-752

Thurston, T. L. M. (2009). The tbk1 adaptor and autophagy receptor ndp52 restricts the proliferation of ubiquitin-coated bacteria. Nat. Immunol. 10, 1215-1222. doi: $10.1038 /$ ni. 1800

Till, A., Lakhani, R., Burnett, S. F., and Subramani, S. (2012). Pexophagy: the selective degradation of peroxisomes. Int. J. Cell Biol. 2012:512721. doi: 10.1155/ 2012/512721

Tomkinson, B., and Lindås, A. C. (2005). Tripeptidyl-peptidase II: a multi-purpose peptidase. Int. J. Biochem. Cell Biol. 37, 1933-1937. doi: 10.1016/j.biocel.2005. 02.009

Tourrière, H., Chebli, K., Zekri, L., Courselaud, B., Blanchard, J. M., Bertrand, E., et al. (2003). The RasGAP-associated endoribonuclease G3BP assembles stress granules. J. Cell Biol. 160, 823-831. doi: 10.1083/jcb.200212128

Trempe, J. F., Sauvé, V., Grenier, K., Seirafi, M., Tang, M. Y., Meñade, M., et al. (2013). Structure of parkin reveals mechanisms for ubiquitin ligase activation. Science 340, 1451-1455. doi: 10.1126/science. 1237908

Tresse, E., Salomons, F. A., Vesa, J., Bott, L. C., Kimonis, V., Yao, T. P., et al. (2010). $\mathrm{VCP} / \mathrm{p} 97$ is essential for maturation of ubiquitin-containing autophagosomes and this function is impaired by mutations that cause IBMPFD. Autophagy 6 , 217-227. doi: 10.4161/auto.6.2.11014

Tripathi, D. N., Zhang, J., Jing, J., Dere, R., and Lyn, C. (2016). A new role for ATM in selective autophagy of peroxisomes ( pexophagy ). Autophagy 12, 711-712. doi: $10.1080 / 15548627.2015 .1123375$

Tsuboyama, K., Koyama-Honda, I., Sakamaki, Y., Koike, M., Morishita, H., and Mizushima, N. (2016). The ATG conjugation systems are important for degradation of the inner autophagosomal membrane. Science 354, 1036-1041. doi: $10.1126 /$ science.aaf6136

Verma, R., Oania, R. S., Kolawa, N. J., and Deshaies, R. J. (2013). Cdc48/p97 promotes degradation of aberrant nascent polypeptides bound to the ribosome. eLife 2013:e00308. doi: 10.7554/eLife.00308

Vidal, R. L., Figueroa, A., Court, F. A., Thielen, P., Molina, C., Wirth, C., et al. (2012). Targeting the UPR transcription factor XBP1 protects against Huntington's disease through the regulation of FoxO1 and autophagy. Hum. Mol. Genet. 21, 2245-2262. doi: 10.1093/hmg/dds040

Vogl, D. T., Stadtmauer, E. A., Tan, K. S., Heitjan, D. F., Davis, L. E., Pontiggia, L., et al. (2014). Combined autophagy and proteasome inhibition a phase 1 trial of hydroxychloroquine and bortezomib in patients with relapsed/refractory myeloma. Autophagy 10, 1380-1390. doi: 10.4161/auto.29264

Walter, K. M., Schönenberger, M. J., Trötzmüller, M., Horn, M., Elsässer, H. P., Moser, A. B., et al. (2014). Hif-2 $\alpha$ Promotes degradation of mammalian peroxisomes by selective autophagy. Cell Metab. 20, 882-897. doi: 10.1016/j. cmet.2014.09.017

Wandel, M. P., Pathe, C., Werner, E. I., Ellison, C. J., Boyle, K. B., von, et al. (2017). GBPs inhibit motility of Shigella flexneri but are targeted for degradation by the bacterial ubiquitin ligase IpaH9.8. Cell Host Microbe 22, 507-518.e5. doi: 10.1016/j.chom.2017.09.007

Wanders, R. J. A., Waterham, H. R., and Ferdinandusse, S. (2016). Metabolic interplay between peroxisomes and other subcellular organelles including mitochondria and the endoplasmic reticulum. Front. Cell Dev. Biol. 3:83. doi: $10.3389 /$ fcell. 2015.00083

Wang, W., and Subramani, S. (2017). Role of PEX5 ubiquitination in maintaining peroxisome dynamics and homeostasis. Cell Cycle 16, 2037-2045. doi: 10.1080/ 15384101.2017.1376149

Wang, X. J., Yu, J., Wong, S. H., Cheng, A. S., Chan, F. K., Ng, S. S., et al. (2013). A novel crosstalk between two major protein degradation systems. Autophagy 9, 1500-1508. doi: 10.4161/auto.25573 
Wang, Y., Serricchio, M., Jauregui, M., Shanbhag, R., Stoltz, T., Di Paolo, C. T., et al. (2015). Deubiquitinating enzymes regulate PARK2-mediated mitophagy. Autophagy 11, 595-606. doi: 10.1080/15548627.2015.1034408

Waris, S., Wilce, M. C. J., and Wilce, J. A. (2014). RNA recognition and stress granule formation by TIA proteins. Int. J. Mol. Sci. 15, 23377-23388. doi: 10.3390/ijms151223377

Wauer, T., and Komander, D. (2013). Structure of the human Parkin ligase domain in an autoinhibited state. EMBO J. 32, 2099-2112. doi: 10.1038/emboj. 2013.125

Welchman, R. L., Gordon, C., and Mayer, R. J. (2005). Ubiquitin and ubiquitinlike proteins as multifunctional signals. Nat. Rev. Mol. Cell Biol. 6, 599-609. doi: $10.1038 / \mathrm{nrm} 1700$

Whitney, M. L., Jefferson, L. S., and Kimball, S. R. (2009). ATF4 is necessary and sufficient for ER stress-induced upregulation of REDD1 expression. Biochem. Biophys. Res. Commun. 379, 451-455. doi: 10.1016/j.bbrc.2008. 12.079

Wild, P., Farhan, H., McEwan, D. G., Wagner, S., Rogov, V. V., Brady, N. R., et al. (2011). Phosphorylation of the autophagy receptor optineurin restricts Salmonella growth. Science 333, 228-233. doi: 10.1126/science.120 5405

Wileman, T. (2013). Autophagy as a defence against intracellular pathogens. Essays Biochem. 55, 153-163. doi: 10.1042/bse0550153

Wong, Y. C., and Holzbaur, E. L. F. (2014). Optineurin is an autophagy receptor for damaged mitochondria in parkin-mediated mitophagy that is disrupted by an ALS-linked mutation. Proc. Natl. Acad. Sci. U.S.A. 111, E4439-E4448. doi: 10.1073/pnas.1405752111

Wooten, M. W., Geetha, T., Babu, J. R., Seibenhener, M. L., Peng, J., Cox, N., et al. (2008). Essential role of sequestosome $1 / p 62$ in regulating accumulation of Lys63-ubiquitinated proteins. J. Biol. Chem. 283, 6783-6789. doi: 10.1074/ jbc.M709496200

Wu, W. K. K., Wu, Y. C., Yu, L., Li, Z. J., Sung, J. J. Y., and Cho, C. H. (2008). Induction of autophagy by proteasome inhibitor is associated with proliferative arrest in colon cancer cells. Biochem. Biophys. Res. Commun. 374, 258-263. doi: 10.1016/j.bbrc.2008.07.031

Wu, Z., and Pfeffer, L. M. (2016). MicroRNA regulation of F-box proteins and its role in cancer. Semin. Cancer Biol. 4, 80-87. doi: 10.1016/j.semcancer.2015. 09.016

Wyant, G. A., Abu-Remaileh, M., Frenkel, E. M., Laqtom, N. N., Dharamdasani, V., Lewis, C. A., et al. (2018). Nufip1 is a ribosome receptor for starvation-induced ribophagy. Science 360, 751-758. doi: 10.1126/science.aar2663

Xia, P., Wang, S., Du, Y., Zhao, Z., Shi, L., Sun, L., et al. (2013). WASH inhibits autophagy through suppression of Beclin 1 ubiquitination. EMBO J. 32, 2685-2696. doi: 10.1038/emboj.2013.189

Xiong, X., Tao, R., DePinho, R. A., and Dong, X. C. (2012). The autophagyrelated gene 14 (Atg14) is regulated by forkhead box $\mathrm{O}$ transcription factors and circadian rhythms and plays a critical role in hepatic autophagy and lipid metabolism. J. Biol. Chem. 287, 39107-39114. doi: 10.1074/jbc.M112.412569

Xu, C., Fan, C. D., and Wang, X. (2015). Regulation of Mdm2 protein stability and the p53 response by NEDD4-1 E3 ligase. Oncogene 34, 342-350. doi: 10.1038/ onc. 2013.557

Xu, C., Feng, K., Zhao, X., Huang, S., Cheng, Y., Qian, L., et al. (2014). Regulation of autophagy by E3 ubiquitin ligase RNF216 through BECN1 ubiquitination. Autophagy 10, 2239-2250. doi: 10.4161/15548627.2014.981792

Xu, J., Wang, S., Viollet, B., and Zou, M. H. (2012). Regulation of the proteasome by AMPK in endothelial cells: the role of O-GlcNAc transferase (OGT). PLoS One 7:e36717. doi: 10.1371/journal.pone.0036717

Xu, P., Das, M., Reilly, J., and Davis, R. J. (2011). JNK regulates FoxO-dependent autophagy in neurons. Genes Dev. 25, 310-322. doi: 10.1101/gad.1984311

Yamano, K., and Youle, R. J. (2013). PINK1 is degraded through the N-end rule pathway. Autophagy 9, 1758-1769. doi: 10.4161/auto.24633

Yonashiro, R., Ishido, S., Kyo, S., Fukuda, T., Goto, E., Matsuki, Y., et al. (2006). A novel mitochondrial ubiquitin ligase plays a critical role in mitochondrial dynamics. EMBO J. 25, 3618-3626. doi: 10.1038/sj.emboj.7601249

Yonekawa, T., Gamez, G., Kim, J., Choon Tan, A., Thorburn, J., Gump, J., et al. (2015). RIP1 negatively regulates basal autophagic flux through TFEB to control sensitivity to apoptosis. EMBO Rep. 16, 700-708. doi: 10.15252/embr

Yoshii, S. R., Kishi, C., Ishihara, N., and Mizushima, N. (2011). Parkin mediates proteasome-dependent protein degradation and rupture of the outer mitochondrial membrane. J. Biol. Chem. 286, 19630-19640. doi: 10.1074/jbc. M110.209338

Yu, L., Chen, Y., and Tooze, S. A. (2018). Autophagy pathway: cellular and molecular mechanisms. Autophagy 14, 207-215. doi: 10.1080/15548627.2017. 1378838

Yuan, G., Khan, S. A., Luo, W., Nanduri, J., Semenza, G. L., and Prabhakar, N. R. (2011). Hypoxia-inducible factor 1 mediates increased expression of NADPH oxidase-2 in response to intermittent hypoxia. J. Cell. Physiol. 226, 2925-2933. doi: $10.1002 /$ jcp. 22640

Yun, J., Puri, R., Yang, H., Lizzio, M. A., Wu, C., Sheng, Z. H., et al. (2014). MUL1 acts in parallel to the PINK1/parkin pathway in regulating mitofusin and compensates for loss of PINK1/parkin. eLife 3:e01958. doi: 10.7554/eLife. 01958.001

Zalckvar, E., Berissi, H., Mizrachy, L., Idelchuk, Y., Koren, I., Eisenstein, M., et al. (2009). DAP-kinase-mediated phosphorylation on the BH3 domain of beclin 1 promotes dissociation of beclin 1 from Bcl-XL and induction of autophagy. EMBO Rep. 10, 285-292. doi: 10.1038/embor. 2008.246

Zhang, H., Bosch-Marce, M., Shimoda, L. A., Yee, S. T., Jin, H. B., Wesley, J. B., et al. (2008). Mitochondrial autophagy is an HIF-1-dependent adaptive metabolic response to hypoxia. J. Biol. Chem. 283, 10892-10903. doi: 10.1074/ jbc.M800102200

Zhang, J., Tripathi, D. N., Jing, J., Alexander, A., Kim, J., Powell, R. T., et al. (2015). ATM functions at the peroxisome to induce pexophagy in response to ROS. Nat. Cell Biol. 17, 1259-1269. doi: 10.1038/ncb3230

Zhang, T., Dong, K., Liang, W., Xu, D., Xia, H., Geng, J., et al. (2015). G-protein coupled receptors regulate autophagy by ZBTB16-mediated ubiquitination and proteasomal degradation of adaptor protein Atg14L. eLife 4:e66734. doi: 10. 7554/eLife.06734

Zhang, X., and Qian, S.-B. (2011). Chaperone-mediated hierarchical control in targeting misfolded proteins to aggresomes. Mol. Biol. Cell 22, 3277-3288. doi: 10.1091/mbc.E11-05-0388

Zhao, J., Brault, J. J., Schild, A., Cao, P., Sandri, M., Schiaffino, S., et al. (2007). FoxO3 coordinately activates protein degradation by the autophagic/lysosomal and proteasomal pathways in atrophying muscle cells. Cell Metab. 6, 472-483. doi: 10.1016/j.cmet.2007.11.004

Zhao, J., and Goldberg, A. L. (2016). Coordinate regulation of autophagy and the ubiquitin proteasome system by MTOR. Autophagy 12, 1967-1970. doi: 10.1080/15548627.2016.1205770

Zhao, J., Zhai, B., Gygi, S. P., and Goldberg, A. L. (2015). mTOR inhibition activates overall protein degradation by the ubiquitin proteasome system as well as by autophagy. Proc. Natl. Acad. Sci. U.S.A. 112, 15790-15797. doi: 10.1073/pnas. 1521919112

Zheng, Y. T., Shahnazari, S., Brech, A., Lamark, T., Johansen, T., and Brumell, J. H. (2009). The adaptor protein p62/SQSTM1 targets invading bacteria to the autophagy pathway. J. Immunol. 183, 5909-5916. doi: 10.4049/jimmunol. 0900441

Zhong, X., and Pittman, R. N. (2006). Ataxin-3 binds VCP/p97 and regulates retrotranslocation of ERAD substrates. Hum. Mol. Genet. 15, 2409-2420. doi: $10.1093 / \mathrm{hmg} / \mathrm{ddl} 164$

Zhu, K., Dunner, K., and McConkey, D. J. (2010). Proteasome inhibitors activate autophagy as a cytoprotective response in human prostate cancer cells. Oncogene 29, 451-462. doi: 10.1038/onc.2009.343

Zhu, X., Zhang, J., Sun, H., Jiang, C., Dong, Y., Shan, Q., et al. (2014). Ubiquitination of inositol-requiring enzyme 1 (IRE1) by the E3 ligase CHIP mediates the IRE1/TRAF2/JNK pathway. J. Biol. Chem. 289, 30567-30577. doi: $10.1074 /$ jbc.M114.562868

Conflict of Interest Statement: The authors declare that the research was conducted in the absence of any commercial or financial relationships that could be construed as a potential conflict of interest.

Copyright (c) 2018 Kocaturk and Gozuacik. This is an open-access article distributed under the terms of the Creative Commons Attribution License (CC BY). The use, distribution or reproduction in other forums is permitted, provided the original author(s) and the copyright owner(s) are credited and that the original publication in this journal is cited, in accordance with accepted academic practice. No use, distribution or reproduction is permitted which does not comply with these terms. 